\title{
The subsegmental structure of German plural allomorphy
}

\author{
Jochen Trommer ${ }^{1}$
}

Received: 14 October 2018 / Accepted: 13 June 2020 / Published online: 14 July 2020

(C) The Author(s) 2020

\begin{abstract}
Plurals in the native stratum of German nouns exhibit a complex interlacing of arbitrary lexical classes and virtually exceptionless generalizations across them. Thus while it is not fully predictable phonologically or semantically which suffix allomorph a plural noun takes and whether it undergoes umlaut (vowel fronting), specific suffixes consistently trigger or block umlaut (Augst 1979; Wurzel 1998; Wunderlich 1999), and all plural forms obey a fixed prosodic template (Wiese 1996b, 2009). This combination of regular and irregular has given rise to the claim that German noun plurals defy a morpheme-based analysis and require global paradigm structure conditions (Bittner 1991; Wurzel 1998; Carstairs-McCarthy 2008) or construction-specific constraints (Neef 1998; Wunderlich 1999; Wiese 2009). In this paper, I present a new, purely concatenative analysis of German plurals combining and extending on elements of the classical autosegmental analyses for German umlaut (Yu 1992; Lieber 1992; Féry 1994) and schwa (Hall 1992; Noske 1993; Wiese 1996b) couched in Stratal OT (Kiparsky 2015; Bermúdez-Otero 2018) and Containment Theory (Prince and Smolensky 1993; Revithiadou 2007; van Oostendorp 2008). I show that assuming a general plural suffix consisting of a featurally underspecified segmental root node and a floating CORONAL feature allows for a purely phonological explanation of both paradigmatic implications and the templatic shape of noun plurals, which have so far been treated as independent problems, and gives rise to a principled account of apparent exceptions.
\end{abstract}

The research reported in this paper was generously funded by the German Research Foundation (DFG) through the project TR 521/6-1 "Featural Affixes: The Morphology of Phonological Features".

Electronic supplementary material The online version of this article (https://doi.org/10.1007/s11049-020-09479-7) contains supplementary material, which is available to authorized users.

J. Trommer

jtrommer@uni-leipzig.de

1 Institut für Linguistik, Universität Leipzig, Beethovenstrasse 15, 04107 Leipzig, Germany 
Keywords Nonconcatenative Morphology · Featural Affixation · Umlaut · Morphological Subregularities · Prosodic templates · Phonologically conditioned allomorphy $\cdot$ Autosegmental Phonology $\cdot$ Containment Theory

\section{Introduction}

\subsection{Wiese's and Wunderlich's dilemmas}

Plurals in the native stratum of German nouns exhibit a complex interlacing of phonologically unpredictable lexical classes and broad, virtually exceptionless generalizations across them. This analytic tension between predictability and idiosyncrasy emerges most clearly in the analyses of Richard Wiese and Dieter Wunderlich. Thus Wiese (1996b, 2009) observes that plurals in the native stratum of German instantiate a consistent prosodic template: Whereas singular nouns may end in any kind of syllable, virtually all plural nouns end in the sequence of a full-vowel syllable and a reduced syllable, headed either by schwa ([ə]), (1-a), a-schwa ([e]) (1-b), or by a syllabic sonorant (1-c-f). ${ }^{1}$

(1) The German plural template ( $\left.\sigma_{\text {full }} . \sigma_{\text {weak }}\right)$ (Wiese 1996b, 2009)

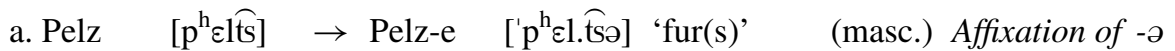

b. Kind $\quad\left[\mathrm{k}^{\mathrm{h}} \mathrm{Int}\right] \rightarrow$ Kind-er ['k $\mathrm{h}$ In.de] 'child(ren)' (neut.) Affixation of $-\boldsymbol{e}$

c. Held [helt] $\rightarrow$ Held-en ['hel.dn] 'hero(es)' (masc.) Affixation of $-n$

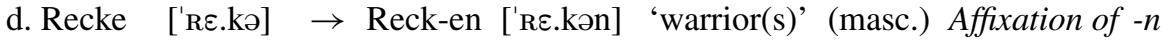

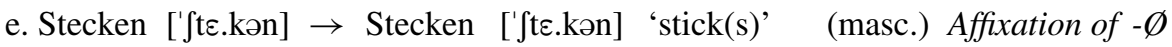

f. Esel ['Pe:.zl] $\rightarrow$ Esel ['Pe:.zl] 'donkey(s)' (masc.) Affixation of - $\varnothing$

While this generalization can be captured succinctly by assuming that the plural affix is a prosodic template in the sense of Prosodic Morphology (McCarthy and Prince 1993, 1996; Wiese 1996b, and Wiese 2009 for a constraint-based version of this intuition), this doesn't account for the fact that the constant templatic shape of plurals is achieved by different affixation patterns, which are not completely predictable by phonological shape and/or gender, as shown by the quasi-minimal pairs in (2):

\footnotetext{
${ }^{1}$ Transcriptions are mainly phonological, but take account of fully predictable final devoicing ([kint]), prevocalic aspiration of stops in stressed syllables ([p $\left.\mathrm{p}^{\mathrm{h}} \widehat{\mathrm{lt}}\right]$ ), and glottal stop epenthesis before syllableinitial word-initial or stressed vowels (['Pe:.zl] ). Abbreviations, glosses and symbols used in the following are $1 / 2 / 3=1 \mathrm{st} / 2 \mathrm{nd} / 3 \mathrm{rd}$ person, $\mathrm{C}$ (onsonant), $\mathrm{V}$ (owel), $\mathrm{pl}=$ plural, $\mathrm{sg}=$ singular, fem(inine), masc(uline), neut(er), nom(inative), gen(itive), dat(ive), acc(usative), obl(ique), inf(initive), prs = present tense, COR(ONAL) (also: “c”), LAB(IAL) (also: "l”), DOR(SAL) (also: “d”), PhAR(YNGEAL) (also: “p”), $\bullet$ = segmental root node, $\mu=$ mora, $\sigma=$ syllable, $\square=$ morphological color.
} 


\section{Unpredictability of segmental plural allomorphs}

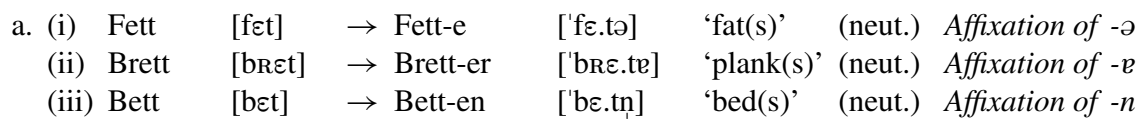

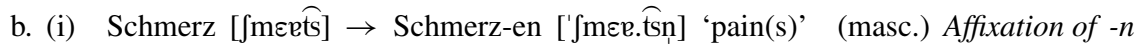

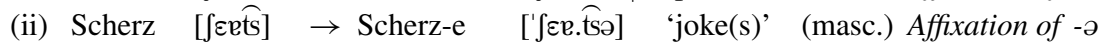

Since this allomorphy is not purely phonological, a considerable amount of it has to be stated independently of the template. But positing explicit allomorphy rules (like [+Plural] $\rightarrow-\varepsilon / \ldots$, see e.g. Yang 2016) which derive the different patterns in (2) would render Wiese's plural template a redundant statement of a generalization already following as an epiphenomenon of independent morphological rules.

The second, closely related, analytic dilemma is rooted in the fact that German noun plurals differ across two logically independent dimensions (Wunderlich 1999) ${ }^{2}$ : the choice of a suffix allomorph, already illustrated in (1) and (2), and the presence vs. absence of umlaut, the phonological fronting of back and low vowels characteristic of many morphological processes in German. ${ }^{3}$ As shown in (3), with more quasi-identical pairs, umlaut can appear or be absent with roots of basically the same phonological shape (and the same gender) independently of whether the segmental suffix is identical $(3-\mathrm{a}, \mathrm{b}, \mathrm{c})$ or not $(3-\mathrm{d}, \mathrm{e}, \mathrm{f})$ :

\section{Umlaut and plural allomorphs}

\begin{tabular}{|c|c|c|c|c|c|c|}
\hline $\begin{array}{l}\text { (i) } \\
\text { (ii) }\end{array}$ & $\begin{array}{l}\text { Kuss } \\
\text { Bus }\end{array}$ & $\begin{array}{l}{\left[\mathrm{k}^{\mathrm{h}} v \mathrm{~s}\right]} \\
{\left[\mathrm{b}^{\mathrm{h}} v \mathrm{~s}\right]}\end{array}$ & $\begin{array}{l}\rightarrow \text { Küss-e } \\
\rightarrow \text { Buss-e }\end{array}$ & $\begin{array}{l}\left.\text { ['k }{ }^{\mathrm{h}} \mathrm{y} . \mathrm{s} ə\right] \\
\text { ['bv.sə] }\end{array}$ & $\begin{array}{l}\text { Kiss(c) } \\
\text { 'bus(e }\end{array}$ & $\begin{array}{l}\text { masc.) Affix } \\
\text { masc.) Affix }\end{array}$ \\
\hline $\begin{array}{l}\text { (i) } \\
\text { (ii) }\end{array}$ & $\begin{array}{l}\text { Sohn } \\
\text { Thron }\end{array}$ & & $\begin{array}{l}\rightarrow \text { Söhn-e } \\
\rightarrow \text { Thron-e }\end{array}$ & & & $\begin{array}{l}\text { xation of -ə } \\
\text { xation of -ə }\end{array}$ \\
\hline $\begin{array}{l}\text { (i) } \\
\text { (ii) }\end{array}$ & $\begin{array}{l}\text { Vater } \\
\text { Anker }\end{array}$ & & $\begin{array}{l}\rightarrow \text { Väter } \\
\rightarrow \text { Anker }\end{array}$ & & & (masc.) A \\
\hline $\begin{array}{l}\text { (i) } \\
\text { (ii) }\end{array}$ & $\begin{array}{l}\text { Naht } \\
\text { Saat }\end{array}$ & & $\begin{array}{l}\rightarrow \text { Näht-e } \\
\rightarrow \text { Saat-en }\end{array}$ & & & $\begin{array}{ll}\text { (fem.) } & \text { Affix } \\
\text { (fem.) } & \text { Affix }\end{array}$ \\
\hline $\begin{array}{l}\text { (i) } \\
\text { (ii) }\end{array}$ & $\begin{array}{l}\text { Braut } \\
\text { Frau }\end{array}$ & $\begin{array}{l}\text { [bravt] } \\
\text { [fRaver] }\end{array}$ & $\begin{array}{l}\rightarrow \text { Bräut-e } \\
\rightarrow \text { Frau-en }\end{array}$ & & $\begin{array}{l}\text { 'bride(s)' } \\
\text { 'woman/women' }\end{array}$ & $\begin{array}{l}\text { (fem.) Affixation of -ə } \\
\text { (fem.) Affixation of }-n\end{array}$ \\
\hline $\begin{array}{l}\text { (i) } \\
\text { (ii) } \\
\text { (ii) }\end{array}$ & $\begin{array}{l}\text { Grund } \\
\text { Mund } \\
\text { Hund }\end{array}$ & $\begin{array}{l}{[\text { [mont] }} \\
{[\text { hont }]}\end{array}$ & $\begin{array}{l}\rightarrow \text { Münd-er } \\
\rightarrow \text { Hund-e }\end{array}$ & & $\begin{array}{l}\text { 'mouth(s)' } \\
\text { 'dog(s)' }\end{array}$ & $\begin{array}{l}\text { (masc.) Affixation of }-2 \\
\text { (masc.) Affixation of }-\boldsymbol{e} \\
\text { (masc.) Affixation of }-\partial\end{array}$ \\
\hline
\end{tabular}

\footnotetext{
${ }^{2}$ While Wunderlich (1999) provides the most succinct formulation of the analytic dilemma, the empirical observations he discusses have been well-known for a long time, see for example Augst (1979) for an early summary of the empirical literature, Wurzel (1998) for another theoretically influential analysis, and Sect. 7 for more references. In the supplemental material, I provide additional evidence that these generalizations in fact hold.

${ }^{3}$ The term 'umlaut' is ambiguously also used to identify the historical change by which front suffix vowels have lead to the fronting of stem vowels (the historical origin of the synchronic alternation discussed here) and the orthographic marking of front vowels, even if they are not the result of a synchronic fronting process as in the non-alternating noun roots Möhre [møı.rə] 'carrot' and Bär [bє:e] 'bear'.
} 
At the same time, there are highly reliable predictive correlations between the choice of suffix allomorph and the presence of umlaut. Whereas plurals in $-e(-\partial)$ and $-\varnothing$ may co-occur with umlaut or not, depending on the specific lexeme, nouns with plural $-n$ never umlaut (4-a,b) and nouns with plural -er [-e] virtually always umlaut (4-c,d):

(4) (Non-)co-occurrence of umlaut and segmental plural allomorphs

a. No umlaut + suffix $-n$
(i) Pate $\quad\left[\mathrm{p}^{\mathrm{h}}\right.$ a:.tə] $\rightarrow$ Pate-n $\quad$ ['p ${ }^{\mathrm{h}}$ a.t.tən] 'godfather'
(masc.)
(ii) Frau [frav] $\rightarrow$ Frau-en ['frav.ən] 'woman/women' (fem.)
(iii) Suppe ['zo.pə] $\rightarrow$ Suppe-n ['zo.pən] 'soup(s)'

b. Umlaut + suffix $-n$

c. Umlaut + suffix - er

(i) Band [bant] $\rightarrow$ Bänd-er ['ben.de] 'tie(s)'

(ii) Huhn [hu:n] $\rightarrow$ Hühn-er ['hy:.ne] 'chicken(s)' (neut.)

(iii) Mann [man] $\rightarrow$ Männ-er ['me.ne] 'man/men' (masc.)

d. No umlaut + suffix - er

The attraction of umlaut by -er is highlighted by the existence of a handful of plural doublets, where nouns, one in $-e$, and one in -er have different plurals with slightly different semantic/pragmatic connotations (5). Strikingly these words don't show umlaut if they form the plural in -e, but umlaut becomes obligatory in the -er forms.

(Non-)co-occurrence of umlaut and segmental plural allomorphs

$\begin{array}{llllllll}\text { a. } & \text { (i) Wort } & \text { [voet] } & \rightarrow & \text { Wort-e } & \text { ['voe.tə] } & \text { 'word(s)' } & \text { (neut.) } \\ & \text { (ii) Wort } & \text { [voet] } & \rightarrow & \text { Wört-er } & \text { ['vœe.te] } & \text { 'word(s)' } & \text { (neut.) } \\ \text { b. } & \text { (i) Land } & \text { [lant] } & \rightarrow & \text { Land-e } & \text { ['lan.də] } & \text { 'land(s)' } & \text { (neut.) } \\ & \text { (ii) Land } & \text { [lant] } & \rightarrow & \text { Länd-er } & \text { ['len.de] } & \text { 'land(s)' } & \text { (neut.) }\end{array}$

Thus Wunderlich's observations pose a similar dilemma as Wiese's generalization: The general unpredictability of umlaut and plural allomorphy illustrated in (2) and (3) seems to require specifying theses choices lexically (e.g. by diacritic features or by listing) for every lexeme, but this wouldn't capture the systematic nature of the generalizations in (4) and (5). In the following section, I will sketch the gist of my approach, which provides a unified account to both Wunderlich's and Wiese's generalizations, and solves the analytic double bind they face.

\subsection{The proposal in a nutshell}

The proposal I develop here is to resolve Wunderlich's and Wiese's dilemmas by analyzing German plural morphology as the effect of concatenative affixation of 'defective' subsegmental material in the sense of Generalized Nonlinear Affixation (Bermúdez-Otero 2012), combining and elaborating on two independent assumptions 
from the pre-OT literature on German: that umlaut-triggering affixes contain a floating feature encoding frontness (Yu 1992; Lieber 1992; Féry 1994), and the representation of affixal [ə] via a defective segment-sized phonological unit (corresponding to the C- or X-slot of Wiese 1986; Hall 1992; Noske 1993). This accounts for the templatic shape of plurals since incomplete segments are less strictly protected by faithfulness constraints and hence give rise to phonological Emergence-of-the-Unmarked effects (shown in detail in Sect. 5), and allows us to systematically relate umlaut and segmental morphology under the assumption that the floating feature may either surface as vocalic fronting or as the place-of-articulation specification of coronal segments as predicted by Unified Feature Theory (Clements and Hume 1995) (see Sect. 3). That the templatic shape of plurals holds for all plurals (not only for -ə) is derived from the novel assumption that there is a single fully general plural affix, attaching to all plural nouns-consisting of an unspecified root node (written as "•") and a floating CORONAL feature (6-a) (comprising a VPLACE node in the feature geometry of Clements and Hume 1995) and two more restricted markers for feminine (6-b) and neuter (6-c) plurals that specify additional segmental features which may combine with the general plural affix in the appropriate contexts (I refer to the phonological shapes of these affixes by the abbreviations given in brackets such as

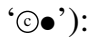

Representations for German plural affixes
VPL
a. $[+\mathrm{pl}] \quad \leftrightarrow \quad \mathrm{COR} \quad(\odot \bullet)$
b. $[+\mathrm{pl}+\mathrm{fem}] \quad \leftrightarrow \quad$ NAS $\quad$ (II)
c. $\left.[+$ pl -fem-masc $] \leftrightarrow\right|_{\text {PHAR }} ^{\text {CPL (D) }}$

The substantial phonological underspecification of the plural marker in (6-a) allows phonology to spell out the optimal shape of the feature-less segment, resulting in the default case in $-e([\ni])(7-a)$, the maximally unmarked segment in German, but in - $n$ if the base already ends in schwa (7-b) since German doesn't allow for sequences of adjacent schwas, a consequence of a more general ban against string-adjacent weak syllable nuclei $(* \underline{v \underline{v} \breve{v}})$ in the language (see Neef 1998 and Sect. 5.1 for detailed discussion).

--Allomorphy

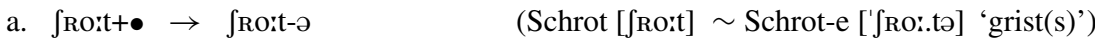

b. bo:tə+ $\rightarrow$ bo:tə-n (Bote ['bo:tə] $\sim$ Bote-n ['bo:ton] 'messenger(s)') 
However, in most forms, plural is realized morphologically by two of the affixes in (6), resulting in a classical case of multiple (extended) exponence. Thus from a phonological point of view, a feminine noun such as Welt [velt] 'world' could realize the plural segment as [ə] (as for masculine Schrot in (7-a)), but morphology leads also to insertion of (6-b) to spell out [+feminine]. After phonological optimization, the resulting segment $-n$ realizes, both the segmental root node of (6-a) and the floating nasal feature of (6-b), as shown in (8-a). Similarly for the neuter noun Feld [felt] 'field' the general plural affix associates to the pharyngeal feature of (6-c) spelling out [+pl-fem -masc] to form a low central vowel (8-b) (subscripts indicate associated affix features):

$$
\begin{aligned}
& \bullet+\{(1),(1)\}-M e r g i n g \\
& \text { a. velt }+\bullet+\text { (n) } \rightarrow \text { velt }-\mathrm{n}_{\mathrm{n}}
\end{aligned}
$$

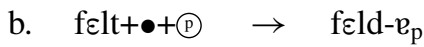

The examples in (7) and (8) are slightly oversimplified in that they disregard the floating CORONAL (+VPLACE) feature which is an inherent part of (6-a). Floating CORONAL is in fact phonologically suppressed in specific cases, but shows up either in the suffix as part of - $n$ as shown in (9-a) for Saat [za:t] Saat-en [zar.tn] 'seed(s)' (the full analysis that would also apply to Welt in (8-a)) or as umlaut (vowel fronting) as in (9-b) for Naht [nait] Näht-e ['nع:.tə] 'seam(s)' under the standard assumption that front vowels are characterized by the feature CORONAL (Hume 1994; Clements and Hume 1995; Lahiri and Evers 1991).

\section{(c-Allomorphy}
a. za:t+c $\bullet+(\mathrm{n}) \rightarrow$ zait $_{\mathrm{c}, \mathrm{n}}$
$(6-a+b)$
b. na:t+C $\bullet+(n) \rightarrow n \varepsilon_{\mathrm{c}}: \mathrm{t}-\partial$
$(6-a+b)$

The theoretical importance of these data is in revealing that 'floating' features are not simply a notational alternative to procedural morphophonological rules for encoding non-segmental changes in stems. The floating exponents of German plurals also show up as part of what is traditionally seen as the suffix, they combine with other floating exponents, and alternate between stem-internal and suffixal morphology. This combinatorial freedom and contextual variability is expected if the primitives of plural exponence are autosegmental pieces of phonological structure, but cannot be captured if processes such as umlaut are implemented as the result of morphophonological rules (Janda 1982; Anderson 1992), readjustment rules (Embick and Halle 2005), or morphophonological constraints (Neef 1998; Alderete 2001; Xu and Aronoff 2011).

The remainder of the paper is structured as follows. In Sect. 2, I lay out background assumptions on the architecture of Optimality Theory, adopting the Stratal Autosegmental Containment approach, and on the featural representation of German segments. The core of the subsegmental analysis is developed in detail and shown to derive central implications between suffix choice and umlaut in Sect. 3. Sect. 4 extends the analysis to phonologically predictable cases of suffix allomorphy, and provides arguments that German plurals instantiate crucial instances of phonological opacity which cannot be covered in an account relying only on surface constraints, but follow naturally in Stratal Containment. Wiese's generalization on the templatic 
shape of noun plurals is derived in Sect. 5, and Sect. 6 shows that nouns taking exceptional plural allomorphs are also best captured in a subsegmental analysis by positing floating root features. Previous theoretical work on German plurals is critically discussed in Sect. 7. Finally, Sect. 8 contains a short summary of the paper.

\section{Background assumptions}

The Generalized Nonlinear Affixation approach (GNA, Bermúdez-Otero 2012; Bye and Svenonius 2012; Zimmermann 2017; Paschen 2018) to which I contribute here is a research program which generalizes the tradition of Autosegmental Phonology (Goldsmith 1976; McCarthy 1979; Marantz 1982) and Prosodic Morphology (McCarthy and Prince 1996), where tonal and templatic exponence is interpreted as affixation of partially specified phonological material (e.g. floating tones or timing slots without segmental melodies) to all productive cases of nonconcatenative morphology in line with the concatenativist hypothesis in (10):

\section{The Concatenativist Hypothesis: \\ Morphology $=$ Concatenation + Phonological alternations}

Recent work in the GNA approach has shown that even cases of nonconcatenative morphology that seem to be inherently procedural, such as morphologically triggered shortening, segment deletion and polarity receive a natural analysis in this general framework (Bye and Svenonius 2012; Zimmermann 2013; Trommer and Zimmermann 2014; Trommer 2014, 2015; Zimmermann 2017). German plurals have been taken as a different type of challenge to the Concatenativist Hypothesis. An affixational analysis has been argued to be incapable to capture submorphemic generalizations (Köpcke 1988; Neef 1998) such as the triggering of umlaut by -er-suffixes as well as the prosodic consistency in German plurals (Wiese 2009). In the following sections, I will show that a strict GNA approach not only solves these problems, but also provides deeper phonological explanations for these generalizations and captures them in a more natural way than approaches employing morphophonological constraints requiring spellout for specific features (Hammond 1995; Russel 1995; Klein 2000; MacBride 2004; Xu and Aronoff 2011) or paradigmatic distinctness (Neef 1998; Kurisu 2001; Carstairs-McCarthy 2008) (see Sect. 4 for detailed discussion).

This points to a final important aspect of the Nonlinear Affixation approach: The heuristic value of the GNA program and the Concatenativist Hypothesis-to closely link nonconcatenative morphology and productive phonological alternations-stands and falls with its coupling to a strong version of the Indirect Reference Hypothesis (Nespor and Vogel 1986; Selkirk 1986; Inkelas and Zec 1995), which disallows direct reference to morphosyntactic information in phonological rules and constraints. Morphologically sensitive constraints as in indexed-constraint approaches (Pater 2000, 2007 ) or its rough equivalent, the assumption of different cophonologies for specific morphological constructions (Orgun 1996; Inkelas and Zoll 2005; Inkelas 2014), substantially undermine the empirical content of the Concatenativist Hypothesis since 
they allow phonology to perform most of the operations usually assumed in approaches to morphology employing spellout constraints or rules (Anderson 1992; Xu and Aronoff 2011; Staubs 2011) in a morphologically distinctive way (see BermúdezOtero 2012 for discussion).

In the following, I will therefore assume that the possible effects of morphosyntactic information on phonological computation is minimal. It is restricted to the notion of morphological color in Autosegmental Colored Containment Theory, and to the stratal architecture of word-internal morphophonology, which I will discuss in the following two sections.

\subsection{Autosegmental Colored Containment Theory}

Autosegmental Colored Containment Theory (Zimmermann 2014, 2017; Trommer 2011, 2015; Zaleska 2018; Paschen 2018) is an implementation of the restrictive original version of Optimality Theory proposed in Prince and Smolensky (1993) in that it adopts hierarchical autosegmental representations and the Containment requirement on candidate generation. In a nutshell, containment-based systems retain unpronounced phonological structure as floating material in the output of phonological computation - a possibility coming for free in any formalism adopting hierarchical autosegmental and prosodic representations-allowing direct comparison between inputs and outputs and thus obviating the overly powerful coindexing mechanism of Correspondence Theory for implementing faithfulness constraints (Walther 2001). The version adopted here slightly departs from the Prince and Smolensky version of Containment by adopting the representation of epenthesis through morphological colors from Colored Containment Theory (van Oostendorp 2006; Revithiadou 2007), and by generalizing the Containment assumption to association lines ('Radical Containment').

Morphological colors: Following van Oostendorp (2006) and Revithiadou (2007), I assume that morphological structure is minimally reflected in phonological representations by coloring. At the interface of morphology and phonology, every morpheme $M$ of an underlying representation is assigned a unique color which is inherited to all nodes and association lines that are part of $M$. Colors have two consequences for phonological computation. First, they allow us to detect whether two phonological elements belong to different morphemes, providing a general autosegmental notion of morpheme boundary. This aspect of the theory, although crucial to foundational results of Colored Containment Theory (see e.g. van Oostendorp 2007), will not be relevant for the German data discussed here. Second, colors allow us to distinguish underlying ('colored') material from epenthetic material: Epenthetic material is colorless, and by the Containment Assumption GEN doesn't license the change or removal of the color of underlying material.

Possible operations of GEN: By the Radical Containment Assumption, phonological material can never be literally removed from phonological input representations in the course of phonological computation (Prince and Smolensky 1993; van Oostendorp 2008:1365). The candidate-generating function GEN is thus restricted to the following changes it may perform on underlying forms (phonetic visibility is conceived as an elementary attribute of association lines, but not of phonological nodes): 


\section{Possible operations of GEN:}

a. Insert epenthetic nodes (prosodic nodes, feature nodes, segmental root nodes) or phonetically visible association lines between nodes

b. Mark a colored association line as phonetically invisible

(11-a) implements the slightly implicit assumptions held on Containment and GEN in the earliest version of Optimality Theory (Prince and Smolensky 1993), whereas (11-b) replaces deletion of association lines by a less invasive operation: marking for phonetic invisibility (indicated in the following by dotting). (12) shows different candidates generated by this version of GEN for the input (12-a) two vowels (with underlyingly associated moras), and some plausible repairs of the resulting hiatus (see Casali 1996, 1997, for a detailed containment-based analysis) where epenthetic/colorless nodes are marked by grey background shading and epenthetic association lines by dashing (- - ). In (12-b) a single association line is inserted, generating a diphthong ([au]), in (12-c) additional syllable and foot nodes are added and associated, and in (12-d) an additional glottal stop:
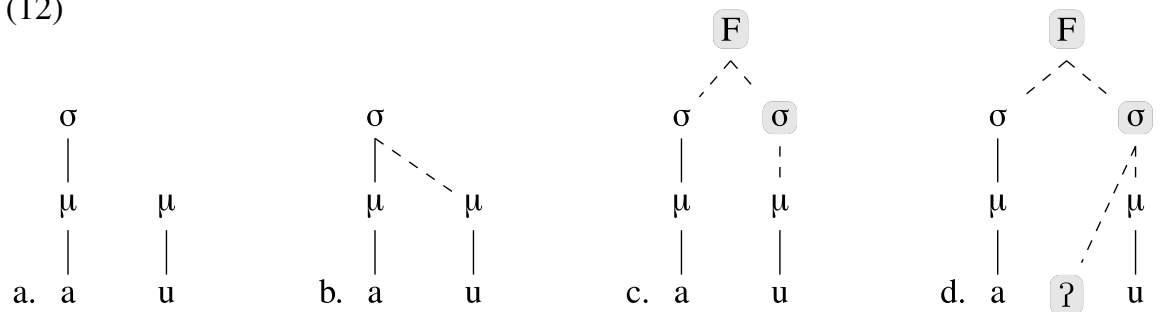

Deletion as Phonetic (Non-)pronunciation: (Non-)pronunciation of underlying material is implemented as phonetic non-interpretation of phonological material following the axiom in (13):

\section{Axiom of phonetic realization}

A phonological node is phonetically realized iff it is dominated by the highest prosodic node of the candidate through a path of phonetically visible association lines

Thus in (12-b,c,d) all underlying material is pronounced since it is dominated through (underlying or epenthetic) phonetic association lines by the highest prosodic node (a $\sigma$-node in (12-b), and a foot node in (12-c,d)). (14) shows candidates produced by GEN leading to partial non-pronunciation. In (14-b), the association line between the syllable and its mora is marked as non-phonetic by dotting $(\cdots)$, thus neither the mora nor the vowel [a] below it are pronounced. Crucially, (14-a) (the output candidate identical to the input) also leads to partial non-pronunciation even though all input structure is preserved in the phonological output. [u] and its mora are not dominated by the highest P-node (the syllable), and hence invisible for phonetic spellout. (14-c,d) are two more complex candidates with compensatory lengthening, where one of the vowels is unpronounced since the association line connecting it to a mora 
is rendered invisible, but the mora itself is fully integrated via epenthetic association lines, and hence pronounced as additional length:

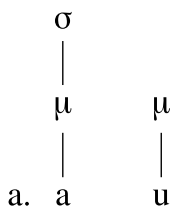

[a]

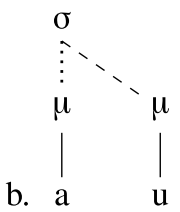

$[\mathrm{u}]$

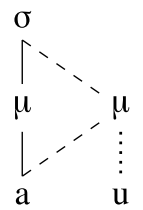

[a:]

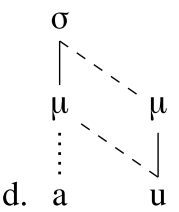

[u:]

Since 'deletion' in Autosegmental Containment is roughly equivalent to a generalized notion of 'floating,' I will also use the classical circle notation for indicating phonetic non-realization (e.g. (u) for the second vowel in (14-b)). For convenience, I will abbreviate the term 'phonetically realized' in the following simply by 'phonetic' and will call colored (i.e., underlying) phonological material 'morphological' since it is interpreted by morphology as part of specific morphemes.

Markedness constraints and the Cloning Hypothesis: Following Trommer (2011), I assume that containment-based markedness constraints are restricted by the hypothesis in (15) which limits sensitivity to underlying material to generalized constraints ('clones') mimicking independently motivated markedness constraints on surface representations:

\section{The Cloning Hypothesis:}

Every markedness constraint has two incarnations, a phonetic and a general clone: The general clone refers to complete phonological representations. The phonetic clone refers to the phonetically realized substructure of phonological representations.

Phonetic clones are standard markedness constraints on phonetic output representations, whereas general clones evaluate input and output representations together (i.e., the combination of all input and output structure). Whereas these constraints are structurally identical, they refer to different sub-representations of candidates (or more exactly of input-candidate mappings), but can be ranked independently in individual grammars (see McCarthy 1996, 2003; Ettlinger 2008 for related approaches in Correspondence Theory). Phonetic clones are marked by underlining, while general clones are not graphically marked. Consider as an example the constraint against double linking of CORONAL features which will play a crucial role in the analysis of umlaut below. Both the generalized $\left(* \mathrm{COR}_{2} \bullet\right)$ and the phonetic clone of this constraint $\left(* \underline{\mathrm{COR}}_{2}\right.$.) penalize a CORONAL feature which is linked morphologically to a single segment (16-c) and spreads phonetically to another segment, resulting in surface double linking (16-b) (e.g. /o ... $\left.\mathrm{y}_{\mathrm{Cor}} / \Rightarrow\left[\varnothing_{\mathrm{Cor}} \ldots \mathrm{y}_{\mathrm{Cor}}\right]\right)$. While shifting of the CORONAL feature as in (16-a) (i.e., spreading and concomitant overt deassociation from its original node (e.g. /o ... $\left.\mathrm{y}_{\mathrm{Cor}} / \Rightarrow\left[\emptyset_{\mathrm{Cor}} \ldots \mathrm{u}\right)\right]$ ) obviously doesn't violate * $\underline{\mathrm{COR}}_{2}$. (CORONAL is phonetically linked to only one segment), it still violates the generalized markedness constraint $* \mathrm{COR}_{2}$. since the overall representation contains both phonetically visible and invisible association lines (16-a): 
Phonetic vs. generalized markedness constraints

\begin{tabular}{|c|c|c|}
\hline Input: = c. & ${ }^{*} \mathrm{CoR}_{2}$. & $* \mathrm{CoR}_{2}$ \\
\hline $\begin{array}{ccc} & \ddots & \bullet \\
& \ddots & \vdots \\
& & \vdots \\
& & \text { Cor }\end{array}$ & $*$ & $\begin{array}{l}1 \\
\vdots \\
\vdots \\
\vdots \\
1\end{array}$ \\
\hline 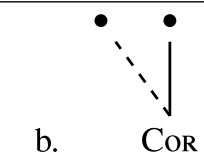 & $*$ & $\begin{array}{l}1 \\
1 \\
1 \\
1 \\
1 \\
1\end{array}$ \\
\hline $\begin{array}{ll}\bullet & \bullet \\
& \left.\right|_{\text {c. }}\end{array}$ & & $\begin{array}{l}1 \\
\vdots \\
\vdots \\
\vdots \\
1\end{array}$ \\
\hline
\end{tabular}

Note that generalized constraints cannot fully replace phonetic versions of specific constraints. Thus the ban on front round vowels in a language such as English which disallows them (see also Sect. 4.3 for minor effects on German plurals) must be the phonetic clone of the constraint, ${ }^{*}{ }_{\mathrm{COR}} \bullet_{\mathrm{LAB}}$. The general clone ${ }^{*}{ }_{\mathrm{COR}} \bullet{ }_{\mathrm{LAB}}$ would not be satisfied by changing an underlying /y/ resulting in surface [i] or [u]. Due to Containment, the resulting sound would still have the underlying COR and LAB specifications accessible to the generalized clone.

\subsection{Stratal organization}

In line with the classical theoretical work on German morphophonology (Wiese 1988, 1996b; Giegerich 1987; Hall 1992), I assume that the lexical morphophonology of German is organized in different strata, accounting both for morphological and phonological differences. In particular, I will assume the version of Stratal Optimality Theory (Kiparsky 2000, 2015; Bermúdez-Otero 2018, to appear) laid out in Trommer (2011) which comprises three lexical strata, (1) the Root Level (optimizing roots and stem-level affixes before their concatenation), (2) the Stem Level (evaluating combinations of stem-level affixes and roots, but also word-level affixes before concatenation), and (3) the Word Level evaluating complete words.

I assume that the native layer of plural formation that I analyze in this paper, is located at the Stem Level, whereas the s-plural productive in borrowings (such as Kid $\sim$ Kid-s 'children') and stems with non-standard phonotactics (e.g. the few noun roots ending in non-reduced vowels such as Oma Oma-s 'grandma(s)') is part of the Word Level (see Wiese 2009 and references cited there on detailed arguments for the special status of plural-s). Even though all plural morphology under discussion in this paper is identified with the Stem Level, the stratal organization plays a restricted role in the analysis in restricting the possible shapes of inputs (e.g. excluding schwa+nasal syllables), and accounting for the neutralization of crucial stem-level contrasts in the Phrase-Level (postlexical) phonology resulting in surface opacity (see Sect. 4). 


\subsection{Assumptions on German vowels and syllable nuclei}

I adopt the Unified Feature Geometry of Clements and Hume (1995) with slight modifications adapting it to the German vowel system. The major design feature of the Clements-Hume system setting it apart from other feature-geometric proposals (e.g. Sagey 1986 and Halle et al. 2000) is that vowels and consonants utilize the same place features (being dominated by different non-terminal nodes (VPLACE vs. CPLACE), where VPLACE is also obligatorily dominated by a CPLACE node) which renders it well-suited to capture the alternation between consonantal suffix place and vocalic fronting in umlaut which I analyze here. Note that, departing slightly from Clements and Hume, I assume that [ \pm consonantal] (in their proposal the inverse feature [ \pm vocoid] $)$ is not an inherent part of the segmental root node but on a separate tier associated to the root, which allows a simpler representation of the fact that the underspecified plural segment $\bullet$ is underlyingly neither a consonant nor a vowel acquiring a [ \pm consonantal] specification according to its context.

Full vowels: Following Lahiri and Evers (1991), I assume that back and front vowels are characterized by the privative features [DOR(SAL] and [COR(ONAL)] respectively, dominated by the VPLACE node (Clements and Hume 1995), illustrated for $[e / \varepsilon],[o / \supset]$ and $[\varnothing / œ]$ in $(17-a, b, c)$, whereas the low vowel [a] is only specified for [PhAR(YNGEAL)] (17-d), hence neither DORSAL nor CORONAL. Full vowels are hence specified by exactly one lingual place feature (and additionally [LABIAL] in the case of the back round vowels). Vocalic height in full vowels is represented by the AP(ERTURE) node dominating the features $[ \pm$ high $]$ and $[ \pm$ low $]$.
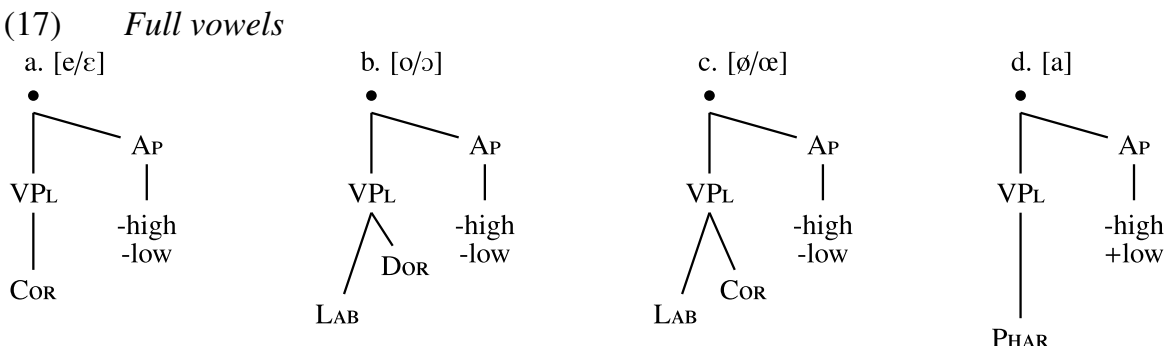

In line with Yu (1992, see also Lieber 1992 and Scharinger 2006 for experimental evidence), I interpret the possibility of a stem vowel to undergo umlaut as a consequence of underspecification. Thus the vowel of a noun such as Sohn [zo:n] 'son' umlauting to plural Söhn-e ['zø:.nə] has height and rounding features (in the case of Sohn [-high -low LABIAL]), but is specified for neither DOR nor COR, notated here as "O" (18-a) (fully parallel: the underspecified high round back vowel " $\mathrm{U}$ " as in Gut [guit] Güter [gy:.te] 'good(s)' (18-b)). In the singular, DoR is filled in by default resulting in a back vowel, while in the plural the floating COR of the suffix associates to the vowel resulting in $[\varnothing:]$. On the other hand, a minimally distinctive non-umlauting noun such as Thron [tro:n] 'throne', plural Thron-e ['tro:.nə] is underlyingly fully specified as DORSAL as in (17-b). Similarly, an umlauting low vowel (notated as capital "A") as in Rat [Ra:t] Räte ['RE:.tə] 'council(s)' is not specified for PHARYNGEAL, but only for [+low-high] (18-b) in contrast to the fully specified immutable [a] in (17-d). 
(18-c) becomes Pharyngeal in the singular by default, but results in [ $\varepsilon]$ (17-a) if the floating plural COR associates to it (collaterally changing [+low] to [-low]). See Sect. 4.3 for an in-depth discussion of vocalic underspecification.

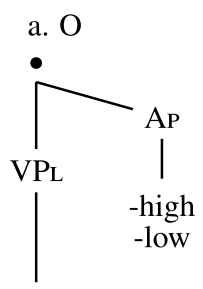

$\mathrm{LAB}$ b. U

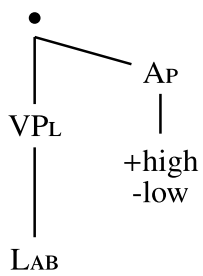

c. A

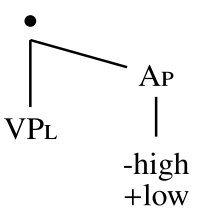

Reduced vowels: The central mid vowel [ə], is arguably the default (epenthetic) vowel of German (Wiese 1986, 1996b; Hall 1992; Noske 1993), which corresponds to its status in the analysis of plural allomorphy proposed here: Schwa is the realization of the underspecified plural segment, if no other factors enforce a more specified segment. Following van Oostendorp (1995), I take [ə] to be a maximally underspecified vowel. In particular, I assume that it not only lacks specific place but also height features (in terms of the assumed feature geometry: the APERTURE node), hence that it only bears a VPLACE node. The lack of height features also characterizes the low central vowel $[\mathrm{e}]$, which I will call 'a-schwa' in the following. The a-schwa has an additional PHARYNGEAL feature dominated by VPLACE; it is thus representationally a reduced [a]. (19) shows the representations for reduced vowels (19-a,b) and the defective segment of the plural affix (19-c):

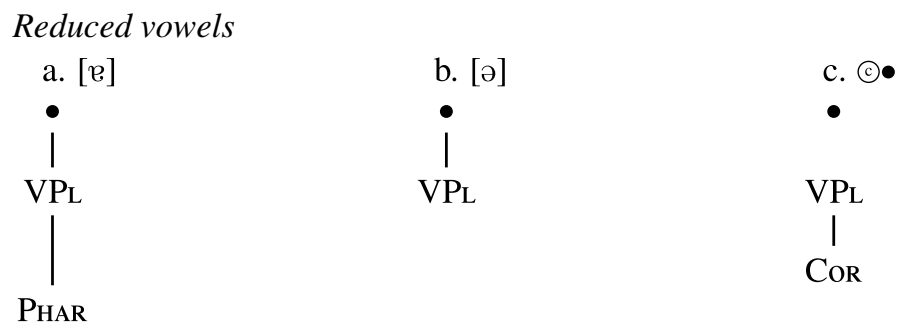

Syllabic sonorants: The status of schwa is closely connected to the variable realization of sonorants in post-consonantal position (orthographic en, em, el). For example, a noun such as Atem 'breath' pronounced as [?a:.təm] in the literary standard pronunciation is naturally produced as [?a:.tm] in colloquial speech. Thus grammatically there is free variation between syllabic consonants and coda consonants headed by schwa, whereas the presence of schwa is clearly phonemic in other contexts (cf. e.g. the contrast between Beet [be:t] 'flower bed' and Bete [be:.tə] 'beet root'). I will take here the conservative position that in the input to the stratum where plural morphophonology applies (the Stem Level) final postconsonantal sonorants uniformly head weak syllables headed by sonorant consonants (as in ['?a:.tm]), hence are not preceded by schwa, whereas the observed free variation is due to variable constraint ranking at the Phrase Level (Wiese 1986, 1996b; Noske 1993, see Sect. 4.1 for de- 
tails). A special case is the rhotic [R] that cannot occur in rhymes where it alternates with the a-schwa [e] (e.g. in Bär [be:e] Bären['be:.rən] 'bear(s)'), which I will discuss in detail in Sects. 3.4 and 4.2.

\section{The core analysis}

In this section, I show that a Generalized Nonlinear Affixation analysis of German plural formation provides a solution to Wunderlich's Dilemma—systematic relations between aspects of plural spellout in the face of ultimate unpredictability-by deriving the central generalizations in (20): (Augst 1979; Wurzel 1998; Neef 1998; Wunderlich 1999, and the online supplementary material) $:^{4}$

\section{Central generalizations on plural umlaut and suffix allomorphy}

Generalization I: Umlaut and plural- $n$ are in complementary distribution

Generalization II: Feminine nouns strongly prefer plural- $n$ in contexts where non-feminine nouns do not

Generalization III: Noun roots ending in ...ə always take plural- $n$ (and consequently never show umlaut)

Generalization IV: Nouns with plural -er always umlaut

In the following subsections, I will introduce step-by-step the optimality-theoretic constraints which capture these generalizations. In Sect. 5, I will show that a minimal extension of the analysis developed here also captures Wiese's Generalization-the word-final strong-weak template in noun plurals. I start my discussion by introducing the bare backbone mechanics I assume for umlaut, the two constraints in (21):

\section{Central constraints governing umlaut}
a. $\mathrm{c} \rightarrow \mathrm{V}$
Assign $*$ to every CORONAL node which is not linked to a full vowel
(i.e., to a [-cons] segment with an APERTURE node)
b. $\quad * \mathrm{~V}_{2\{\mathrm{c}, \mathrm{d}, \mathrm{p}\}} \quad$ Assign $*$ to every vowel which is linked to more than 1 lingual PLACE feature
(CORONAL, DORSAL, or PHARYNGEAL)

$\mathrm{c} \rightarrow \mathrm{V}$ captures the preference for associating a floating CORONAL feature to a vowel (instead of a consonant or to leaving it floating). This preference is restricted by higher ranked $* \mathrm{~V}_{2\{\mathrm{c}, \mathrm{d}, \mathrm{p}\}}$ which encodes the fact that German vowels are either front,

\footnotetext{
${ }^{4}$ Apart from generalization II, the restrictions in (20), while well-known for a long time, have been outside the focus of most of the extensive literature on German plural whose major goal is to identify the 'central' 'major' 'regular' and 'productive' allomorphs of plural formation (Augst 1979; Sonnenstuhl et al. 1999; Wiese 2009). In contrast, the analysis here aims to capture the fact that the observations in (18) hold for all allomorphs. See Sect. 6 for an analysis of exceptional nouns and Sect. 7 for discussion of previous theoretical work attempting to capture these generalizations.
} 
back or low, but never combine the relevant VPLACE features. Thus $* \mathrm{~V}_{2\{\mathrm{c}, \mathrm{d}, \mathrm{p}\}}$ blocks association of CORONAL to vowels that are already specified for DORSAL or PHARYNGEAL (i.e., fully specified back and low vowels) resulting in representations as in (22):

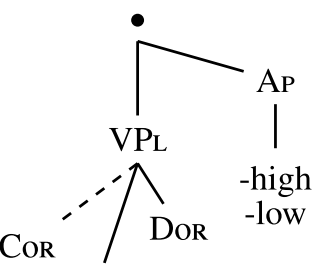

a.

$\mathrm{LAB}$

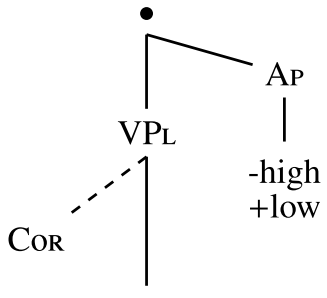

b.

PHAR

The effect of $\mathrm{c} \rightarrow \mathrm{V}$ is best visible in one of the most transparent patterns, masculine nouns with $-e$ and obligatory umlaut in the plural, such as Sohn [zo:n] $\sim$ Söhne ['zø:.nə] 'sons(s)' (23-a). Recall from Sect. 2.3 that the stem vowel of Sohn is mid ([-high -low]) and LABIAL, but otherwise underspecified for VPLACE (indicated by capital $O$ in the input) as in (18-a), and the only underlying affix here is the generic plural marker, whose floating CORONAL feature (c) is realized by association to the stem vowel (indicated by subscripting) resulting in front [ $\varnothing:]$ whereas its segmental root node is realized as [ə] (23-a-ii).

By assumption, a minimally distinct noun such as Thron [tro:n] Thron-e ['tro:.nə] 'throne(s)', for which umlaut plural is impossible, differs underlyingly only in that the stem vowel is specified by association to DORSAL (indicated by subscripted 'd', see (17-b) for the full vowel representation for (23-b-i), and (22-a) for (23-b-ii)). Since $* \mathrm{~V}_{2\{\mathrm{c}, \mathrm{d}, \mathrm{p}\}}$ outranks $\mathrm{c} \rightarrow \mathrm{V}$, umlaut as in (23-b-ii) is blocked. Since MAX CORONAL is ranked too low to have an effect, the feature remains floating and unpronounced (23-b-i) (see Sect. 3.2 for a formal account of this fact):

a. Input: zO:n+C• (Sohn 'son', masc.)

\begin{tabular}{|c||c|c|}
\hline & $* \mathrm{~V}_{2\{\mathrm{c}, \mathrm{d}, \mathrm{p}\}}$ & $\mathrm{c} \rightarrow \mathrm{V}$ \\
\hline \hline i. $z 0: \mathrm{n}(\mathrm{c} \partial$ & & $* !$ \\
\hline ii. $\mathrm{z} \emptyset_{\mathrm{c}}$ :nə & & \\
\hline
\end{tabular}

b. Input: tro: ${ }_{\mathrm{d}} \mathrm{n}+(\mathrm{C} \bullet$ (Thron 'throne', masc.)

\begin{tabular}{|c|c|c|}
\hline & $* \mathrm{~V}_{2\{\mathrm{c}, \mathrm{d}, \mathrm{p}\}}$ & $\mathrm{c} \rightarrow \mathrm{V}$ \\
\hline i. tro $\mathrm{t}_{\mathrm{d}} \mathrm{n}(\mathrm{C})$ & & * \\
\hline ii. $\operatorname{tr} \emptyset_{\mathrm{c}, \mathrm{d}}$ :nว & $* !$ & \\
\hline
\end{tabular}

The analysis for low-vowel stems is completely parallel. An alternating root such as Rat [Ra:t] Räte ['Rع:.tə] 'council(s)' has a stem vowel whose aperture features are low ([+low -high]), but which is fully underspecified for VPLACE (indicated by capital $A$ (18-c), allowing for satisfaction of $\mathrm{c} \rightarrow \mathrm{V}$ (24-a) without violating $* \mathrm{~V}_{2\{\mathrm{c}, \mathrm{d}, \mathrm{p}\}}$, whereas a root vowel that is underlyingly specified as PHARYNGEAL as in Maat [ma:t] Maat-e ['ma:.tə] 'steward(s)' is immune to association of floating CORONAL (24-b) (see (17-d) for the full vowel representation for (24-b-i), and (22-b) for (24-b-ii)): 
a. Input: $\mathrm{RA}: \mathrm{t}+\subset \bullet$ (Rat 'council', masc.)

\begin{tabular}{|l||c|c|}
\hline & $* \mathrm{~V}_{2\{\mathrm{c}, \mathrm{d}, \mathrm{p}\}}$ & $\mathrm{c} \rightarrow \mathrm{V}$ \\
\hline \hline i. $\mathrm{Ra}$ atcə & & $* !$ \\
\hline ii. $\mathrm{R} \varepsilon_{\mathrm{c}}$ :tə & & \\
\hline
\end{tabular}

b. Input: $\mathrm{ma}_{\mathrm{p}} \mathrm{t}+\mathrm{C} \bullet$ (Maat 'steward', masc.)

\begin{tabular}{|c||c|c|}
\hline & $* \mathrm{~V}_{2\{\mathrm{c}, \mathrm{d}, \mathrm{p}\}}$ & $\mathrm{c} \rightarrow \mathrm{V}$ \\
\hline \hline i. $\mathrm{ma}_{\mathrm{p}} \mathrm{t} \mathrm{t} \mathrm{c} \rho$ & & $*$ \\
\hline ii. $\mathrm{m} \varepsilon_{\mathrm{c}, \mathrm{p}} \mathrm{it} \partial$ & $* !$ & \\
\hline
\end{tabular}

So far, the analysis is a conservative constraint-based restatement of classic autosegmental analyses: Floating features are associated whenever possible, restricted by underspecification to contexts where it is not feature-changing (see Lodge 1989; Yu 1992; Scharinger 2009 for earlier proposals tying German umlaut to underspecification). Note however an important containment effect: $* \mathrm{~V}_{2\{\mathrm{c}, \mathrm{d}, \mathrm{p}\}}$ is the general clone of the constraint under containment (cf. (15) in Sect. 2.1). Thus even if we make the underlying PHARYNGEAL association of the vowel in (24-b) phonetically invisible and associate it to CORONAL, the constraint is still violated. Underspecification captures the fact that plural umlaut (and its consequences for segmental plural allomorphy) is not fully predictable from the bare singular stem, which is the first half of Wunderlich's problem. ${ }^{5}$ In the following subsections, I will extend the analysis to also capture the implicational generalizations on plural formation to solve this dilemma.

\subsection{Generalization I: Complementary distribution of umlaut and plural-n}

We are now in a position to derive the mutual exclusiveness of plural- $n$ and umlaut, based on underlying affix material, the CORONAL feature shared by all plural forms and the floating [nasal] introduced by feminine plurals. Their surface realization is crucially governed by the four constraints in (25):

Constraints governing [CORONAL] and [nasal]

a. ${ }^{*} \mathrm{COR}_{2}$ • Assign $*$ to every CORONAL node which is linked to more than one segmental root node

b. MAX n Assign $*$ to every morphological nasal feature which is not phonetically realized

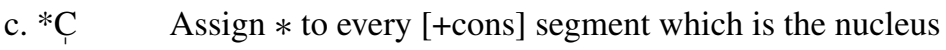
of a syllable

d. $\left.{ }^{*} \mathrm{CC}\right]_{\sigma} \quad$ Assign $*$ to every pair of adjacent [+cons] segments in a syllable rhyme

${ }^{*} \mathrm{COR}_{2}$. is the crucial constraint in deriving the complementarity of umlaut and $-n$. In a feminine noun such as Naht [na:t] Nähte ['nع:.tə] 'seam(s)' the underlying

\footnotetext{
${ }^{5}$ Whereas it is ultimately unpredictable whether a given noun root shows umlaut (hence is underspecified under the subsegmental analysis) or not, there are statistical correlations between phonotactic patterns (e.g. consonant clusters) and semantic features (such as animacy), and the tendency to umlaut, as shown by Köpcke $(1993,1994)$. The goal of the analysis here is to capture only the categorical strictly phonologically motivated generalizations on umlaut and plural, hence I will not be concerned with these tendencies.
} 
vowel is again underspecified, allowing in principle for umlaut. The floating coronal feature could now either be realized as part of a $n$-suffix as in (26-a) (or even a stem segment as in (26-b)) or as umlaut as in the correct output in (26-c). That the umlaut candidate, where the nasal feature realizing the feminine plural affix remains floating is preferred over the $n$-candidate (which hosts the floating nasal) is due to the ranking of $\mathrm{c} \rightarrow \mathrm{V}$ above MAX $\mathrm{n}$, but this doesn't exclude a further option: the affix feature might be associated to both the suffix segment and the stem vowel as in (26-f) (double association of CORONAL is marked here informally as two subscript c's connected by a horizontal line), which is blocked by ${ }^{*} \mathrm{COR}_{2}$. Thus the constraint ensures that the plural CORONAL feature is available only in one segment and can either trigger umlaut or form part of a coronal nasal, but not serve both duties simultaneously. Note finally that inserting an additional epenthetic CORONAL feature as in (26-d,e) is also excluded by $\mathrm{c} \rightarrow \mathrm{V}$ since the epenthetic CORONAL would also not be associated to a full vowel. ${ }^{6}$

Input: $\mathrm{nA}: \mathrm{t}+\mathrm{C} \bullet+(\mathrm{n})$ (Naht 'seem', fem.)

\begin{tabular}{|c|c|c|c|c|c|c|c|}
\hline & & $* \mathrm{CoR}_{2}$ & $* \mathrm{~V}_{2\{\mathrm{c}, \mathrm{d}, \mathrm{p}\}}$ & $c \rightarrow V$ & MaX n & $* \mathrm{C}$ & $\left.{ }^{*} \mathrm{CC}\right]_{\sigma}$ \\
\hline & a. na:tn ${ }_{c, n}$ & & 1 & $* !$ & & * & \\
\hline & b. na:t(c)ə(n) & & 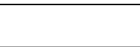 & $* !$ & * & & \\
\hline 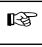 & c. $n \varepsilon_{\mathrm{c}}: \mathrm{t \partial}$ (n) & & 1 & & $*$ & & \\
\hline & d. $n \varepsilon_{c}: \operatorname{tn}_{\mathrm{c}, \mathrm{n}}$ & & 1 & $* !$ & & * & \\
\hline & e. $n \varepsilon_{c} \cdot \operatorname{trn} n_{c, n}$ & & 1 & $* !$ & & & \\
\hline & f. $n \varepsilon_{\mathrm{c}} \underline{\mathrm{tn}}_{\mathrm{c}, \mathrm{n}}$ & $* !$ & 1 & & & * & \\
\hline
\end{tabular}

The tableau in (27) illustrates the complementary situation, a feminine noun (Saat [za:t] Saaten ['za:.tn] 'seed(s)') with an underlyingly fully specified back vowel. As in (24-b), the floating coronal feature cannot trigger umlaut due to undominated $* V_{2\{c, d, p\}}(27-c, d, e)$ and is thus forced to combine with the floating root node and the nasal feature of the feminine plural suffix to form $-n$ (27-a) by virtue of MAX $n$ (excluding (27-b)):

(27) Input: $\mathrm{za}_{\mathrm{p}} \mathrm{t}+\mathrm{C} \bullet+\mathrm{C}$ (Saat 'seed', fem.)

\begin{tabular}{|c|c|c|c|c|c|c|c|}
\hline & & $* \mathrm{CoR}_{2}$ & $* V_{2\{c, d, p\}}$ & $c \rightarrow V$ & Max n & $* \mathrm{C}$ & $* \mathrm{CC}]_{\sigma}$ \\
\hline 哩 & a. $\mathrm{za}_{\mathrm{p}}: \mathrm{tn}_{\mathrm{c}, \mathrm{n}}$ & & 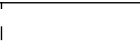 & * & & $*$ & \\
\hline & b. $\mathrm{za}_{\mathrm{p}}: \mathrm{t}(\mathrm{C}) \mathrm{n}$ & & । & $*$ & $* !$ & & \\
\hline & c. $\mathrm{z} \varepsilon_{\mathrm{c}, \mathrm{p}}$ :tə & & $* !$ & & & & \\
\hline & d. $z \varepsilon_{\mathrm{p}, \mathrm{c}} \cdot \operatorname{tn}_{\mathrm{c}, \mathrm{n}}$ & & $* !$ & $*$ & & * & \\
\hline & e. $\mathrm{z} \varepsilon_{\mathrm{p}, \mathrm{c}} \mathrm{stn}_{\mathrm{c}, \mathrm{n}}$ & $* !$ & $* !$ & & & $*$ & \\
\hline
\end{tabular}

\footnotetext{
${ }^{6}$ The ranking of $* \mathrm{COR}_{2}$. above $\mathrm{c} \rightarrow \mathrm{V}$ also ensures that other CORONAL features which are underlyingly part of full segments will neither spread or shift to other vowels (cf. the discussion of the constraint in Sect. 2.1). See Sect. 5.4 for a discussion of further constraints which restrict the realization options for plural-•.
} 
Note that the novel, purely phonological, explanation for Generalization I provide here is essentially parallel to classical analyses of floating featural affixes such as labialization in Chaha (Akinlabi 1996; Rose 1997, 2007), where the same morphemic material can show up in different segmental positions in a word according to phonological well-formedness conditions (see also Zoll 1996 and Kim and Pulleyblank 2009 for cases of glottalization which alternate with full glottal segments). In Sect. 4, I will show that generalizations of this type are inherently problematic for amorphous approaches to morphophonology which deny that phonological exponence is piecebased (Neef 1996; Russel 1999; Inkelas 2012, 2014).

\subsection{Generalization II: The feminine-nasal correlation}

The predisposition of feminine nouns for plural- $n$ in contexts where masculine and neuter nouns exhibit - $ə$ is evident from non-umlauting masculine nouns such as Maat $\sim$ Maate (24-b) which forms a quasi-minimal pair with feminine Saat $\sim$ Saaten in (27). This difference is an emergent effect of $* \mathrm{C}$ which ensures that non-umlauting masculine and neuter nouns, which have a freely available (floating) token of CORONAL, still avoid forming an $n$-suffix as in (28-a). Note that (28-a) doesn't violate $\left.{ }^{*} \mathrm{CC}\right]_{\sigma}$ since the stem-final $t$ is not in a rhyme, but the onset of the following syllabic $n .^{7}$ (28) gives the full derivation of a masculine non-umlauting noun such as Maate (24-b). Since masculine nouns lack the floating nasal feature introduced by the [+feminine +plural] affix, and (c) isn't protected by any high-ranked faithfulness constraint, MAX $\mathrm{n}$ becomes inert, and the suffixal coronal feature stays floating and unpronounced (since the constraint is undominated, I omit $* \mathrm{COR}_{2}$. and candidates violating it in (28) and the following tableaux): ${ }^{8}$

Input: $\mathrm{ma}_{\mathrm{p}} \mathrm{it+( \textrm {C } \bullet}$ (Maat 'steward', masc.)

\begin{tabular}{|c|c|c|c|c|c|c|}
\hline & & $* \mathrm{~V}_{2\{\mathrm{c}, \mathrm{d}, \mathrm{p}\}}$ & $c \rightarrow V$ & Max n & ${ }^{*} \mathrm{C}$ & $* \mathrm{CC}]_{\sigma}$ \\
\hline & a. $\operatorname{ma}_{\mathrm{p}}: \mathrm{tn}_{\mathrm{c}}$ & & $*$ & & $* !$ & \\
\hline 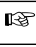 & b. $\mathrm{ma}_{\mathrm{p}} \mathrm{it}(\mathrm{C} \partial$ & & $*$ & & & \\
\hline & c. $m \varepsilon_{c, p}$ itə & $* !$ & & & & \\
\hline
\end{tabular}

A similar asymmetry with suffixal $-n$ showing up in feminines, but not in neuter and masculine nouns, holds for nouns ending in syllabic $l$, where feminine nouns consistently show $-n$, but non-feminine nouns show no segmental suffix at all, as shown in (29). Once again, umlaut is in complementary distribution with suffix- $n$ :

\footnotetext{
${ }^{7}$ The big majority of native German noun roots are consonant-final. See Sect. 5.3 for discussion of exceptional vowel-final roots.

${ }^{8}$ The tableau in (28) also shows that the preference of realizing $\bullet$ as [ə] over [n] is triggered by $* \mathrm{C}$, not the stricter ban on consonantal place insertion (cf. Sect. 5.4) since [ə] is chosen even where an underlying CORONAL feature is available.
} 
(29) Nouns ending in $C+l^{9}$

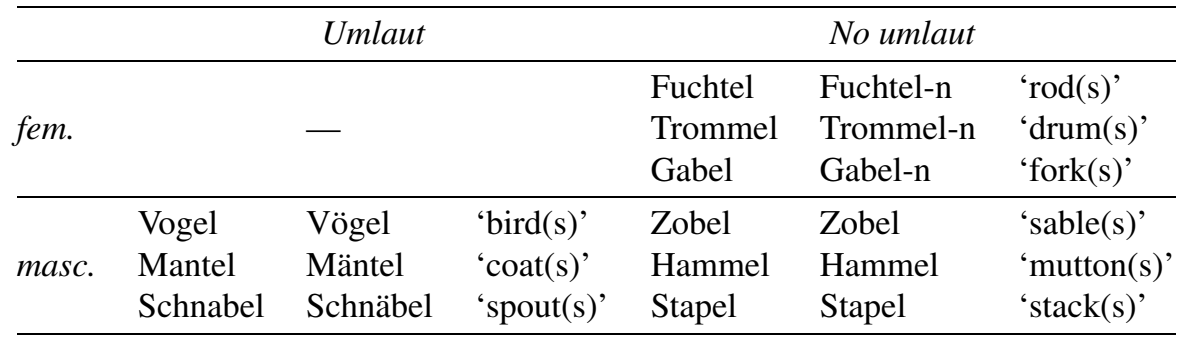

Now recall that noun roots orthographically ending in $e n$ and $e l$ have syllabic final consonants in the Stem-Level phonology, but exhibit free variation with [əl] and [ən] at the Phrase Level. I assume that word-final syllabic sonorants already acquire their status as syllabic nuclei at the Root Level, and are forced to preserve their syllabic role at the Stem Level by the faithfulness constraint in (30):

(30) IDENT v: Assign $*$ to every segmental root node which is a morphological but not a phonetic syllable nucleus

Assuming that IDENT $v$ is undominated, as in (31), it blocks the possibility to break up a $[1 \mathrm{n}]$ cluster by an epenthetic $\partial$ as in $(31-\mathrm{a}, \mathrm{b})$, and $* \mathrm{CC}]_{\sigma}$ becomes decisive in choosing non-realization of the defective affix-• (31-d) over $-n$ (31-c). For explicitness, (31) also contains the faithfulness constraint MAX $\bullet$ which requires segmental realization of the defective plural segment, but is ranked below all other markedness and faithfulness constraints discussed so far (' $\odot$ ' denotes an undominated hence phonetically unrealized root node). ${ }^{10}$

Input: $\mathrm{ta}_{\mathrm{p}} \mathrm{idl+}+\mathrm{C} \bullet$ (Tadel 'reproach', masc.)

\begin{tabular}{|c|c|c|c|c|c|c|c|c|c|}
\hline & & ID $v$ & $* \mathrm{~V}_{2\{\mathrm{c}, \mathrm{d}, \mathrm{p}\}}$ & NoSKIP & $c \rightarrow V$ & Max n & ${ }^{*} \mathrm{C}$ & $\left.{ }^{*} \mathrm{CC}\right]_{\sigma}$ & MAx $\bullet$ \\
\hline & a. $\operatorname{ta}_{\mathrm{p}}: \mathrm{d} \cdot 1 \partial \subset$ & *! & & 1 & * & & & & \\
\hline & b. ta $_{\mathrm{p}}: \mathrm{d} ə \mathrm{l} \subset$ & $* !$ & & 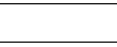 & * & & & & \\
\hline & c. $\operatorname{ta}_{\mathrm{p}}: \mathrm{dln}_{\mathrm{c}}$ & & & 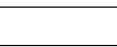 & * & & * & *! & \\
\hline 里 & d. $\operatorname{ta}_{\mathrm{p}}: \mathrm{dl} \subset \odot$ & & & 1 & * & & * & & * \\
\hline & e. $\mathrm{t}_{\mathrm{c}, \mathrm{p}}: \mathrm{dl} \odot$ & & *! & 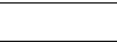 & & & * & & * \\
\hline
\end{tabular}

Feminine nouns again differ in triggering morphological insertion of a floating nasal feature. Since MAX $\mathrm{n}$ is ranked above $* \mathrm{CC}_{\sigma}$, we get a full segmental $n$-suffix:

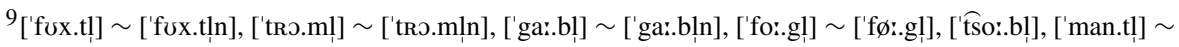
['men.tl]], ['ha.ml], [']na:.bl] ['Jne:.bl]], ['Jta:.pl]].

${ }^{10}$ Note that German doesn't generally allow deletion of non-defective vowels or consonants, hence there must be additional high-ranked MAX constraints protecting fully specified segments. See Sect. 5 for detailed discussion of segmental faithfulness constraints.
} 
(32) Input: na $:$ dl+c) $\bullet+$ (n) (Nadel 'needle', fem.)

\begin{tabular}{|c|c|c|c|c|c|c|c|c|c|}
\hline & & ID $v$ & $* \mathrm{~V}_{2\{\mathrm{c}, \mathrm{d}, \mathrm{p}\}}$ & NoSkIP & $\mathrm{c} \rightarrow \mathrm{V}$ & Max n & ${ }^{*} \mathrm{C}$ & $\left.{ }^{*} \mathrm{CC}\right]_{\mathrm{o}}$ & MAx $\bullet$ \\
\hline & a. a $_{\mathrm{p}}: \mathrm{d} .1 \mathrm{C} \subset$ & $* !$ & & I. & * & & & & \\
\hline 用 & b. $\mathrm{na}_{\mathrm{p}}: \mathrm{dln}_{\mathrm{c}, \mathrm{n}}$ & & & & * & & * & * & \\
\hline & c. $n a_{p}: d l \subset \bigodot$ n & & & & * & $* !$ & * & & * \\
\hline & d. $\mathrm{n} \varepsilon_{\mathrm{c}, \mathrm{p}} \mathrm{dln} \mathrm{n}_{\mathrm{c}, \mathrm{n}}$ & & $* !$ & 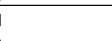 & * & & * & $*$ & \\
\hline
\end{tabular}

The feminine-nasal correlation also extends to [e]-final nouns (cf. masculine Anker $\sim$ Anker ['Pay.ke] 'anchor' vs. feminine Ader ['Pa..de] Ader-n ['Pa:.den] 'vein(s)'), a pattern I will take up in detail in Sect. 4.2.

\subsection{Generalization III: Schwa-final nouns always take - $n$ (and never umlaut)}

Whereas consonant-final nouns show a marked - $n$ vs. -ə/- $\varnothing$ asymmetry reflecting the feminine/non-feminine distinction, this contrast breaks down with ə-final nouns which all form their plural following an identical pattern, independently of gender (in fact all umlauting examples discussed so far didn't have final [ə]). While the generalization has two parts (1) Nouns lexically ending in ... never umlaut (Pate

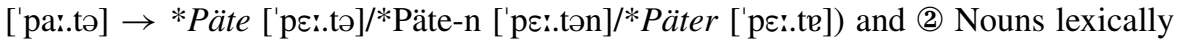
ending in ...ə always suffix $-n$ (Pate ['pa:.tə] $\rightarrow$ Pa.te-n ['pa:.tən]/*Pate ['pa:.tə]), under the approach here both parts are inextricably linked because the analysis developed so far already predicts that umlaut and plural- $n$ are in complementary distribution.

The gist of the derivation of Generalization III is that schwa is a defective intervenor which cannot itself serve as the host for floating material, but blocks association of the umlaut trigger (floating VPLACE + CORONAL) to the full vowels preceding it. Technically this amounts to the standard autosegmental no-gapping restriction that association might not skip intervening nodes (Archangeli and Pulleyblank 1994; Walker 1998; Ní Chiosáin and Padgett 2001), which is formulated with reference to VPLACE and PLACE nodes in (33):

NoSKIP Assign $*$ to every triple of VPLACE nodes $\left(\mathrm{N}_{1}, \mathrm{~N}_{2}, \mathrm{~N}_{3}\right)$ such that:

(i) $\mathrm{N}_{1} \prec \mathrm{N}_{2} \prec \mathrm{N}_{3}$

(ii) $\mathrm{N}_{1}$ and $\mathrm{N}_{3}$ are associated to the PLC-node $\mathrm{P}$

(iii) $\mathrm{N}_{2}$ is not associated to $\mathrm{P}$

(34) shows an exemplary configuration violating NOSKIP. The floating CORONAL of the generic plural suffix associates to the VPLACE node of the [a] in Rate ['Ra:.tə] $\sim$ Rate- $n$ ['Ra:.tən] 'rate(s)' (fem.) which leads to a violation because the empty VPLACE node of the final [ə] intervenes: 


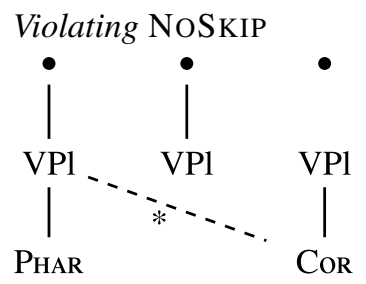

$\mathrm{Ra} \quad$ te $\quad[+\mathrm{pl}]$

Under the assumption that NoSKIP is undominated (alongside $* \mathrm{~V}_{2\{\mathrm{c}, \mathrm{d}, \mathrm{p}\}}$ ) the featural affixation analysis straightforwardly captures the second part of Generalization III (the observation that $\partial$-final nouns never exhibit umlaut) as shown in (35) for Rate. All umlauting candidates (35-c,d,) are ruled out directly by NOSKIP, and the lowerranked faithfulness constraints ensure that affixal root node, [nasal], and [CORONAL] form an $n$-suffix:

Input: RA:tə+@•+@ (Rate 'rate', fem.)

\begin{tabular}{|c|c|c|c|c|c|c|c|}
\hline & & $* \mathrm{~V}_{2\{\mathrm{c}, \mathrm{d}, \mathrm{p}\}}$ & NoSKIP & $c \rightarrow V$ & Max $n$ & ${ }^{*} \mathrm{C}$ & MAX • \\
\hline & a. $R a_{p}: t ə n_{c, n}$ & & & * & & & \\
\hline & b. $\mathrm{Ra}_{\mathrm{p}}$ itə(c)(n & & & * & $* !$ & & \\
\hline & c. $\mathrm{R} \varepsilon_{\mathrm{c}}: \mathrm{t}$ 次 & & $* !$ & & & & \\
\hline & d. $R \varepsilon_{\mathrm{c}} \mathrm{s} t \partial \mathrm{n}_{\mathrm{c}, \mathrm{n}}$ & & $* !$ & & * & & \\
\hline & 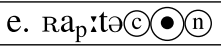 & & & $*$ & & & $* !$ \\
\hline
\end{tabular}

The same result follows for ə-final masculine nouns such as Pate 'godfather' under the proviso that an undominated phonotactic constraint rules out two adjacent weak syllable nuclei $(* \underline{\underline{v} \breve{v}})$ as in (36-b), a combination systematically excluded in German (see Sect. 5 for a full analysis). Note also that in contrast to (35-a) the [nasal] feature in (36-a) is epenthetic, indicating that general faithfulness constraints against nasal epenthesis (e.g. DEP n) are ranked too low to be effective (for consonant-final masculine roots such as Maat $\sim$ Maat-e creation of a nasal suffix is excluded by ${ }^{*} \mathrm{C}$, not by faithfulness constraints, cf. tableau (28)):

(36) Input: pA:tə+(C) (Pate 'godfather', masc.)

\begin{tabular}{|c|c|c|c|c|c|c|c|}
\hline & & $* \mathrm{~V}_{2\{\mathrm{c}, \mathrm{d}, \mathrm{p}\}}$ & NoSKIP & $c \rightarrow V$ & Max n & $* \mathrm{C}$ & MAX • \\
\hline & a. $\mathrm{pa}_{\mathrm{p}}: \mathrm{tən}_{\mathrm{c}}$ & & & * & & & \\
\hline & (b. $\mathrm{pa}_{\mathrm{p}} \mathrm{it \partial ( \textrm {c } ə )}$ & & & * & & & \\
\hline & c. pa $:$ tə@ $\bullet$ & & & * & & & $* !$ \\
\hline & d. $\mathrm{p} \varepsilon_{\mathrm{c}}: \mathrm{t \partial n}_{\mathrm{c}}$ & & $* !$ & & & & \\
\hline
\end{tabular}

This effectively derives part 2 of Generalization III (ə-final nouns always suffix $-n$ ): $n$ is the only phonotactically licit realization of the root node provided by the generic plural suffix, and independently enforced by faithfulness constraints on suffixal segments for feminine nouns as in (35). Note finally that it is irrelevant whether the non-front stem vowels in ə-final nouns are assumed to be specified or unspecified for 
vocalic place. Blocking of umlaut follows under the assumption of underspecification as in (35) and (36), and would only be redundantly enforced through $* \mathrm{~V}_{2\{\mathrm{c}, \mathrm{d}, \mathrm{p}\}}$ if we posit underlying PHARYNGEAL or DORSAL specifications.

Importantly, there is good evidence that the complementary distribution of stemfinal schwa and plural umlaut is not an idiosyncratic morphological pattern, but follows a more general phonological restriction. German diminutives which show virtually exceptionless umlaut (Féry 1994; Wiese 1996a; Klein 2000) (e.g. Bänd-chen ['bønt.çən] from Band [bant] 'volume' and Söhnchen ['zø:n.çən] from Sohn [zo:n] 'son') trigger dropping of stem-final schwas (e.g. Läd-chen ['1e:t.çən] from Lade ['lar.də] 'chest' and Büd-chen ['by:.tçən] from Bude ['bu:.də] 'booth') thus effectively eliminating the problematic intervenor (see Trommer 2016 for a phonological account of why diminutive umlaut is 'stronger' than plural umlaut and Hermans and van Oostendorp 2008 for discussion of a related pattern in Limburg Dutch). German verbs ending in coronal stops exhibit a regular schwa epenthesis process before inflectional suffixes starting with a coronal obstruent (37-c,d), but not after other consonants $(37-a, b)$. Crucially, schwa epenthesis is suppressed if the verb exhibits umlaut in the 2sg and 3sg present (37-e,f) (Neef 1996):

Schwa (non-)epenthesis in German verbs

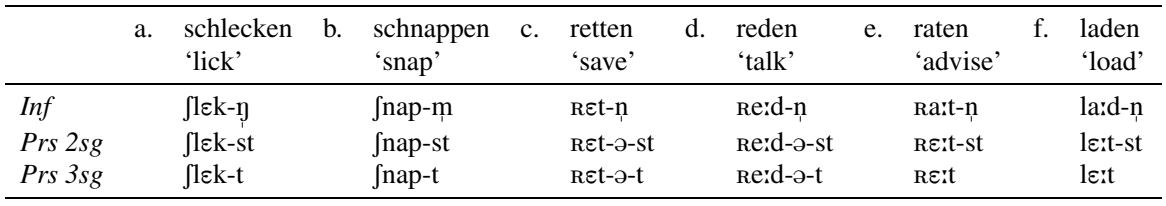

Whereas an analysis of these patterns is beyond the scope of this paper, it should be clear that the complementarity between intervening schwa and umlaut is pervasive and achieved by at least three different repair strategies: deletion of schwa in diminutives, suppression of schwa-epenthesis in verb inflection, and failure to umlaut in nominal plurals. These three patterns hence form a classical phonological conspiracy (Kisseberth 1970; Kager 1999), which is directly captured in a phonological analysis based on a ban against intervening schwas, as proposed here, but remains accidental in a purely morphological analysis of plural allomorphy.

\subsection{Generalization IV: e-plurals always umlaut}

Plural-er $(-e)$ is the near mirror image to plural- $n$ : While $-n$ is dominant with feminine nouns, - er is restricted to non-feminine, especially neuter nouns (see Sect. 6.1 for an analysis of exceptional masculine nouns with plural -er); and where $-n$ is in complementary distribution with umlaut, er-plurals always exhibit umlaut whenever the stem vowel is not already front. (38) shows this distributional gap schematically: 


\begin{tabular}{|c|c|c|c|}
\hline & Plural non-front $V$ & Plural & ont $V$ \\
\hline Singular back $V$ & - & $\begin{array}{l}\text { Rad/Räder } \\
\text { Buch/Bücher } \\
\text { Ross/Rösser }\end{array}$ & $\begin{array}{l}\text { 'bike(s)' } \\
\text { 'book(s)' } \\
\text { 'horse(s)' }\end{array}$ \\
\hline Singular front $V$ & - & $\begin{array}{l}\text { Kind/Kinder } \\
\text { Feld/Felder } \\
\text { Kleid/Kleider }\end{array}$ & $\begin{array}{l}\text { 'child(ren)' } \\
\text { 'field(s)' } \\
\text { 'cloth(es)' }\end{array}$ \\
\hline
\end{tabular}

Under the subsegmental analysis proposed here, all instances of neuter plural -er result from a combination of the generic plural suffix $\odot \bullet$ and the more specific gendernumber affix (6-c) repeated in (39):

$$
\text { Representation for plural-er }
$$

Given this representation, the restriction of regular -er to neuter nouns follows directly from the morphosyntactic feature specification of (39). In the following, I will show that its obligatory co-occurrence with umlaut falls out as a natural consequence of the feature-geometric analysis developed so far.

Let us first have a look at the feature-geometric details of an umlauting plural with -er. In contrast to the other number suffixes, ( $)$ contains a CPLACE node, it is in effect a defective consonantal [R] (lacking a segmental root node). ${ }^{12}$ That it cannot surface as a 'real' consonant is due to the phonotactic restriction against [R] in syllable rhymes (cf. Sects. 2.3 and 4.2 below). ${ }^{13}$ Since (D) also lacks a root node and a VPLACE node, and MAX PHAR is ranked below DEP VPL and DEP •, the only scenario where it can surface is when a free VPLACE $+\bullet$ becomes available. This is exactly what happens in neuter nouns with umlaut, as shown in (40-a) for Räd-er in contrast to a non-umlauting neuter noun plural such as Schaf-e (40-b). The coronal feature of the generic plural suffix shifts to the underspecified VPL node of

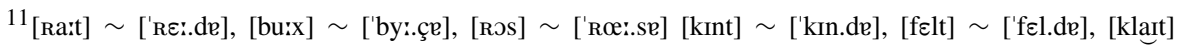
$\sim$ [klar.de].

${ }^{12}$ Even though (D) isn't specified [+cons] (it lacks a root node), in the feature geometry of Clements and Hume (1995), only consonants have CPLACE nodes directly dominating specific PLACE features such as PHARYNGEAL. Thus (D) is structurally identified as a consonant.

${ }^{13}$ I assume that all floating place affixes have a concomitant CPLACE or VPLACE node since this provides the necessary means to linearize them as suffixes in an autosegmental framework where nodes on different tiers are not inherently linearly ordered (recall that in the feature-geometric approach adopted here, Coronal, Dorsal, and Pharyngeal are all on different, independent tiers). A 'pure' floating PHARYNGEAL suffix would be expected to appear immediately after the last PHARYNGEAL feature of the root, predicting incorrect infixation patterns.
} 
the noun, thus vacating its own VPLACE node By additional association of the pluralVPL to the tautomorphemic root node a complete vocalized [e] results. For Schaf-e, COR cannot associate to the noun VPL (already associated to PHAR) hence blocking spreading of affix PHAR to plural VPL:
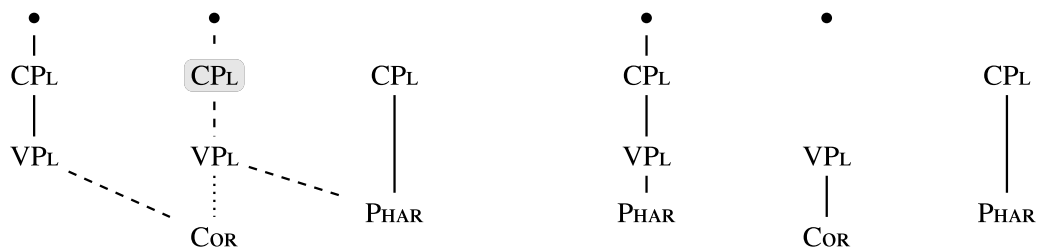

a. $(\mathrm{R})$

(d)

b. $(\rho)$

a

(f) $\quad$ ə

I implement the link between CORONAL and PHARYNGEAL shifting by the constraint in (41), which requires every PLACE feature (COR, PHAR, DOR, or LAB) to be associated to an underlying (colored) CPLACE or VPLACE node (where ' $\square$ ' symbolizes color):

$\square \leftarrow$ PLC Assign $*$ to every PLACE node which is not phonetically dominated by a colored VPLACE or CPLACE node

$\square \leftarrow$ PLC is satisfied by both forms in (40) since every instance of PHAYRYNGEAL and CORONAL is dominated phonetically by a colored CPLACE or VPLACE node (although these are not necessarily pronounced, such as the final CPLACE node in (40-b) which is not dominated by a segmental root node). On the other hand, $\square \leftarrow$ PLC blocks hypothetical examples of non-umlauting stems with $-\boldsymbol{e}$, where CORONAL is left afloat (42-a) or linked to an epenthetic VPLACE node as in (42-b) (recall also that pharyngeal $[\mathrm{R}]$ is excluded in rhymes, hence CPLACE - PHARYNGEAL cannot associate directly to the floating plural root node):
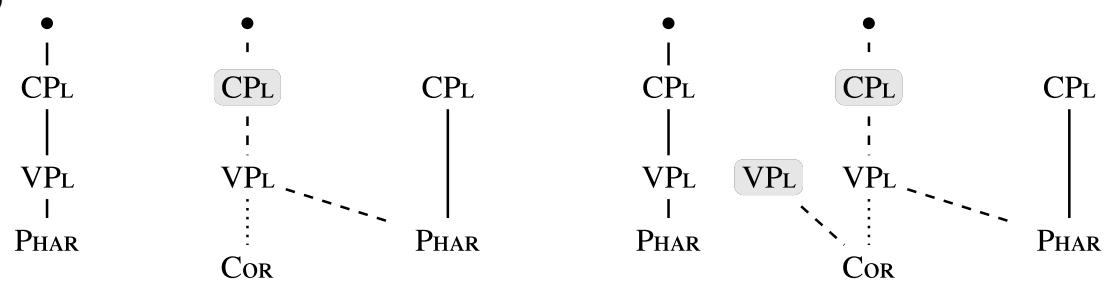

a. a

e

b. a

$e$

Crucially, under this analysis, there is no sense in which plural-er 'enforces' umlaut. It is in fact the other way around: Only if underspecification of root vowels independently creates a free segment+VPL slot, this configuration enforces plural-er by Emergence of the Unmarked for low-ranked MAX PHARYNGEAL, as shown by the contrast of (43-b) and (43-e) (corresponding to (40-a)): 


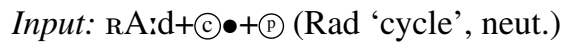

\begin{tabular}{|c|c|c|c|c|c|c|c|}
\hline & $* \mathrm{~V}_{2\{\mathrm{c}, \mathrm{d}, \mathrm{p}\}}$ & NoSkIP & $\square \leftarrow$ PLC & $\mathrm{c} \rightarrow \mathrm{V}$ & MaX n & ${ }^{*} \mathrm{C}$ & MAX p \\
\hline a. $\mathrm{R} \varepsilon_{\mathrm{c}}: \mathrm{d} e_{\mathrm{p}} \mathrm{n}_{\mathrm{c}}$ & & I & | & $* !$ & & & \\
\hline b. $\mathrm{Ra}_{\mathrm{p}}: \mathrm{d} e_{\mathrm{p}}(\mathrm{c}$ & & I & $* !$ & * & & & \\
\hline c. $R \varepsilon_{c}: d \partial(P)$ & & 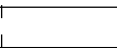 & 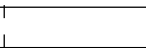 & & & & *! \\
\hline d. $\mathrm{Ra}_{\mathrm{p}}: \mathrm{d} \partial(\mathrm{C})(\mathrm{P}$ & & । & । & $* !$ & & & * \\
\hline e. $R \varepsilon_{c}: d e_{p}$ & & I & $\mathrm{T}$ & & & & \\
\hline
\end{tabular}

For a neuter noun such as Schaf [ja:f] Schaf-e ['fa:.fə] 'sheep' (sg./pl.) without umlaut (and hence a stem vowel specified for [PHARYNGEAL]), $\square \leftarrow$ PLC blocks reassociation of PHARYNGEAL as in (44) (where (44-b) corresponds to (42), and (44-d) to (40-b):

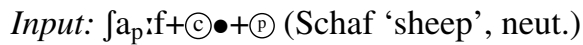

\begin{tabular}{|c|c|c|c|c|c|c|c|c|}
\hline & & $* \mathrm{~V}_{2\{\mathrm{c}, \mathrm{d}, \mathrm{p}\}}$ & NoSkIP & $\square \leftarrow$ PLC & $\mathrm{c} \rightarrow \mathrm{V}$ & Max n & $*{ }_{1} \mathrm{C}_{1}$ & Max p \\
\hline & a. $\int \varepsilon_{\mathrm{p}, \mathrm{c}}: \mathrm{fe}_{\mathrm{p}} \mathrm{n}_{\mathrm{c}}$ & $* !$ & 1 & 1 & $*$ & & & \\
\hline & b. $\int a_{p}: f e_{p}(c)$ & & 1 & $* !$ & $*$ & & & \\
\hline & c. $\int \varepsilon_{\mathrm{p}, \mathrm{c}} \mathrm{i}$ fə(口) & $* !$ & 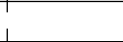 & 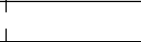 & & & & $*$ \\
\hline & d. $\int a_{p}: f \partial \subset \subset$ & & 1 & 1 & $*$ & & & * \\
\hline & e. $\int \varepsilon_{\mathrm{p}, \mathrm{c}} \mathrm{f} \mathrm{e}_{\mathrm{p}}$ & $* !$ & 1 & 1 & & & & \\
\hline
\end{tabular}

It follows correctly as a corollary that schwa-final nouns can never take plural -er since they block umlaut. Note finally that there is an apparent problem for the correlation between -er suffixation and umlaut: frontvowel stems with -er such as Kind [kınt] Kinder ['kın.de] 'child(ren)'. I will take up this pattern in Sect. 4.3.

\section{Surface opacity}

The subsegmental analysis highlights the fact that the generalizations governing German plural exponence are in crucial respects surface-opaque. Thus we might attempt to capture the complementarity between plural suffix- $n$ and umlaut (Generalization I) by a phonological surface constraint as in (45):

$$
* \mathrm{~V}_{\text {front }} \ldots \mathrm{n}
$$

Crucially, (45) would overapply. Beyond excluding plurals such as *Päten, it also rules out many correct German word forms such as the infinitives wetten ['ve.ton] 'to bet' and dösen ['dø:.zən] 'to doze'. This cannot be amended by restricting (45) to nominal plural forms since here also $n$ and front vowels can freely co-occur if either the [n] or the front vowel are an underlying part of a noun root as in Becken

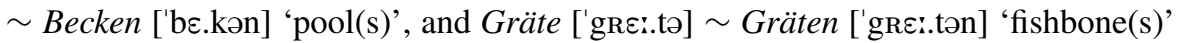
respectively. What is blocked is not phonological surface co-occurrence, but double realization of the same morphological exponent. This kind of opacity, which follows 
naturally in a morpheme-based account, is inherently problematic for an amorphous approach where morphological exponence is governed by phonological constraints on surface representations (Neef 1996; Russel 1999; MacBride 2004). The same kind of opacity also holds for generalization IV ([e]-plurals always umlaut) which cannot be captured without recourse to concatenative morphological structure by something like (46):

$$
* \mathrm{~V}_{\text {non-front }} \ldots \mathrm{e}
$$

Thus whereas a singular such as Rad can only have an umlauting plural (Räd-er not *Rader), there are non-umlauting roots when $[\mathrm{e}]$ is not the segmental plural affix, but part of the noun root, as in Anker $\sim$ Anker 'anchor(s)', Otter $\sim$ Otter 'otter' besides umlauting examples such as Vater $\sim$ Väter and Mutter $\sim$ Mütter.

The third case of opacity which cannot be captured by a surface constraint is the schwa-umlaut generalization (Generalization III). For example, the plurals of Lade 'tray' (Laden) and of Fladen 'thin bread' (Fladen) are virtually homophonous, but the plural of Laden 'shop' is Läden whereas Lade could in principle not be umlauting in the plural. Thus umlaut markedly differentiates between Laden and Lade-n.

This last example however also points to a potential opacity problem for the concatenativist analysis proposed here: If the impossibility of Läden as the plural of Lade is due to the phonological intervention of [ə], why does schwa not intervene in the same way in the plural Läden for Laden? Similarly, vocalic intervention seems to be potentially problematic for [e]-final roots such as Vater/Väter for which we might expect intervention against umlauting (i.e. against CORONAL-spreading) in analogy to Lade and Pate.

The answer I propose in this section is that these cases not only involve opacity of morphological structure, but also genuinely phonological opacity where the plurals for Laden and Lade are different in intermediate steps of their derivational history, a fact which falls out naturally from the cyclic architecture of Stratal Containment and the traditional assumption that the relevant word-final post-sonorants (orthographic $e l$, en, etc.) are syllabic consonants at the point when they enter the Stem-Level phonology. I will work out this analysis in Sect. 4.1 for root-final $n$-cases and show in Sect. 4.2 that it also derives the behavior of root-final [e] by taking into account the fine structure of feature-geometric representations.

\subsection{Umlaut-non-intervention of final schwas}

(47) presents more data illustrating the crucial asymmetry in syllabic $n$-final plurals between the possibility of umlaut with underlying root- $n$ and its impossibility with affixal $-n$ : 
(47) $\quad n$-final nouns ${ }^{14}$

\begin{tabular}{llllll}
\hline & \multicolumn{2}{c}{ Plural-n } & \multicolumn{2}{c}{ Stem-n } \\
\hline \multirow{4}{*}{ No umlaut $n$} & Lade & Laden 'drawer(s)' & Fladen & Fladen & 'flat bread(s)' \\
& Pate & Paten & 'godfather(s)' & Wagen & Wagen 'coach(es)' \\
& Horde & Horden 'horde(s)' & Orden & Orden & 'medal(s)' \\
& Bude & Buden 'booth(s)' & Kuchen & Kuchen 'cake(s)' \\
\hline \multirow{2}{*}{ Umlaut } & & - & Laden & Läden & 'shop(s)' \\
& & - & Boden & Böden 'floor(s)' \\
& & - & Kragen & Krägen 'collar(s)' \\
\hline
\end{tabular}

Now remember from Sect. 2.3 that orthographic en is phonetically variably pronounced as schwat $n$ (e.g. ['la:.dən]) or as a syllabic [n] (['lai.dn]). My interpretation of these facts in terms of Stratal OT follows the traditional position of Wiese (1996b) that at the input of the Stem Level nouns like Laden have consistently syllabic sonorants (/la:.dn/), not schwas. The only schwa syllables at this level are hence word-final schwas that are lexically distinctive (cf. Lade vs. the verb lad 'to invite'). ${ }^{15}$ $n$-affixation at the Stem Level leads then to a final [ə+n] sequence. The phrase-level phonology of German neutralizes postconsonantal sonorants, and schwa+sonorant variants (Wiese 1986, 1996b; Noske 1993), resulting in free variation between both realizations. ${ }^{16}$

Late neutralization allows us to locate the opacity in umlaut blocking at the Stem Level (the stratum where plural inflection is concatenated and evaluated phonologically). Here Lade- $n$ has a schwa, whereas Laden has not:

$$
\text { Inputs Stem Level Phrase Level }
$$

Lade

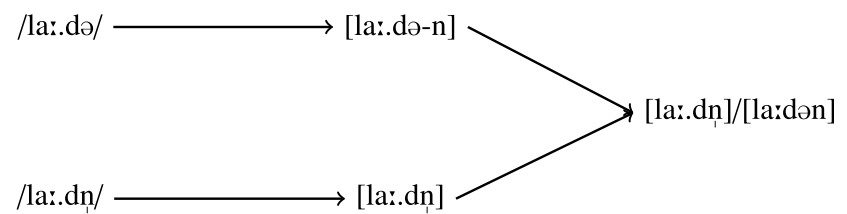

\footnotetext{
${ }^{14}$ ['la:.də] $\sim$ ['la:.dən], ['la:.dən] ['le:.dən], ['pa:.tə] ['pa:.tən], ['va:.gən], ['həx.də] ['həx.dən], ['Pəe.dən], ['bu:.də] ['bu:.dən], ['ku:.xən], ['la:.dən] ['le:.dən], ['bo:.dən] ['bø:.dən], ['kra:.gən] ['kre:.gən], ['?o:.fən] ['?ø:.fən].

${ }^{15}$ Wiese assumes that the schwa in such forms is a 'noun-forming suffix' (p. 126) represented as an empty prosodic position (p. 244). I leave it open here why schwa is absent before sonorants in underlying representations. This could be either the effect of constraints imposed on the lexicon by the acqusition mechanism (see e.g. Rasin and Katzir 2015 for a worked-out proposal that derives morpheme structure constraints from an explicit learning algorithm), the Root-level stratum assumed here (Trommer 2011), or in a version of Stratal OT with stratum-internal cycles (Kiparsky 2000, 2015), by a previous evaluation cycle at the Stem Level.

${ }^{16}$ Note that this analysis apart from the involved variation simply follows the standard approach of OT to allophony and related neutralization processes, where neutralization is bidirectional. In variants where there is no schwa, the nasal assimilates in place to the preceding obstruent, e.g. ['va:.gən] ['va:.gy] 'coach' and ['le:.bən] ['le:.bm] 'life', a process which also arguably applies at the Phrase Level.
} 
At the Stem Level, the syllabic status of final syllabic sonorants is protected by the undominated faithfulness constraint IDENT $v$ (30).

Now, since there is no schwa in nouns with a root-final syllabic $n$, NOSKIP is not violated (as in the suboptimal candidates in (35) and (36), and the possibility of umlaut becomes contingent on the full or partial specification of the stem vowel, predicting the distinctive behavior of Fladen (with fully specified underlying $a$, and hence no umlaut), and umlauting Laden (49). IDENT $v$ blocks the realization of the underspecified plural root node as schwa (49-a) so that it remains floating and unpronounced:

Input: 1A:dn+C) (Laden 'shop', masc.)

\begin{tabular}{|c|c|c|c|c|c|}
\hline & ID $v * V_{2\{c, d, p\}}$ & NoSKIP & $\mathrm{c} \rightarrow \mathrm{V}$ & Max n & $*{ }_{1}$ \\
\hline a. $1 \varepsilon_{\mathrm{c}}$ :d.nə & $* !$ & & & & $*$ \\
\hline b. $1 a_{\mathrm{p}}: \mathrm{dn}_{1} \mathrm{C} \odot$ & 1 & & $* !$ & & $*$ \\
\hline c. $l \varepsilon_{\mathrm{c}}: \mathrm{dn}_{1} \bullet$ & 1 & 1 & & & $*$ \\
\hline
\end{tabular}

\subsection{Non-intervention in e-final roots}

Noun roots ending in $[\mathrm{e}]$ (underlying [R]) present a further variant of the opacity problem of vocalic intervention. These nouns show the familiar three options, (1) umlaut with $\varnothing$-plural (without [n]) (50-a,c), (2) masculine plurals without umlaut and $\varnothing$-suffix (50-b), and (3) feminine plurals without umlaut, but with plural- $n$ (50-d):

\begin{tabular}{lllll}
\multicolumn{4}{l}{ Basic plural patterns of [e]-final nouns } \\
a. & Vater & Väter & 'father(s)' & (masc.) \\
& Bruder & Brüder & 'brother(s)' & (masc.) \\
b. Taler & Taler & 'Taler' (coin(s)) & (masc.) \\
& Sommer & Sommer & 'summer(s)' & (masc.) \\
c. & Mutter & Mütter & 'mother(s)' & (fem.) \\
& Tochter & Töchter & 'daughter(s)' & (fem.) \\
d. Ader & Ader-n & 'vein(s)' & (fem.) \\
& Nummer & Nummer-n & 'number(s)' & (fem.)
\end{tabular}

(51) and (52) show the basic analysis for Vater and Taler. Note that (51-b) and (52-b) violate the generalized markedness constraint $\left.{ }^{*} \mathrm{CC}\right]_{\sigma}$ since $n$ is a surface and $x$ an underlying consonant:

Input: fA:tR+@• (Vater 'father', masc.)

\begin{tabular}{|c|c|c|c|c|c|}
\hline & $* \mathrm{~V}_{2\{\mathrm{c}, \mathrm{d}, \mathrm{p}\}} \quad$ NoSKIP & $\mathrm{c} \rightarrow \mathrm{V}$ & Max $n$ & $* \mathrm{CC}]_{\sigma}$ & MAX • \\
\hline a. f $\varepsilon_{c}: \operatorname{ten} n_{c}$ & 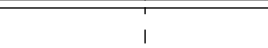 & $* !$ & & $*$ & \\
\hline b. $\mathrm{fa}_{\mathrm{p}}: \mathrm{ten}_{\mathrm{c}}$ & 1 & $* !$ & & $*$ & \\
\hline c. fa $:$ tec $\bullet$ & 1 & $* !$ & & & $*$ \\
\hline d. f $\varepsilon_{\mathrm{c}} \mathrm{itg} \bullet$ & 1 & & & & $*$ \\
\hline
\end{tabular}

17 ['fa:.te] ['fes.te], ['brui.de] ['bry:.de], ['ta:.le], ['zo.me], ['mo.te] ['my.te], ['tox.te] ['tœx.te], ['Pa:.de] ['Pa:.den], ['nv.me] ['nv.men]. 
(52) Input: ta $\mathrm{p}_{\mathrm{p}} \mathrm{l} \mathrm{l}_{\mathrm{i}}+\mathrm{C} \bullet$ (Taler (coin), masc.)

\begin{tabular}{|c|c|c|c|c|c|c|c|}
\hline & & $* \mathrm{~V}_{2\{\mathrm{c}, \mathrm{d}, \mathrm{p}\}}$ & NoSKIP & $c \rightarrow V$ & Max n & $* \mathrm{CC}]_{\sigma}$ & MAX $\bullet$ \\
\hline & a. $t \varepsilon_{\mathrm{p}, \mathrm{c}} \cdot \operatorname{len} \mathrm{n}_{\mathrm{c}}$ & *! & 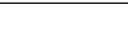 & $*$ & & * & \\
\hline & b. $\operatorname{ta}_{\mathrm{p}}: \operatorname{len}_{\mathrm{c}}$ & & & $*$ & & $* !$ & \\
\hline$\Leftrightarrow$ & c. $\operatorname{ta}_{\mathrm{p}}: \operatorname{le}(\mathrm{C} \bullet$ & & 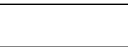 & $*$ & & & $*$ \\
\hline & d. t $\varepsilon_{\mathrm{p}, \mathrm{c}} \mathrm{ll} \bullet$ & $* !$ & 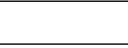 & & & & * \\
\hline
\end{tabular}

These evaluations presuppose that NOSKIP is not violated in the winning candidates (51-d) and (52-c2), but since the output correspondent of $/ \mathrm{R} /$ is the vowel [e] (hence a segment with a VPLACE node), we would expect that it intervenes for association of CORONAL to preceding stem vowels, leading to a fatal violation of NOSKIP. Hence umlaut for Vater in (51) should be blocked counter to fact.

In the following, I will show that the non-intervention of [e] follows from the very fact that it is derived from [R], and not an underlying vowel. ${ }^{18}$ Apart from their complementary distribution, the central motivation for the claim that $[\mathrm{e}]$ is vocalized [R] comes from the pervasive role of alternations between [ $\mathrm{e}]$ and $[\mathrm{R}]$ in stem-final position illustrated in (53) with examples from the verbal paradigm, where the $1 \mathrm{sg}$ forms (with the suffix -ə) show [R] in onset, and the imperatives (which are bare roots) [e] in coda position:

\begin{tabular}{|c|c|c|}
\hline \multicolumn{3}{|c|}{ R-vocalization in verbs } \\
\hline $1 s g$ & Imperative & \\
\hline [hø:.R-ə] & [hø:e] & 'hear' \\
\hline [mu.R-ə] & {$[\mathrm{m} v e]$} & 'grumble' \\
\hline [le:.r-ə] & [le:p] & 'teach' \\
\hline [fa:.R-ə] & [fa:e] & 'drive' \\
\hline
\end{tabular}

Following the bulk of the literature on German phonology, I will assume that all instances of output $[\mathrm{R}] /[\mathrm{e}]$ are /R/ at the the input of the Stem Level (see Hall 1993; Wiese $1996 \mathrm{~b}$ and references cited there). To show that the autosegmental approach predicts the fact that derived [e] does not intervene in umlaut (CORONAL) association, I will first spell out a specific implementation of [R]-vocalization. I assume that both [R] and [e] are characterized by the feature PHARYNGEAL (Clements 1991; McCarthy 1994). In the Clements and Hume feature geometry adopted here, Rvocalization then amounts to inserting a VPLACE node and to reassociating the consonantal PLACE feature to the epenthetic class node as shown in (54):

\footnotetext{
${ }^{18}$ Alternatively, one might assume that non-intervention of $[\mathrm{e}]$ follows from the fact that $[\mathrm{R}]$-vocalization happens only at the Word-Level. but this would be at odds with the fact that plural inflection creates [e] from VPLACE nodes in neuter nouns, as argued in Sect. 3.4.
} 
(54)

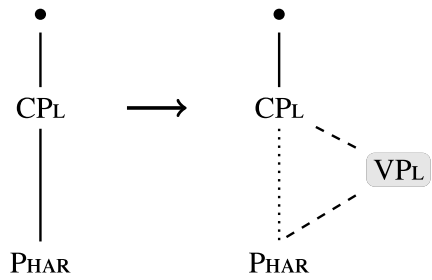

e

I implement $[\mathrm{R}]$-vocalization by two constraints. $\left.{ }^{*} \underline{\mathrm{R}}\right]_{\sigma}$ captures the insight of Wiese (1996b) that uvular [R] is blocked in all rhyme positions in German:

$\left.{ }^{*} \underline{\mathrm{R}}\right]_{\sigma} \quad$ Assign $*$ to every pharyngeal sonorant consonant which is phonetically in the rhyme of a syllable

IDENT PHARYNGEAL ensures that pharyngeal segments remain pharyngeal even under vocalization:

$$
\begin{array}{ll}
\text { IDENT PHAR } & \text { Assign } * \text { to every segmental root node which is linked } \\
& \text { to a PHARYNGEAL node morphologically, but not } \\
& \text { phonetically }
\end{array}
$$

Both constraints are ranked above $\square \leftarrow$ PLC which would otherwise block surface association of PHARYNGEAL to an epenthetic VPLACE node. (57) shows the interaction of all three constraints: ${ }^{19}$

(57) Input: $=\mathrm{a}$.

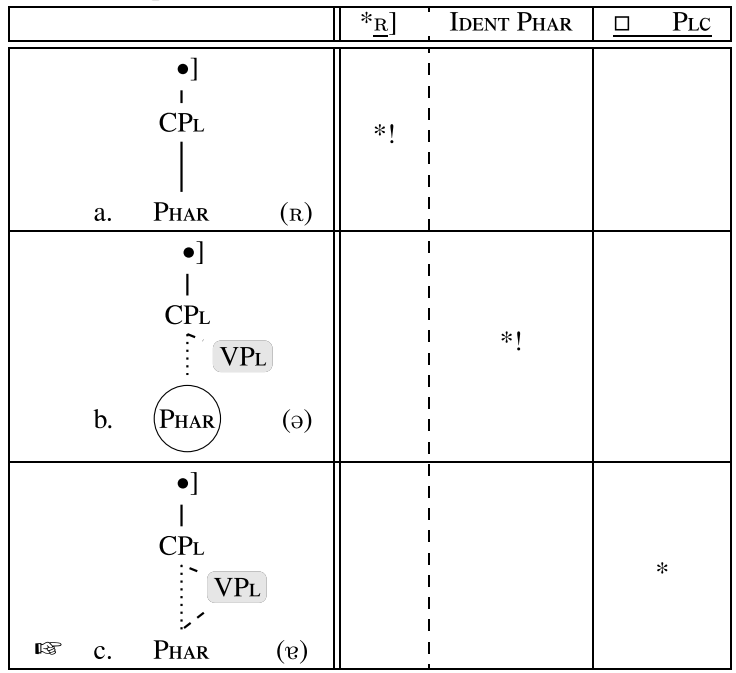

\footnotetext{
${ }^{19}$ Note that IDENT PHARYNGEAL doesn't protect the floating CPLACE - PHARYNGEAL complex of the neuter plural suffix discussed in Sect. 3.4. which isn't underlyingly linked to a segmental root node.
} 
(57) illustrates the common core of all [R]-vocalizations in German (i.e., also instances where vocalization happens in codas as in [hø:.R-ə] ['hø:e] 'hear', cf. (53) above). For the cases under discussion here, where $[\mathrm{R}]$ is post-consonantal and a syllable nucleus at the input of Stem-Level phonology, $\left.{ }^{*} \underline{R}\right]_{\sigma}$ conspires with IDENT $v$ to enforce vocalization, as shown for the derivation of $(\mathrm{Pa})_{\sigma}(\mathrm{d} e)_{\sigma}$ from underlying $(\mathrm{a}:)_{\sigma}\left(\mathrm{d}_{1}\right)_{\sigma}$ in (58). Insertion of a (the major repair process of German for phonotactic violations) could avoid the violation of $\left.{ }^{*} \underline{R}\right]_{\sigma}$ by 'moving' $[\mathrm{R}]$ into onset position as in $(58-b, c)$, but this would violate IDENT $v$, which, as we have already seen above, is crucially undominated in the Stem-Level phonology of German.

Input: $(\mathrm{a}:)_{\sigma}\left(\mathrm{d}_{1}\right)_{\sigma}($ Ader 'vein', fem.)

\begin{tabular}{|l||c:c|}
\hline & $\left.{ }^{*} \underline{R}\right]_{\sigma}$ & IDENT $v$ \\
\hline \hline a. $(\text { ( } \mathrm{a}:)_{\sigma}(\mathrm{d} R)_{\sigma}$ & $* !$ & \\
\hline b. $(\text { ( } \mathrm{a}:)_{\sigma}(\mathrm{d} \partial)_{\sigma}(\mathrm{R} \partial)_{\sigma}$ & & $* !$ \\
\hline c. $(\text { ( } \mathrm{a}: \mathrm{d})_{\sigma}(\mathrm{R} \partial)_{\sigma}$ & & $* !$ \\
\hline d. $(\mathrm{Pa})_{\sigma}(\mathrm{d} e)_{\sigma}$ & & \\
\hline
\end{tabular}

Now the potential intervention problem can be made more concrete as in (59) for the plural of Vater (omitting the feature specification of the initial consonant). This configuration fatally violates NOSKIP, since the epenthetic VPLACE node intervenes between the VPLACE node dominating the affixal COR and the VPLACE node of the stem vowel just as for Pate in (34):

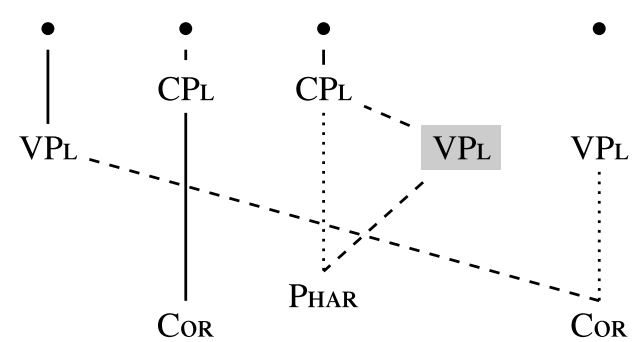

$\mathrm{f} \quad \ddot{a} \quad \mathrm{t} \quad \mathrm{e}$

This is the point where it becomes crucial that the VPLACE node in the [e] of Vater is epenthetic unlike the corresponding node in the [ə] of Pate. In (59), this node is inserted before the VPL node of the plural suffix, but while GEN in Containment Theory doesn't allow for metathesis (i.e. moving the intervening VPL node in Pate), insertion of an epenthetic node is possible in any linear position. Hence a minimally different output candidate for Väter would have the epenthetic VPLACE node after the VPLACE node of the plural suffix as in (60). Since here no VPL intervenes between the plural VPL and the base VPL, NOSKIP is satisfied. 
(60)

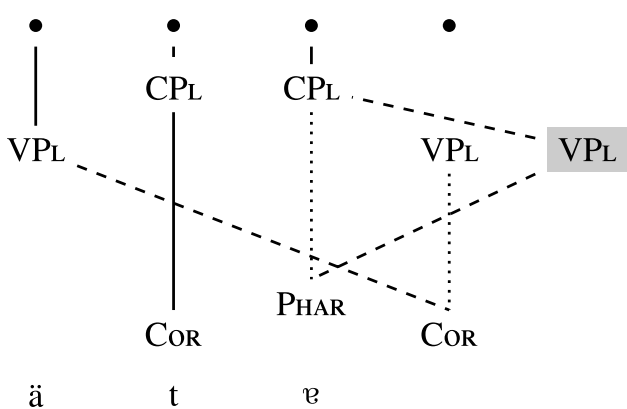

There is an additional problem which might be suspected here. Although (60) avoids skipping, it seems to aggravate a problem already lurking in (59), namely line crossing. But this is in fact an optical illusion under the standard assumption that line crossing only obtains for elements on the same plane (Cole 1987; Clements and Hume 1995:266; Padgett 2011). Thus technically the association between COR and VPL in (60) would only cross another association line between the VPLACE tier and the CORONAL tier, but all other place associations in (60) involve either the PHARYNGEAL or the CPLACE tiers and belong hence to other planes.

Since the VPLACE node of [e] does hence not intervene for the purposes of NOS KIP, the derivation of umlaut becomes fully parallel to the cases with other base-final sonorants as already shown for Väter in (51).

\subsection{Covert umlaut}

In Sect. 3.4, I have argued that plurals with suffixal -er always umlaut. An apparent problem for this claim is the fact that there are nouns that take plural -er, but have immutable front vowels such as Kind [kint] Kind-er ['kın.de] 'child(ren)' or Feld [felt] Feld-er ['fel.de] 'field(s)'. In this section, I show that the behavior of these words is a natural consequence of the defectiveness assumption for umlautable root vowels, which allows different degrees of underspecification. High and mid vowels that are underspecified for lingual place (i.e., DORSAL and CORONAL) but have an underlying LABIAL (rounding) specification alternate between back round and front round vowels (e.g. Grund [gRunt] Gründ-e ['gRYn.də] 'reason(s)', Rock [Rok] Röck-e ['Rœ.kə] 'gown(s)'). Non-low vowels which are not underlyingly specified as LABIAL (as in Kind and Feld) umlaut in the plural by associating the floating CoRONAL of the plural suffix, but are also realized as front in the singular (by epenthesizing CORONAL) since German disallows unrounded non-low back vowels ([u] and [r]). To make this concrete, I assume the constraint in (61) (a more specific version of HAVEPLACE, see McCarthy 2008:279 and references cited there), which has so far been implicit in the analysis, and enforces underspecified full vowels to adopt a default specification whenever no floating CORONAL is accessible (recall from Sect. 2.3 that full vowels are by definition vocalic segments that dominate an APERTURE node).

SPEC-V: A vowel with an APERTURE node must be specified for lingual PLACE 
Moreover, I will use $*\{u, \gamma\}$ as a shorthand for the constraints which exclude these segments from the Standard German vowel inventory, $*\{y, \varnothing\}$ for the well-known markedness of front round mid vowels (Liljencrants and Lindblom 1972; Flemming 2002), and FTH LAB as a cover term for constraints blocking insertion or deletion of underlying LABIAL features. The tableaux in (62) and (63) show the ranking of these constraints, and their role in deriving the umlaut pattern for the alternation in Grund [gRont] Gründ-e ['gRYn.də] 'reason(s)' (masc.) (similarly neut. Buch [bu:x] Büch-er ['by:.çe] 'book(s)'), where the feature-geometric representations are abbreviated by non-hierarchical feature structures (strikethrough as in "ILAB" indicating phonetic invisibility and grey shading as in "COR" epenthesis) for reasons of space; I will restrict my attention here to high vowels since mid vowels work in a completely parallel way. The plural (63) shows again integration of floating (c) and fronting, driven by $\mathrm{c} \rightarrow \mathrm{V}$. In the singular, SPEC-V enforces insertion of either CORONAL or Dorsal, FTH LAB excludes a realization as [i] or [u] $(62-\mathrm{a}, \mathrm{c})$, and vocalic markedness $(*\{y, \varnothing\})$ favors $[u](62-d)$ over $[y](62-b)$ :

Standard overt umlaut configuration: singular (Grund)

\begin{tabular}{|c|c|c|c|c|c|c|c|c|}
\hline \multicolumn{3}{|c|}{ Input: [+high-low LAB] } & SPEC-V & $* \mathrm{~V}_{2\{\mathrm{c}, \mathrm{d}, \mathrm{p}\}}$ & $*\{\mathrm{u}, \gamma\}$ & FTH LAB & $\mathrm{c} \rightarrow \mathrm{V}$ & $*\{\mathrm{y}, \varnothing\}$ \\
\hline & a. $[+$ high-low $/ 4 A B$ & CoR ] (i) & & | & | & $* !$ & & \\
\hline & b. [+high-low LAB & Cor ] $(y)$ & & 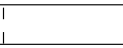 & & & & $* !$ \\
\hline & c. $\left[+\right.$ high-low $\prod_{A \wedge B}$ & Dor ] (u) & & । & $* !$ & $*$ & & \\
\hline 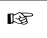 & d. [+high-low LAB & Dor ] $(\mathrm{u})$ & & | & & & & \\
\hline \multicolumn{3}{|c|}{ e. $[+$ high-low LAB $]$} & $* !$ & I & 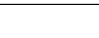 & & & \\
\hline
\end{tabular}

(63) Standard overt umlaut configuration: plural (Gründe)

\begin{tabular}{|c|c|c|c|c|c|c|}
\hline Input: [+high-low LAB]+(c) & SPEC-V & $* \mathrm{~V}_{2\{\mathrm{c}, \mathrm{d}, \mathrm{p}\}}$ & $*\{\mathrm{u}, \gamma\}$ & FTH LAB & $\mathrm{c} \rightarrow \mathrm{V}$ & $*\{\mathrm{y}, \varnothing\}$ \\
\hline a. [+high-low $14 \wedge k$ CoR] & & 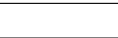 & 1 & $* !$ & & \\
\hline b. [+high-low LAB CoR] & & 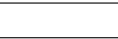 & ! & & & * \\
\hline c. [+high-low $1 / \not k \beta$ Dor ]+(c) (u) & & 1 & $* !$ & $*$ & $*$ & \\
\hline d. [+high-low LAB DoR ]+C) (u) & & & 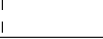 & & $* !$ & \\
\hline e. $[+$ high-low LAB]+C) & $* !$ & & 1 & & $*$ & \\
\hline
\end{tabular}

As already shown in the skeletal analysis for Thron $\sim$ Throne in (23-b) (Sect. 3), segments underlyingly specified as DORSAL avoid umlauting due to undominated $* \mathrm{~V}_{2\{\mathrm{c}, \mathrm{d}, \mathrm{p}\}}$. This is replicated with the fuller constraint ranking for Pfund [pfont] $\sim$ Pfunde ['pfon.də] 'pound(s)' (neut.) in (64) and (65) (recall that $* \mathrm{~V}_{2\{\mathrm{c}, \mathrm{d}, \mathrm{p}\}}$ is a containment-based generalized markedness constraint and hence also sensitive to phonetically unrealized PLACE features as $\not D / 6 k$ in in $(64-\mathrm{a}, \mathrm{b}))$ :

(64) No umlaut - stable [u]: singular (Pfund)

\begin{tabular}{|c|c|c|c|c|c|c|c|c|c|}
\hline \multicolumn{4}{|c|}{ Input: [+high-low DoR] } & \multirow[t]{2}{*}{ SPEC-V } & \multicolumn{2}{|c|}{$* \mathrm{~V}_{2\{\mathrm{c}, \mathrm{d}, \mathrm{p}\}}, *\{\mathrm{u}, \gamma\}$} & \multirow[t]{2}{*}{ FTH LAB } & \multirow[t]{2}{*}{$\mathrm{c} \rightarrow \mathrm{V}$} & \multirow[t]{2}{*}{$*\{\mathrm{y}, \varnothing\}$} \\
\hline & a. [+high-low Dphld & CoR ] & (i) & & $* !$ & 1 & & & \\
\hline & b. [+high-low DPhd & COR LAB ] & (y) & & $* !$ & 1 & $*$ & & $*$ \\
\hline 䗆 & c. [+high-low DoR & LAB ] & (u) & & 1 & 1 & * & & \\
\hline & d. [+high-low Dor] & & (ui) & & I & $* !$ & & & \\
\hline
\end{tabular}




\begin{tabular}{|c|c|c|c|c|c|c|c|c|}
\hline \multicolumn{3}{|c|}{ Input: [+high-low Dor]+(c) } & SPEC-V & $* \mathrm{~V}_{2\{\mathrm{c}, \mathrm{d}, \mathrm{p}\}}$ & $*\{\mathrm{u}, \gamma\}$ & FTH LAB & $\mathrm{c} \rightarrow \mathrm{V}$ & $*\{y, \varnothing\}$ \\
\hline & a. [+high-low Dold CoR] & (i) & & $* !$ & & & & \\
\hline & b. [+high-low Dhol CoR LAB ] & (y) & & $* !$ & & * & & * \\
\hline 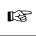 & c. [+high-low Dor LAB ]+@ & (u) & & & I & * & * & \\
\hline & d. [+high-low DoR $]+\subset$ c & (u) & & & $* !$ & & * & \\
\hline
\end{tabular}

(66) and (67) now show the crucial case of covert umlaut for the vowel in Kind Kinder which by assumption is specified neither for lingual PLACE nor for LABIAL. Whereas undominated FTH LAB has blocked unrounding for Grund Gründ-e above, here it excludes rounding $([\mathrm{u}]$ and $[\mathrm{y}])$ in both the singular and the plural (66-b,d), (67-b,d). Since a back unrounded vowel is also blocked (by * $\{u, \gamma\},(66-c)$, (66-c)), [i] is the output in both singular and plural, the only difference being that the CORONAL feature in the plural form originates in the suffix whereas it is epenthetic in the singular:

(66) Covert umlaut configuration: singular (Kind)

\begin{tabular}{|c|c|c|c|c|c|c|c|c|c|}
\hline \multicolumn{4}{|c|}{ Input: [+high-low] } & \multirow[t]{2}{*}{ SPEC-V } & \multirow{2}{*}{\multicolumn{2}{|c|}{$* \mathrm{~V}_{2\{\mathrm{c}, \mathrm{d}, \mathrm{p}\}}, *\{\mathrm{u}, \gamma\}$}} & \multirow[t]{2}{*}{ FTH LAB } & \multirow[t]{2}{*}{$\mathrm{c} \rightarrow \mathrm{V}$} & \multirow[t]{2}{*}{$*\{\mathrm{y}, \varnothing\}$} \\
\hline$\leftrightarrow$ & a. [+high-low & CoR ] & (i) & & & & & & \\
\hline & b. [+high-low & Cor LAB ] & (y) & & 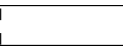 & $\begin{array}{l}1 \\
1\end{array}$ & $* !$ & & $*$ \\
\hline & c. [+high-low & Dor ] & (u) & & । & $* !$ & & & \\
\hline & d. [+high-low & DOR LAB ] & (u) & & I & I & $* !$ & & \\
\hline & e. [+high-low] & & & $* !$ & I & $\mathrm{I}$ & & & \\
\hline
\end{tabular}

(67) Covert umlaut configuration: plural (Kinder)

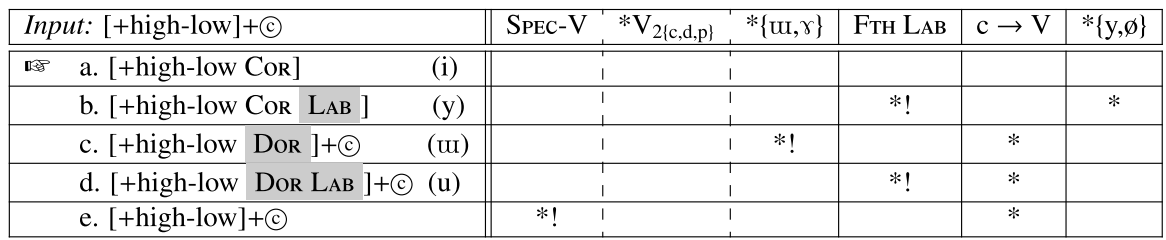

Crucially, under the constraint ranking assumed, all possible underspecification patterns for CORONAL, DORSAL and LABIAL in full vowels result in an attested empirical pattern, as summarized in (68). Maximal specification for LAB and either COR and DoR will lead to consistent realization of the underlying form due to undominated FTH LAB and $* \mathrm{~V}_{2\{\mathrm{c}, \mathrm{d}, \mathrm{p}\}}(68-\mathrm{a}, \mathrm{b})$. Vocalic markedness produces the same output for [+high-low DOR] (68-c) as I have shown in tableaux (64) and (65). (68-d) is the standard umlaut pattern for high vowels derived in tableaux (62) and (63). I assume that nouns such as Wind [vint] Wind-e ['vin.də] 'wind(s)' (masc.) and Schiff [JIf] Schiff-e ['J.fə] 'ship(s)' (neut.) are simply underlyingly specified as CoronAL. Due to $* \mathrm{~V}_{2\{\mathrm{c}, \mathrm{d}, \mathrm{p}\}}$ the floating (c) of the plural suffix cannot associate to the root vowel node. As a consequence, Schiffe blocks evacuation of $\odot$ to the root node and association of (D) to its VPLACE node and the plural suffix is spelled out as [ə] as in non-umlauting Schaf $\sim$ Schafe above (tableaux (44)), whereas (68-f) (Kind $\sim$ Kinder, tableaux (66) and (67)) is completely parallel to overtly umlauting Rad $\sim$ Räder (tableaux (43)) 
which licenses the 'chain shift' of CORONAL and PHARYNGEAL, i.e. umlaut and the spellout of the affix segment as $-\boldsymbol{e}$ :

$$
\begin{aligned}
& \text { Different degrees of } V \text {-underspecification (non-low vowels) } \\
& \begin{array}{llllll} 
& & \multicolumn{5}{c}{S g} & P l & \\
\text { a. [+high-low COR LAB ] } & \rightarrow & \mathrm{y} & \mathrm{y} & \text { (Stück } \sim \text { Stücke) } \\
\text { b. [+high-low DOR LAB ] } & \rightarrow & \mathrm{u} & \mathrm{u} & \text { (Pfund } \sim \text { Pfunde) } \\
\text { c. [+high-low DOR] } & \rightarrow & & & \\
\text { d. [+high-low LAB] } & \rightarrow & \mathrm{u} & \mathrm{y} & \text { (Grund } \sim \text { Gründe) } \\
\text { e. } & \text { [+high-low COR] } & \rightarrow & \mathrm{i} & \mathrm{i} & (\text { Schiff } \sim \text { Schiffe) } \\
\text { f. } & \text { [+high-low] } & \rightarrow & \mathrm{i} & \mathrm{i} & (\text { Kind } \sim \text { Kinder })
\end{array}
\end{aligned}
$$

Let us finally return to low vowels. In Sect. 4.2, I have argued that IDENT PHAR is undominated. Hence low stem vowels specified for this feature are immune to umlaut as shown in (69) and (70):

\begin{tabular}{|c|c|c|c|c|c|c|c|c|}
\hline Input: [-high+low PHAR & & ID PHAR & SPEC-V & $* \mathrm{~V}_{2\{\mathrm{c}, \mathrm{d}, \mathrm{p}\}}$ & $*\{w, \gamma\}$ & FTH LAB & $\mathrm{c} \rightarrow \mathrm{V}$ & ID [+low] \\
\hline a. [-high+low PhthAk & CoR ] $(\varepsilon)$ & $* !$ & 1 & I & & & & \\
\hline b. [-high+low PHAR & Cor ] (a) & & I & & & & & \\
\hline c. [-high+low PHAR & Dor ] (a) & & । & I & & & & \\
\hline d. [-high+low PHAR] & (a) & & l $\quad * !$ & I & & & & \\
\hline
\end{tabular}

(69) No umlaut with low vowel: stable [a]: singular (Schaf)

(70) No umlaut with low vowel: stable [a]: plural (Schafe)

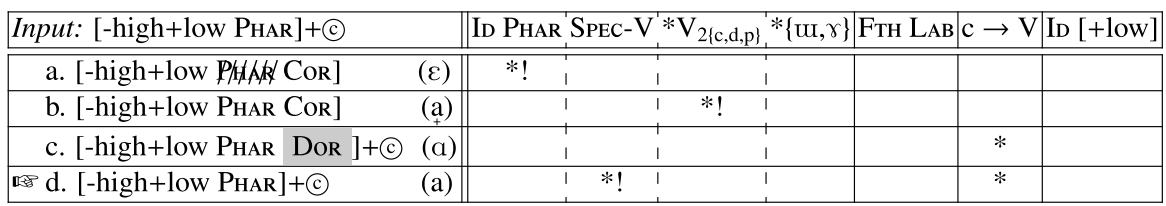

Umlaut applies in low vowels not specified for any place feature, which produces a low vowel specified as PHARYNGEAL in the singular (71-c) to satisfy low-ranked IDENT [+low] (blocking front mid $[\varepsilon]$ as in (71-a)), but $[\varepsilon]$ incorporating the floating plural-(c) in the plural under the pressure of $\mathrm{c} \rightarrow \mathrm{V}(72)$ :

(71) Overt umlaut with low vowel: singular (Rad)

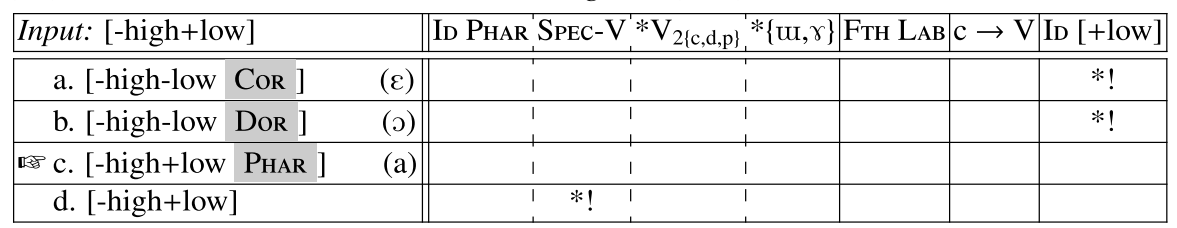

(72) Overt umlaut with low vowel: plural (Räder)

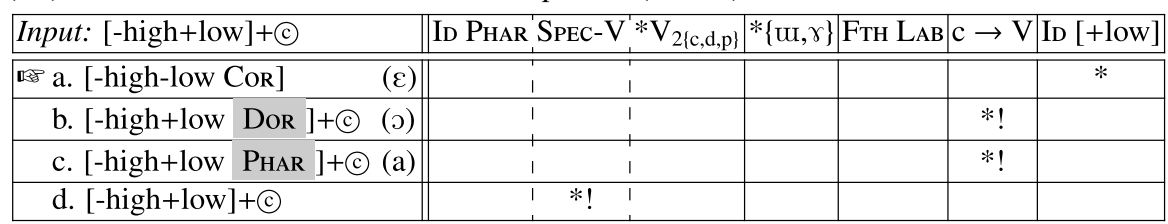




\section{Deriving the template}

Wiese (2009) argues persuasively that German plurals exhibit an Emergence-of-theUnmarked effect (TETU, McCarthyPrince1994): Despite their differences in segmental detail, the majority of plural forms conform to a general template of a penultimate full-vowel syllable and a final reduced syllable (containing one of the reduced vowels $[ə]$ and [ $[\mathrm{e}]$ or a syllabic sonorant) forming an asymmetric binary trochee, as illustrated in (73) (repeated from (1) in Sect. 1.1):

The German plural template ( $\left.\sigma_{\text {full }} \cdot \sigma_{\text {weak }}\right)$ (Wiese $\left.1996 \mathrm{~b}, 2009\right)$

\begin{tabular}{|c|c|c|c|c|c|}
\hline Pelz & {$\left[\mathrm{p}^{\mathrm{h}} \varepsilon \mid \widehat{l s}\right]$} & $\rightarrow$ Pelze & ['pel.đsə] & 'fur(s)’ (masc.) & $n$ of $-\partial$ \\
\hline & {$\left[\mathrm{k}^{\mathrm{h}} \mathrm{Int}\right]$} & Kinder & ['kin & & n of $-\mathrm{e}$ \\
\hline & & $\rightarrow$ & & & \\
\hline & ['Rع.kə] & Recken & ['Rع.kp] & 'warrior(s)' (masc.) & Affixation of $-n$ \\
\hline $\begin{array}{l}\text { Steck } \\
\text { Esel }\end{array}$ & ['fte.kən] & $\begin{array}{l}\rightarrow \text { Stecken } \\
\rightarrow \text { Esel }\end{array}$ & & donkey (s)' (masc ) & \\
\hline
\end{tabular}

This foot type is not only typologically unmarked but also characteristic for the morphophonology of German (for example, it is the dominant pattern in German polysyllabic lexical roots, Golston and Wiese 1998). Wiese captures the TETU effect by faithfulness constraints indexed for singular and plural. Thus for a noun such as Tisch [trf] $\sim$ Tische ['tr.fə] 'table(s)', the plural schwa is not a suffix, but an epenthetic vowel which is inserted under the force of markedness constraints outranking DEP-SEGMENTPlural (75), whereas schwa insertion is blocked in the singular by high-ranked DEP-SEGMENT Singular (74) (“TROCHEE" abbreviates a set of markedness constraints favoring asymmetric syllabic trochees):

(74) Input: trf+sg. (table, masc.)

\begin{tabular}{|l||c|c|c|}
\hline & DEP-SEGMENT Singular & TROCHEE & DEP-SEGMENTPlural \\
\hline \hline a. $\operatorname{tI} \int$ & & $*$ & \\
\hline b. $\operatorname{tr} \int \partial$ & $* !$ & & \\
\hline
\end{tabular}

Input: $\mathrm{tr} \int+\mathrm{pl}$. (table, masc.)

\begin{tabular}{|c||c|c|c|}
\hline & DEP-SEGMENTSingular & TROCHEE & DEP-SEGMENTPlural \\
\hline \hline a. $\operatorname{tr} \int$ & & $* !$ & \\
\hline b. $\operatorname{tr} \int \partial$ & & & $*$ \\
\hline
\end{tabular}

The added value of this system is that noun roots which already end in an unmarked foot such as Anker ['?ay.ke] 'anchor' or Esel ['?e..zl] 'donkey' simply don't insert schwa because they already conform to the markedness constraints, and further insertion would gratuitously violate faithfulness.

While Wiese captures the German plural template in a principled and elegant way, his analysis raises a number of problems. First, the assumption of lexically indexed constraints results just in the proliferation of OT's typological predictions the concatenativist hypothesis is supposed to curb (see Sect. 2). Second, the analysis doesn't derive the observed allomorphy between $-\partial,-\boldsymbol{e}$ and $-n$, and offers no obvious means 
to capture the generalizations derived by the subsegmental analysis in Sect. 3. Thus the availability of an additional CORONAL feature in all variants of German plural and its complementary distribution among umlaut and plural [n] cannot be captured as an Emergence of the Unmarked effect since it leads to typologically marked consonant clusters in $n$-suffixation (as in Saat [za:t] Saaten ['zar.tn] 'seed(s)') and to equally marked round front vowels in umlaut (e.g. Rock [Rok] $\sim$ Röck-e ['Rœ.kə] 'gown(s)'). Third, as noted by Neef (1998), there are few, but systematically predictable exceptions to the final trochee generalization, such as the rare nouns with a final reduced syllable ending in an obstruent (e.g. Abend ['?a:.bənt] $\sim$ Abend-e ['?a:.bən.də] (masc.) 'evening(s)').

In this section, I will show that the German plural template observed by Wiese can-as far as it holds - also be derived under the GNA analysis of German plural, where a TETU effect is not triggered by constraint indexation and a foot template, but by the fact that defective phonological material (especially the underspecified segmental root node) is vulnerable to syllable markedness constraints (and to faithfulness constraints protecting root prosody) in a way fully specified segments are not. As a consequence, plural forms tend to preserve the already highly restricted phonotactics derived at the Root Level and avoid marked structure such as adjacent weak syllable nuclei, or consonant clusters, resulting in a very narrow set of outputs establishing thus the appearance of a plural-specific template. ${ }^{20}$

Concretely, I assume that segmental faithfulness is captured by the three constraints in (76) ranked in order of descending specificity, where MAX • requires phonetic realization of every segmental root node, MAX V of every root node underlyingly specified as [-consonantal] and $\mathrm{MAX} \mathrm{V}_{\text {full }}$ of full vowels, i.e. vowels with an underlying APERTURE node. ${ }^{21}$

$$
\operatorname{MAX} \bullet \bullet^{\mathrm{V} \text {-full }} \gg \operatorname{MAX} \bullet{ }^{\mathrm{V}} \gg \operatorname{MAX} \bullet
$$

Essentially, full vowels are protected by all three constraints, fully specified reduced vowels (i.e., underlying [ə] and [e]) by MAX $\bullet$ V and MAX $\bullet$, but the defective pluralsuffix only by MAX $\bullet$. As a consequence, it suffers deletion under the pressure of low-ranked constraints which leave other vowels intact. In the following subsections, I will show that this effectively derives Wiese's final strong-weak template for all major root shapes (Sects. 5.1 to 5.3). In Sect. 5.4, I discuss the restrictions on the phonological realizations of the defective plural segment, and in Sect. 5.5 I show that the analysis also correctly predicts the plurals for the less frequent stem shapes which are problematic for Wiese's analysis.

\footnotetext{
${ }^{20}$ Wiese (1996b) adduces a further argument for construction-specific prosodic conditions: the fact that attributive adjective inflection consistently contains schwas not required by general phonotactic requirements. Crucially this also follows in a concatenative analysis under the assumption of Noske (1993:164) of a ə-class marker suffixed to all attributive adjectives. Note also that a crucial motivation for positing prosodic constraints triggering schwa-epenthesis in pre-OT work on German (see besides Wiese 1986, 1996b also Féry 1991) was the attempt to derive schwa uniformly from epenthesis, a goal which is inherently problematic in OT due to Richness of the Base (Prince and Smolensky 1993; Kager 1999).

${ }^{21}$ The use of fixed-ranking faithfulness constraints of different specificity here is closely analogous to the implementation of Positional Faithfulness effects as for stressed vowels (Beckman 1998).
} 


\subsection{Roots ending in syllabic sonorants}

The logic of incremental defectiveness captured by the constraints in (76) is most obvious in the case of noun stems with underlyingly final syllabic sonorants. Recall from Sect. 3.2 that the explanation for the realization of the plural for $\operatorname{ta}_{\mathrm{p}} \mathrm{d} d \mathrm{l}+\mathrm{C} \bullet$ as $\mathrm{ta}_{\mathrm{p}}: \mathrm{dl}$ instead of $* \mathrm{ta}_{\mathrm{d}}: \mathrm{d}$.lo๔ is due to the ranking of IDENT $v$ above MAX $\bullet$. There is a further conceivable candidate where the syllabic [1] is immediately followed by [ə], i.e., $\operatorname{ta}_{\mathrm{p}} \mathrm{idl}$. , , but this violates a central phonotactic generalization of Standard German, where nuclei of adjacent weak syllables must be separated by non-syllabic consonants. I implement this by the undominated constraint in (77) which forbids two adjacent weak syllable nuclei (see Neef 1998:254 for the similar constraint 'Syllable Peak Adjacency Condition'):

$$
\begin{aligned}
& * \underline{v \underline{v}} \quad \begin{array}{l}
\text { Assign } * \text { to every pair of adjacent phonetic weak syllable nuclei } \\
\text { (i.e. nuclei without a vocalic APERTURE node) }
\end{array}
\end{aligned}
$$

This constraint captures both the absence of syllabic consonants preceded or followed by reduced vowels and the general ban in German against two adjacent schwas (*[əə]). In fact, syllabic consonants only appear in syllables with onsets (after vowels sonorants are obligatorily syllabified as codas). There are no roots with adjacent schwas, and only a single schwa appears in other inflectional contexts where we would otherwise expect them. Thus compare the adjective tot [to:t] 'dead', plural: tot-e ['tor.tə] with müde ['my:.də] 'tired', plural: ['my:.də]/*['my:.dəə]. To be sure, adjectival plurals do not generally obey the same final strong-weak template as noun plurals (Wiese 1996b:110), as is evident from examples such as mager ['ma:.ge] 'slim', plural: mager-e ['mai.ge.Rə]. ${ }^{22}$ (78) shows the derivation of Tadel including * $\underline{\underline{v} \breve{v}}$ (extending the tableau in (31)):

\begin{tabular}{|c|c|c|c|c|c|c|c|}
\hline & & $* \underline{\underline{v} \breve{v}}$ & $\operatorname{Max} \bullet V$ & ID $v$ & $* \mathrm{C}$ & $* \mathrm{CC}]_{\sigma}$ & MAX • \\
\hline & a. $\operatorname{ta}_{\mathrm{p}}: \mathrm{d} \cdot 1$ ləc) & & & $* !$ & $*$ & & \\
\hline & b. $t_{\mathrm{p}}: \mathrm{d} ə \mathrm{l}(\mathrm{C}$ & & & $* !$ & $*$ & & $*$ \\
\hline & c. $\operatorname{ta}_{\mathrm{p}}: \mathrm{dl}_{\mathrm{i}} \mathrm{n}_{\mathrm{c}}$ & & & & $*$ & $* !$ & \\
\hline 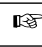 & d. $t_{\mathrm{p}}: \mathrm{dl} \subset \mathrm{c}$ & & & & $*$ & & $*$ \\
\hline & e. $\mathrm{ta}_{\mathrm{p}}: \mathrm{dl} . \partial \subset \mathrm{c}$ & $* !$ & & & $*$ & & \\
\hline
\end{tabular}

$$
\text { Input: } \mathrm{ta}_{\mathrm{p}}: \mathrm{dl}+\mathrm{C} \bullet \text { (Tadel 'reproach', masc.) }
$$

The defective plural-• here forms effectively a minimal pair with [ə]-suffixes in other inflectional contexts such as the plural of adjectives in $e d e l$ ['?e:.dl] $\sim e d l-e$ ['Pe:d.lə] 'noble', and the 1sg present of verbs as in radel ['Rai.dl] 'bike! (Imp.)' radle ['Ra:d.l-ə] 'I bike', where IDENT $v$ is obviously violated and the segmental suffix is realized. This follows from the ranking in (76) if we take the adjectival plural and the $1 \mathrm{sg}$ suffixes to be underlying [ə], which are protected by MAX $\bullet$ V and hence license violations of IDENT $v$ as shown for Ra:d.l-ə in (79):

\footnotetext{
${ }^{22}$ The blocking of [əə] does not follow from more general restrictions such as an anti-hiatus prohibition. Two adjacent full vowels are in principle possible (e.g. Chaos ['ka.os] 'chaos') and even [ə] is possible after full vowels (e.g. Truhe ['tru:.ə] 'chest'). Also two adjacent syllables headed by schwa are licit if the vowels are separated by an onset consonant (e.g. veredele [fee.'Pe..də.lə] 'I refine').
} 
(79) Input: $\mathrm{Ra}_{\mathrm{p}}: \mathrm{dl}+\mathrm{l}+\partial$ ('to bike', Pres. $1 \mathrm{sg}$ )

\begin{tabular}{|c|c|c|c|c|c|c|c|}
\hline & & $* \underline{\underline{v} \breve{v}}$ & $\operatorname{MAX} \bullet V$ & ID $v$ & ${ }^{*} \mathrm{C}$ & $\left.{ }^{*} \mathrm{CC}\right]_{\sigma}$ & MAX $\bullet$ \\
\hline I 18 & a. $\mathrm{Ra}_{\mathrm{p}}$ :d.lə & & & $*$ & $*$ & & \\
\hline & b. $\mathrm{Ra}_{\mathrm{p}}: \mathrm{dl}$ (ə) & & $* !$ & $*$ & $*$ & & $*$ \\
\hline & c. $\mathrm{Ra}_{\mathrm{p}}$ :dl.ə & $* !$ & & & $*$ & & \\
\hline
\end{tabular}

As a consequence, the defectiveness of the plural suffix and the interspersing of IDENT $v$ with vocalic faithfulness constraints derives an essential part of Wiese's weak-strong template. Consider for example the adjective plurals mager ['mai.ge] mager-e ['mai.ge.Rə] 'slim' and schüchtern ['Jyç.ten] schüchtern-e ['Jyç.te.nə] 'shy'. Similarly $1 \mathrm{sg}$ verb forms as in wander ['van.de] 'hike!' wander$e$ ['van.de.Rə] 'I hike' which violate this template (they end in $\sigma_{\text {full }} \sigma_{\text {weak }} \sigma_{\text {weak }}$, not in $\sigma_{\text {full }} \sigma_{\text {weak }}$ ), and form a minimal pair with noun plurals such as Anker and Trichter which obey it. All these roots have a final syllabic [R] preceded by a full-vowel syllable at the point when they reach the Stem-Level phonology. The reason why nouns end up with final strong-weak is simply that the Root Level already enforces the strong-weak template for morphemes ending in a syllabic consonant for all parts of speech, and that the nominal suffix is too weak to justify violation of IDENT $v$. Thus the Root Level doesn't allow for roots of the shape $C_{0} C_{\supset} C_{1}$ or $\ldots V_{\text {full }} C_{0} \partial C_{0} C$ (since every root must have a full vowel, and [ə] is only possible in root-final position immediately following a full-vowel syllable, see Golston and Wiese 1998), which would lead to violations of Wiese's template even under deletion of the defective plural segment. In the next section, I show that the same constraints also derive the apparent templatic effect in [ə]-final noun roots.

\subsection{Roots ending in ....}

Recall that roots in ... ə consistently have plural $-n$, not - - (Pate $\sim$ Pate- $n / *$ Pate-e $)$. This falls out straightforwardly from the ban against two adjacent reduced nuclei $* \underline{\breve{v}}$, excluding realization of $\bullet$ as [ə] (80-c). Choosing to spellout $\bullet$ as $-n$, MAX $\bullet$ can be satisfied without violating IDENT $v$ or $* \mathrm{CC}]_{\sigma}(80-b)$ :

(80) Input: $\mathrm{pa}_{\mathrm{p}} \mathrm{it \partial +}+\mathrm{C}^{\bullet}$ (Pate 'godfather', masc.)

\begin{tabular}{|c|c|c|c|c|c|c|}
\hline & & $* \widetilde{v} \breve{v}$ & Max V & ID $v$ & ${ }^{*} \mathrm{C}$ & MAX $\bullet$ \\
\hline & a. $\mathrm{pa}_{\mathrm{p}} \mathrm{it} . \partial$ & & & & & $* !$ \\
\hline$\rightarrow$ & b. $\mathrm{pa}_{\mathrm{p}} \mathrm{t} t \mathrm{n}_{\mathrm{c}}$ & & & & & \\
\hline & c. $\mathrm{pa}_{\mathrm{p}}$ itə.ə & $* !$ & & & & \\
\hline
\end{tabular}

\subsection{Roots with final full-vowel syllables}

Also the derivation of Wiese's template for roots that end in full-vowel syllables with consonantal codas (such as Maat $\sim$ Maat-e 'steward(s)') follows in a maximally simple way. The unmarked realization of a defective segment in this context is as schwa 
as shown in (81) (cf. tableau (28) in Sect. 3.2 above), but also the realizations as $-e$ (as in neuter Rad $\sim$ Räder) or as $-n$ (as in feminine Saat $\sim$ Saaten) fulfill the template:

(81) Input: $\mathrm{ma}_{\mathrm{p}} \mathrm{it}+\mathrm{C} \bullet$ (Maat 'steward', masc.)

\begin{tabular}{|c|c|c|c|c|c|c|}
\hline & & $* \breve{v \breve{v}}$ & Max V & ID $v$ & $* \mathrm{C}$ & $\operatorname{MAX} \bullet$ \\
\hline & a. $\mathrm{ma}_{\mathrm{p}}: \mathrm{t} \bullet$ & & & & & *! \\
\hline & b. $m a_{p}: t_{1}$ & & & & *! & \\
\hline 吗 & c. $m a_{p} i t \subset \partial$ & & & & & \\
\hline
\end{tabular}

Note that vowel-final noun stems ending in a full vowel (i.e., not [ə] or [e]) are marginal in German and restricted in the native stratum to nouns ending in [ar] and [av] that might be interpreted as phonotactically equivalent to consonant-final stems (i.e., subject to $* \mathrm{CC}]_{\sigma}$ or to a generalized version of this constraint). In fact, they fulfill the strong-weak template in exactly the same way as consonant-final roots with final full-vowel syllables: feminine nouns typically pluralize with syllabic $-n$ (e.g. Frau [fraz] Frau-en ['fraz.ən]/['fraz.n] 'woman/women') masculine nouns with -ə (e.g. Brei [brar] Breie ['brar.ə] 'porridge(s)') and neuters with either -ə or $-\boldsymbol{e}$

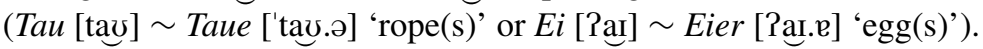

For both consonant- and final-vowel full-vowel roots, template satisfaction of course is also due to the possible segmental realizations of plural- $\bullet$. Thus if $\bullet$ would be realized as $-t$ as in Wal [va:l] *Wal- $t$ [va:lt] (correct: Wale ['va:.lə]) 'whales', we would expect plurals ending in a single strong syllable in violation of the strong-weak template. In the next section, I will discuss which constraints effectively restrict the possible outputs of the plural segment to $-\partial,-e$, and $-n$.

\subsection{Deriving the possible spellouts of}

I take it for granted that in the lexical strata of Standard German, all consonants must be specified for PLACE, effectively excluding a realization of $\bullet$ as a placeless nasal. I assume that the only potentially placeless consonant in the language, the glottal stop, is inserted by a post-lexical process since it is fully predictable from prosodic structure. $^{23}$ The consonantal place requirement is captured by the constraint in (82) (cf. (61) for an analogous constraint for vowels):

SPEC-C: A consonantal segment must be specified for at least one PLACE feature (CORONAL, LABIAL, ...)

Moreover, the possible realizations of the generic plural-• are limited by two general segmental faithfulness restrictions. First, underlyingly reduced vowels (underlying $[ə]$ and $[\mathrm{e}]$ ) are never promoted to full vowel status, and second, there is no insertion

\footnotetext{
${ }^{23}$ Glottal stop insertion ensures onsets in prosodic word-initial and stressed syllables. See Alber (2001) for a detailed analysis.
} 
of consonantal place. Recall that the only epenthetic consonant in the language is the glottal stop, which I take to be post-lexical. We can capture these restrictions by the two constraints in (83):
a. DEP APERTURE:
Assign $*$ to every APERTURE node which is phonetic, but not morphological
b. DEP PLACE ${ }^{\mathrm{C}}$ : Assign $*$ to every PLACE node under a [+cons] segmental root node which is phonetic, but not morphological

Under the representational assumptions for vowels laid out in Sect. 2.3, undominated DEP APERTURE will have the effect that neither schwa sounds nor the defective plural-• can acquire an APERTURE node which would grant them full vowel status. The only possible vocalic realizations for $\bullet$ are hence [ə] and [e]. DEP PLC ${ }^{\mathrm{C}}$ reinforces the mechanism governing the complementary distribution of - $n$ and umlaut developed in Sect. 3.1. Since no PLACE feature, can be inserted to make $\bullet$ an interpretable consonant, its only chance to consonant-hood is to integrate the tautomorphemic floating CORONAL. That this leads to $n$, not to $l$ or $s$ is plausibly due to the fact that $n$ is the unmarked sonorant in German and that sonorants are preferred as syllable nuclei and codas over obstruents (Clements 1990; Golston and Wiese 1996; Wiese 2009). In fact, Krämer and Zec (2017) provide typological results that the crosslinguistic sonority bias for coda consonants is actually a bias for nasals, and Blevins (2006) reports a typological bias for nasal nuclei over liquids. I encode these asymmetries by the constraint in (84):

$$
\underline{\mathrm{n}}]_{\sigma} \text { Assign } * \text { to every phonetic non-nasal rhyme consonant }
$$

(85) shows the effects of DEP PLC ${ }^{\mathrm{C}}$ and $\left.\underline{n}\right]_{\sigma}$ for the plural for Pate (omitting the irrelevant constraints from tableau (80)). Whereas SPEC-C and DEP PLC ${ }^{\mathrm{C}}$ are undominated excluding placeless consonants and PLACE epenthesis throughout the grammar, $\underline{\mathrm{n}}]_{\sigma}$ is ranked low, having effects only for an underspecified segment such as plural-• ("N" in (85-c) stands for a place-less nasal):

Input: $\mathrm{pa}_{\mathrm{p}} \mathrm{it \partial}+\mathrm{C} \bullet$ (Pate 'godfather', masc.)

\begin{tabular}{|c|c|c|c|c|c|c|c|}
\hline & & SPEC-C & DeP PlC ${ }^{C}$ & $* \underline{\underline{v} \breve{v}}$ & $\ldots$ & MAX $\bullet$ & $\underline{\mathrm{n}}]_{\sigma}$ \\
\hline & a. $\mathrm{pa}_{\mathrm{p}}: \mathrm{t} \cdot \odot$ & & & & & $* !$ & \\
\hline & b. $\mathrm{pa}_{\mathrm{p}}: \mathrm{t}$. & & & $* !$ & & & \\
\hline & c. $\mathrm{pa}_{\mathrm{p}}: \mathrm{t} ə \mathrm{~N} \subset$ & $* !$ & & & & & \\
\hline & d. $\mathrm{pa}_{\mathrm{p}} \mathrm{t}$ təm@ & & $* !$ & & & & \\
\hline & e. $\mathrm{pa}_{\mathrm{p}} \mathrm{it \partial l_{ \textrm {c } }}$ & & & & & & $* !$ \\
\hline 诲 & f. $\mathrm{pa}_{\mathrm{p}} \mathrm{t} \mathrm{tən}_{\mathrm{c}}$ & & & & & & \\
\hline
\end{tabular}

In (86), I illustrate the fact that DEP APERTURE must also be undominated to guarantee that in a noun plural such as Maate, the floating CORONAL and the defective root node do not form a full vocalic [i] which would also satisfy $\mathrm{c} \rightarrow \mathrm{V}$ (86-c): 
(86) Input: $\mathrm{ma}_{\mathrm{p}} \mathrm{it+C} \bullet$ (Maat 'steward', masc.)

\begin{tabular}{|c|c|c|c|c|c|}
\hline & DEP AP & $* \underline{\underline{v} \breve{v}}$ & $\mathrm{c} \rightarrow \mathrm{V}$ & $* \mathrm{C}$ & MAX • \\
\hline a. $\mathrm{ma}_{\mathrm{p}} \mathrm{it} \odot$ & & & $*$ & & $* !$ \\
\hline b. $m a_{p}: t_{c}$ & & & $*$ & $* !$ & \\
\hline c. $m a_{\mathrm{p}} \mathrm{ti}_{\mathrm{c}}$ & $* !$ & & & & \\
\hline d. ma $: \mathrm{t}(\mathrm{c})$ & & & $*$ & & \\
\hline
\end{tabular}

\subsection{Violating the template}

Whereas the subsegmental affixation approach correctly derives that Wiese's plural template is satisfied for all canonical shapes of German roots, it also predicts that specific departures should be possible for atypical root shapes. Thus, as shown in Neef (1998), the handful of roots in German which end in a syllabic consonant followed by an obstruent such as Abend ['Pa:.bnt] (masc.) 'evening' and Tugend ['tur.gnt] (fem.) 'virtue' take a segmental plural suffix resulting in a final strong-weak-weak sequence violating the Wiese template as in Abend-e ['Pa:.bn.də] and Tugend-en ['tu:.gy.dn]]. Crucially, these violations follow straightforwardly in the analysis proposed here. Since the final obstruent in these roots is not a nucleus, but a coda at the input to Stem-Level phonology, it can resyllabify as an onset without violating IDENT $v$ as in (87-d) (contrast this with Nadel in tableau (32) in Sect. 3.2, where the final consonant is a nucleus, and resyllabification is blocked). Realizing the defective plural segment is also unproblematic and in the case of Abende even better for $* \mathrm{CC}]_{\sigma}$ than deletion (87-c). ${ }^{24}$ Note that (87-d) doesn't violate $* \underline{\underline{v} \breve{v}}$ since the two weak syllable nuclei (n and ə) are separated by an onset consonant:

Input: $2 \mathrm{a}_{\mathrm{p}} \mathrm{ibnd+(C) \bullet (Abend} \mathrm{'evening',} \mathrm{masc.} \mathrm{pl.)}$

\begin{tabular}{|c|c|c|c|c|c|c|c|}
\hline & $* \underline{\underline{v} \breve{v}}$ & $\operatorname{Max} \bullet V$ & ID $v$ & Max $n$ & $*^{*} \mathrm{C}$ & $\left.{ }^{*} \mathrm{CC}\right]_{\sigma}$ & Max $\bullet$ \\
\hline a. $P a_{\mathrm{p}}: \mathrm{b} \cdot n$ ə. $\mathrm{d} \partial \subset$ & & & $* !$ & & * & & \\
\hline b. $P a_{p}: b$ ə n.dəC) & & & $* !$ & & * & & \\
\hline c. $2 a_{\mathrm{p}} \mathrm{b} \mathrm{bn} \odot \mathrm{d} \odot$ & & & & & * & $* !$ & $*$ \\
\hline d. $? \mathrm{a}_{\mathrm{p}}$ :.bn.də & & & & & * & & \\
\hline
\end{tabular}

A second class of exceptions to Wiese's template are roots with two final fullvowel syllables and penultimate stress such as Plural ['plu:Ral] (masc.) 'plural' and Predigt ['pre..dikt] 'sermon' which fit the final strong-weak schema in the plural (['plu:Ra.lə] and ['pre:.dik.tn]), but do not conform to Wiese's claim that all plurals end in a trochee since plural stress for these stems is antepenultimate not penultimate (['pre:.dik.tn] /*[pre..'dik.tn] and ['plu:ra.lə]/ *[plu:'ra.lə]). Again the subsegmental affixation approach makes the correct predictions here since IDENT $v$ is not violated by resyllabifying the final coda obstruents, and hence MAX $n$ ensures realization of the plural root node as a syllabic [n], as shown in (88):

\footnotetext{
${ }^{24}$ For feminine Tugend, the suffix is realized as $-n$ due to high-ranked MAX [nasal] (cf. Sect. 3.2 and tableau (88)), but the correct output ['tui.gp.dn] still has the same number of $\left.{ }^{*} \mathrm{CC}\right]_{\sigma}$ violations (1 for [y] and 1 for [n]) as the suffix-deletion candidate ['tu..gnt] (1 for [n] and 1 for final [t]).
} 
Input: pre:dikt+() $\bullet+($ (I) (Predigt 'sermon', fem.)

\begin{tabular}{|c|c|c|c|c|c|c|c|}
\hline & & $* \breve{v} \breve{v}$ & $\operatorname{Max} \bullet V$ & ID $v$ & Max n & $* \mathrm{C}$ & MAX $\bullet$ \\
\hline & a. pre:dikt@C@n & & & & $* !$ & & * \\
\hline & b. pre:dik.tə@)(n & & & & $* !$ & & \\
\hline 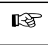 & c. pre:.dik.tn $n_{c, n}$ & & & & & * & \\
\hline
\end{tabular}

A further violation of the claim that plurals end in binary trochees cited by Neef are derived nouns with two final e-syllables (e.g. Zauberer ['tsav.be.re] 'magician' (sg./pl) from the verb zaubern 'perform magic'). Here once more the plural has antepenultimate stress which is problematic for the prosodic approach, but follows in the subsegmental account where the $\emptyset$-plural is derived completely in parallel to stems with a single final e-syllable (see the tableau for Taler in Sect. 4.2).

\section{Exceptional patterns}

The subsegmental analysis developed so far makes correct predictions for the segmental plural allomorphy in the vast majority of German nouns (see the supplemental material for systematic empirical evaluation); however there are specific groups of exceptions in masculine and neuter nouns. In a concatenative GNA analysis, we expect two types of lexeme-specific exceptions to general affixation patterns: suppletive allomorphy of the type also found pervasively in strictly segmental affixation as in English $o x \sim o x$-en vs. box $\sim$ box-es, and deviations triggered by the fact that single lexemes, just as affixes, might contain phonologically defective material. A wellknown case in point are lexical roots in tone languages which have floating tones that appear on affixes (cf. the Kpelle low-tone plural suffix - ràà which acquires an addi-

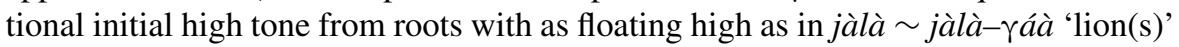

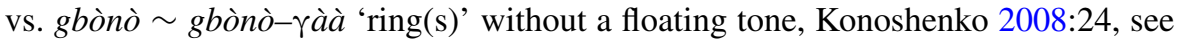
Vago 1976; Clements and Keyser 1983; Wolf 2007 for other non-tonal cases where exceptional roots arguably carry floating material, and Wiese 1996a; Yu 1992 for applications to German umlaut). In this section, I will argue that the major classes of exceptions to the allomorphy patterns identified above for German noun plurals are exactly of these two types.

\subsection{Allomorphy triggered by floating features of roots: Masculine plurals in - $n$}

The major group of exceptional masculine nouns take $-n$ in the plural although they don't end in [ə], for example Ahn [?a:n] Ahn-en ['Pa:.nən] 'ancestor(s)' Planet [pla.'ne:t] Planeten [pla.'ne..tn] 'planet(s)', Graf [gRa:f] Graf-en ['gra:.fən] 'count(s)'. Now recall from the contrast between (81) and (80) that in [ə]-final nouns such as Pate $\sim$ Paten plural- $n$ emerges since adding a further schwa would violate $* \underline{v} \breve{v}$ while schwa is prefered over $n$ after consonants to avoid a $* C_{Y}$ violation (pl. Maat-e vs. *Maat-en). On the other hand, plural- $n$ surfaces even after consonants in nonumlauting feminine forms since these trigger insertion of the featural nasal suffix which must be realized by virtue of higher-ranked MAX [nasal]. Listing forms such as Grafen as full-form exceptions would be technically possible, but would miss an 
important generalization: Just as in all other plural forms, the nouns in this group never exhibit umlaut. This would be completely accidental in a full listing analysis (where *Gräfen should be just as good as Grafen), but follows if we assume that they are compositionally derived from a root and the regular plural suffix comprising a single floating CORONAL feature which cannot surface simultaneously as umlaut and nasal [n]. My proposal to reconcile the exceptionality of the nasal nouns with the rule-based distribution of umlaut is to posit that these nouns lexically carry a floating nasal feature, which associates to the plural root node to create $-n$ as shown in (89):
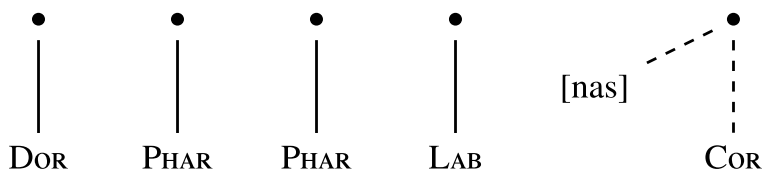

g

$\mathrm{R}$

a:

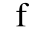

n

Crucially, the realization as [n] already follows from the constraint ranking developed since the floating [nasal] is phonologically indistinguishable from the floating feminine nasal suffix. (90) is hence completely parallel to the derivation for Saat-en 'seeds' in tableau (27):

Input: gRa: $\mathrm{p}$ f(n+C) (Graf-en 'count', masc. pl.)

\begin{tabular}{|c|c|c|c|c|c|c|c|c|}
\hline & & DEP $\bullet$ & $* \mathrm{~V}_{2\{\mathrm{c}, \mathrm{d}, \mathrm{p}\}}$ & NoSKIP & $c \rightarrow V$ & Max $n$ & ${ }^{*} \mathrm{C}$ & MAX • \\
\hline 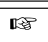 & a. $g_{R a}: f_{n}, n$ & & & 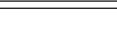 & * & & * & \\
\hline & b. $g R a_{p}: f(n)(c)$ & & & & * & $* !$ & & \\
\hline & c. $\mathrm{gR} \varepsilon_{\mathrm{c}, \mathrm{p}}: \mathrm{f} \cap \mathrm{n}$ & & $* !$ & & & & & \\
\hline & d. gra :f(n) $\bullet$ & & & 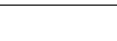 & * & $* !$ & & $*$ \\
\hline
\end{tabular}

In the nominative singular, realizing floating [nasal] by a full segment would require to insert a segmental root node violating high-ranked DEP • (91-a) and hence it remains unparsed and unpronounced (91-c):

Input: gRa:p f( (Graf 'count', masc. nom. sg.)

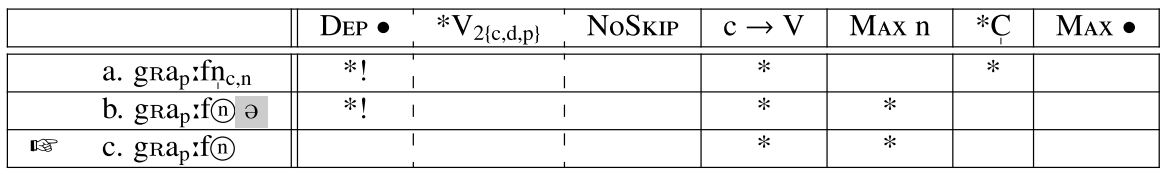

A crucial prediction of the floating-feature account to exceptional $n$-plurals is that the floating [nasal] should be able to surface in non-plural contexts if other morphological constructions provide a suitable host. This prediction is in fact borne out: Most of these nouns exhibit an $-n$ also in oblique (genitive, dative, accusative) singular forms. This is shown in (92) for Graf in comparison to minimally different feminine (Rast) and non- $n$ masculine nouns (Gast). Schwa-final nouns such as Pate take -n not only in the plural, but also in oblique singular forms: ${ }^{25}$

${ }^{25}$ [Rast $] \sim$ ['Ras.tn] $]$, gast $] \sim[$ 'gas.təs $] \sim[$ 'ges.tə] $\sim$ ['gєs.tn] $]$. 
(92)

\begin{tabular}{lcccccccc}
\hline & \multicolumn{2}{c}{ Fem. } & \multicolumn{2}{c}{ Masc. non-n class } & \multicolumn{2}{c}{ Masc. n-class } & \multicolumn{2}{c}{ Masc. o-final } \\
& sg & $p l$ & sg & $p l$ & $s g$ & $p l$ & $s g$ & $p l$ \\
\hline Nom & Rast & Rast-en & Gast & Gäst-e & Graf & Graf-en & Pate & Pate-n \\
Gen & Rast & Rast-en & Gast-es & Gäst-e & Graf-en & Graf-en & Pate-n & Pate-n \\
Dat & Rast & Rast-en & Gast & Gäst-en & Graf-en & Graf-en & Pate-n & Pate-n \\
Acc & Rast & Rast-en & Gast & Gäst-e & Graf-en & Graf-en & Pate-n & Pate-n \\
\hline \multicolumn{2}{c}{} & \multicolumn{2}{c}{ 'rest' } & \multicolumn{2}{c}{ 'guest' } & \multicolumn{2}{c}{ 'count' } & \multicolumn{2}{c}{ 'godfather' } \\
\hline
\end{tabular}

While a full account of German case morphology is beyond the scope of this paper, I will sketch how the oblique allomorphy can be derived in the analysis developed here. A natural assumption is that the oblique exponent is morphologically restricted to masculine nouns (it never appears with feminine or neuter nouns) and is minimally different from the generic plural suffix, containing a CORONAL feature and an otherwise underspecified root node. However in contrast to the plural suffix, it is linked via a CPLACE node to an (otherwise unspecified) root node:

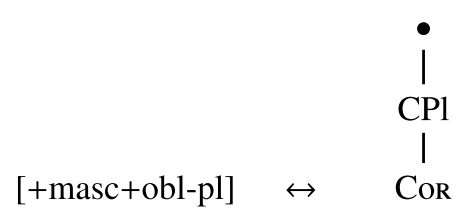

Because CORONAL cannot shift from one segment to another due to ${ }^{*} \mathrm{COR}_{2}$ ( (since it is the generalized, not the phonetic clone of the constraint, see Sect. 2.1), the affix in (93) never results in umlaut as shown in (94-d).

(94) Input: gRa: $\mathrm{f}(\mathrm{D}+\mathrm{c}-\bullet$ (Graf 'count', masc. obl. sg.)

\begin{tabular}{|c|c|c|c|c|c|c|c|c|}
\hline & & DEP $\bullet$ & ${ }^{*} \mathrm{CoR}_{2}$. & $\square \leftarrow$ PLC & $\mathrm{c} \rightarrow \mathrm{V}$ & Max n & $* \mathrm{C}$ & Max $\bullet$ \\
\hline$\| \notin$ & a. $g R a_{p}: f_{1}, n$ & & & & $*$ & & $*$ & \\
\hline & b. $g_{R a}: f(n)(C)$ & & & $* !$ & $*$ & * & & \\
\hline & c. $g_{R a}: f(n)(-)$ & & & & $*$ & *! & & $*$ \\
\hline & d. $\mathrm{gR}_{\mathrm{p}, \mathrm{c}} \mathrm{f} \cap \mathrm{n} \bullet$ & & *! & & & $*$ & & $*$ \\
\hline
\end{tabular}

After a noun without floating [nasal] such as Maat, the defective oblique segment is suppressed since $* \mathrm{C}$ dominates the only faithfulness constraint protecting it, MAX (95-a) and it cannot vocalize to [ə] because this would leave CORONAL afloat and violate $\square \leftarrow$ PLC (95-b):

(95) Input: ma: $_{\mathrm{p}} \mathrm{t}+\mathrm{c}-\bullet$ (Maat 'steward', masc. obl. sg.)

\begin{tabular}{|c|c|c|c|c|c|c|c|c|}
\hline & & DEP • & ${ }^{*} \mathrm{CoR}_{2}$. & $\square \leftarrow$ PLC & $\mathrm{c} \rightarrow \mathrm{V}$ & Max n & $* \mathrm{C}$ & $\operatorname{Max} \bullet$ \\
\hline & a. $m a_{p}: t_{1}, n$ & & & & $*$ & & $* !$ & \\
\hline & b. $\mathrm{ma}_{\mathrm{p}}: \mathrm{t}(\mathrm{c} \partial$ & & & $* !$ & $*$ & & & \\
\hline 证雪 & c. $m a_{p}: t \subset \bullet$ & & & & * & & & $*$ \\
\hline & d. $m \varepsilon_{\mathrm{p}, \mathrm{c}}: \mathrm{t} \bullet$ & & $* !$ & & & & & $*$ \\
\hline
\end{tabular}


In contrast, the oblique affix emerges with [ə]-final nouns such as Pate because here it doesn't violate ${ }^{*} \mathrm{C}$ :

(96) Input: pa:ptə+c-• (Pate, 'godfather', masc. obl. sg.)

\begin{tabular}{|c|c|c|c|c|c|c|c|c|}
\hline & & DEP • & $* \mathrm{CoR}_{2}$ • & $\square \leftarrow$ PLC & $\mathrm{c} \rightarrow \mathrm{V}$ & Max n & ${ }^{*} \mathrm{C}$ & $\operatorname{MAX} \bullet$ \\
\hline 果 & a. $p a_{p}: t ə n_{c, n}$ & & & & * & & & \\
\hline & b. $\mathrm{pa}_{\mathrm{p}}: \mathrm{t} \odot \partial$ & & & & $*$ & * & & $* !$ \\
\hline & c. p $\varepsilon_{\mathrm{p}, \mathrm{c}} \mathrm{t} \partial$ & & $* !$ & & & * & & * \\
\hline
\end{tabular}

Strikingly, it emerges that German has three different $n$-suffixes showing different degrees of defectiveness, the dative plural $-n$ which shows up for all roots in (92) (hence a full stable segment not in need of additional floating material to be realized), the oblique singular, an unstable, but consistent coronal consonant, and the plural root node whose CORONAL alternates between realization as - $n$ and as umlaut since it is underlyingly unassociated to the affixal root node. Thus the GNA analysis reveals that the Syncretism Principle which requires that different exponents in an inflectional system have different underlying phonological specifications (Müller 2003, 2005; Bank 2017), is obeyed to a much larger degree than is apparent in surface phonological realizations.

Masculine plurals in -e: There is a second exceptional class of masculine nouns whose behavior is plausibly linked to the underlying specification of the involved roots for a floating feature: plurals in [e] such as Wurm [voem] Würmer ['vye.me] 'worm(s)', Gott [got] Götter ['gœ.te] 'god(s)' and Mann [man] Männer ['mع.ne] 'man/men'. These show the regular suffix pattern for umlauting neuter nouns in a small subset of the masculines. This pattern can be captured directly by the assumption that these roots carry a floating PHARYNGEAL feature in their lexical entries which hence substitutes for the PHARYNGEAL feature otherwise provided by the neuter plural affix, as shown in (97): for Götter:

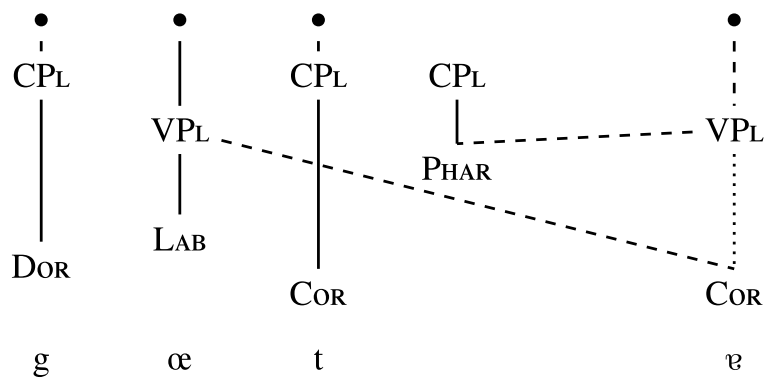

The overall analysis correctly predicts that floating PHARYNGEAL should be otherwise invisible: MAX PHARYNGEAL is ranked low (see the discussion of (43)) and the realization of floating PLACE features is narrowly restricted by $\square \leftarrow$ PLC to the presence of a free VPLACE or CPLACE node, which is provided by the plural VPLACE when this is evacuated by umlaut, but not in affix-less forms such as the nominative singular or by the accusative suffix, whose CPLACE node is locked to the tautomorphemic CORONAL by underlying association to the segmental root node. 


\subsection{Exceptions due to morphological suppletion}

A clear case of morphological suppletion is provided by deverbal neuter derivations with the diminutive suffix -lein which without exceptions have $\varnothing$-suffixation in the plural instead of the predicted -ə or -e, e.g. Mägd-lein ['me:kt-lain] (sg./pl.) 'maid servant(s)' (from Magd [ma:kt]) or Brüder-lein ['bry:.de.lain] (sg./pl.) 'brother(s)' (from Bruder ['brui.de], note that diminutives independently trigger umlaut). I assume that this is a case of a generic zero plural allomorph restricted morphologically to the presence of another affix parallel to standard cases of suppletion, such as the $1 \mathrm{sg}-i$ : in Latin verbs blocking default $1 \mathrm{sg}-o$ (am-o 'I love') after the perfect suffix - $v$ (ama-v- $i$ : 'I have loved', see Embick 2010:47-48 for recent discussion), as shown in (98):

$$
\begin{aligned}
& \text { a. }[+\mathrm{pl}] \leftrightarrow \emptyset / \text {-lein } \\
& \text { b. }[+\mathrm{pl}]
\end{aligned}
$$

Under the standard assumption that affixes with context restrictions block less specific affixes with identical substantive features, but without context restrictions (Kiparsky 1982; Halle and Marantz 1993), (98-a) blocks the generic empty rootnode affix (98-b), and leads to zero exponence for plural since the floating PHARYNGEAL feature introduced by the neuter plural suffix cannot be realized without the host VPLACE and $\bullet$ of (98-b). Exactly the same analysis applies to deverbal neuter derivations with the circumfix ge-... -e such as Gefolge [gə.'fol.gə] 'following' (from folgen 'to follow') and Gehänge [gə.'he.yə] 'pendant' (from hängen 'to hang') which without exceptions have $\varnothing$-suffixation in the plural instead of the predicted $-n$ after final schwa. This is captured by the vocabulary item $[+\mathrm{pl}] \leftrightarrow \varnothing / g e--e \_$in parallel to $(98-a)$.

A suppletion analysis predicts correctly that neuter $g e-\ldots-e$ derivations never show plural umlaut since choosing the $\varnothing$-allomorph means that there is no morphological source for a floating CORONAL which could result in umlaut fronting. Additional independent evidence that the exceptional $\varnothing$-marking in $g e-\ldots-e$ derivations is morphological, not phonological, comes from the fact that masculine and feminine nouns that happen to exhibit the same phonological shape as the neuter ge-... $e$ derivations (e.g. fem. Gemeinde [gə.'main.də] 'parish' Gebärde [gə.'bøe.də] 'gesture', Gerade [gə.'Ra..də] 'line’ or masc. Geselle [gə.'sє.lə] 'companion', Gedanke [gə.'day.kə] 'thought') consistently exhibit suffixal $-n$ in the plural, as predicted by the analysis for ə-final nouns.

A partial suppletion analysis seems to be warranted for a second and much smaller class of masculine nouns that take exceptional plural- $n$ such as Staat $\left[\int\right.$ ta:t $] \sim$ Staat-en ['fta:.tən] 'state(s)' or Juror ['ju.Roe] Juror-en [ju.'Ro:.Rən] 'juror(s)'. In contrast to the roots discussed in Sect. 6.1, nasality here is not a general property of the involved roots, but only of the plural itself since it does not show up in singular oblique forms as shown for the quasi-minimal pair Graf/Staat in (99) (['nax.bae] ['nax.baen]): 


\begin{tabular}{llccccccc}
\hline \multicolumn{4}{c}{ Global-n class } & \multicolumn{4}{c}{ Plural-n class } \\
& \multicolumn{1}{c}{$s g$} & $p l$ & $s g$ & $p l$ & $s g$ & $p l$ & $s g$ & $p l$ \\
\hline Nom & Graf & Graf-en & Nachbar & Nachbar-n & Staat & Staat-en & Juror & Juror-en \\
Obl & Graf-en & Graf-en & Nachbar-n & Nachbar-n & Staat & Staat-en & Juror & Juror-en \\
\hline
\end{tabular}

The plural-only $n$-class can be captured directly by the morpheme entry in (100):

$$
\begin{aligned}
& [+ \text { pl+masc }] \leftrightarrow \leftrightarrow \text { \& nas }] / \quad * \text { Context } * \\
& \text { where } * \text { Context } *=\{\text {-or, Staat, Typ }, \ldots\}
\end{aligned}
$$

The specification of context here contains a disjunctive list of lexemes such as Staat, but is otherwise parallel to the zero exponents restricted to -lein and ge-...e. The majority of the nouns in the plural-only $n$-class seem to involve the suffix -or as in Juror in (99) (see the supplemental material for empirical evidence). Once more, positing fine-grained allomorphy makes different predictions than full-form listing. None of the exceptional $n$-plurals exhibits umlaut (e.g. Tor [to:e] $\sim$ Tor-en/*Tören ['to:.ron] 'fool(s)') as predicted by the complementarity of floating CORONAL in different contexts. In full listing, a form such as Tören should be perfectly wellformed as shown by $n$-plurals with underlyingly stem front vowels such as Föhre ['fø:Rə] Föhre-n ['fø:Rən] 'pine(s)'.

\subsection{Exceptionality and productivity}

A major goal in much of the descriptive and psycholinguistic literature on German plurals going back at least to Mugdan (1977) and Augst (1979) is to cut down the multiplicity of umlaut and suffix patterns to one or a small set of regular and productive allomorphs and to relegate minor and infrequent patterns to the realm of lexical listing and analogy. Thus Sonnenstuhl et al. (1999) claim that only the relatively infrequent $s$-plural is fully productive, and Wiese (2009) argues that the 'core plural system' of German boils down to an $n$-suffix for feminines and a prosodically conditioned -ə alternating with $-\varnothing$ for non-feminines. ${ }^{26}$ The downside of this strategy is, as already noted by Wunderlich (1999), that many of the infrequent patterns are perfectly predictable, thus masculine nouns ending in schwa exhibit completely regular plural- $n$ even though there are relatively few nouns of this shape. In fact, Yang (2016) has recently shown that all suffixation patterns of the German plural can be effectively learned in a principle-based computational model positing productive rules for patterns surpassing a general cognitive exceptionality threshold, basically extracting a subset of the generalizations assumed in this paper from corpus data. (Yang's analysis captures the distribution of umlaut only for neuter nouns, and doesn't address the templatic phonological uniformity of plural allomorphs). Disregarding minor patterns

\footnotetext{
${ }^{26}$ Note that trying to account grammatically for psycholinguistic results on German plurals (a goal well beyond the scope of this paper) also would face the paradoxical challenge that different studies, and even different experimental designs in the same studies provide conflicting and gradient evidence, see e.g. Sonnenstuhl-Henning (2003). The major point of convergence in the literature is that plural-s forms a subsystem markedly distinct from other ways of plural formation, which is hence not considered here.
} 
also misses the fact I have exemplified extensively in this section that all major and minor plural formation strategies share central restrictions (such as the complementarity of plural- $n$ and umlaut) which cannot be captured if some of them are excluded from consideration. My position here is hence following Köpcke (1993) that a theoretical analysis should account for both major and minor patterns of plural formation. However, the subsegmental analysis in fact indirectly predicts that the plural patterns discussed in this section shouldn't be freely transferred to novel items without positive evidence since neither floating stem features nor suppletional allomorphs can be read off from single uninflected surface forms (see Wiese 1996b for a parallel argument for a floating-feature approach to umlaut).

\section{Previous theoretical analyses}

The bulk of the theoretical literature on German noun plurals either focuses on its phonological-prosodic shape (Wiese 1996b, 2009; Neef 1998) or on the paradigmatic restrictions governing suffix allomorphy and umlaut (Carstairs-McCarthy 1987; Wurzel 1998; Pounder 1996; Kilbury 2001; Wiese 2000; Yang 2016). ${ }^{27}$ Thus a major advantage of the subsegmental concatenation approach developed here is that it achieves a unified account of both aspects. ${ }^{28}$

Tellingly, virtually all previous analyses of the implicational relations in the German plural system have taken them as evidence for morphological mechanisms which cannot be reduced to morpheme concatenation. Proponents of Natural Morphology (see Wurzel 1984, 1998; Bittner 1991, and Carstairs-McCarthy 2008 for an optimality-theoretic restatement of Wurzel's major insights) have argued that this system instantiates paradigm structure conditions such as [er/PL] $\supset$ [Uml/PL] ('plural suffix -er implies plural umlaut,' Wurzel 1998:232). Cahill and Gazdar (1999) and Kilbury (2001) suggest implementations in the default inheritance formalism DATR (Evans and Gazdar 1996). While these morphological accounts provide succinct formalizations of central generalizations on noun plurals, they remain phonologically arbitrary. Thus in the formalism of Wurzel's paradigm structure conditions it would be just as easy to formulate a complementary pattern involving umlaut and a uvular/pharyngeal suffix (i.e. -[e]). Here, the subsegmental approach makes the substantive prediction that complementary patterns of this type should be restricted to identical phonological features. Similarly, these approaches don't relate the phonotactic

\footnotetext{
${ }^{27}$ Wegener (1999) analyzes both umlaut and suffixal plural morphology, but treats umlaut (which she captures by lexeme-specific constraint rankings) as strictly orthogonal to suffixal allomorphy. Also Köpcke (1993, 1994) discusses phonological, morphological (and semantic) factors in plural formation, but focuses on subcategorial statistical correlations for specific plural patterns (e.g. the bias for animacy in umlauting nouns) which he takes as evidence for a prototype-based 'schema' model of morphology (see also Frey 2002). Crucially, Köpcke also doesn't address the exceptionless implicational relations captured by the subsegmental analysis.

${ }^{28}$ I will not discuss the broader phonological literature on German umlaut here (see e.g. Wiese 1996a; Lieber 1987, 1992; Yu 1992; Féry 1994; Klein 2000; Scharinger 2009) because it focuses on diminutive umlaut which is substantially different from the noun plural system. The sketch of nominal plural umlaut in Kurisu (2001) addresses only its interaction with suffix-ə and faces similar problems as the analysis of Wunderlich (1999) discussed below.
} 
restrictions of nominal plural inflection to more general phonological wellformedness conditions.

Morphophonological approaches to noun plurals which seek to derive plural morphology as the effect of constraints on phonological form sensitive to morphological categories (Wiese 1996b, 2009; Neef 1998) face the complementary problem. Where they achieve natural explanations for the templatic shape of plurals, they fall short of accounting for the full range of allomorph distribution and implicational relationships between umlaut and suffixation. Thus Neef (1998) has to assume arbitrary lexical classes which are subject to different sets of morphophonological constraints, and Wiese (2009) declares umlaut, plural-er, and less frequent patterns (such as feminine nouns with plural-ə) as unproductive and suppletive. The problem with this claim is that it leaves unexplained the fact that these patterns without exception obey the same prosodic and paradigmatic restrictions as the more frequent forms (see Sect. 6 for detailed demonstration that the subsegmental approach derives these generalizations even for highly idiosyncratic nouns).

The approach which is closest to the one developed here in attempting a unified account of paradigmatic and prosodic generalizations on German plurals is the sketch of an optimality-theoretic analysis in Wunderlich (1999). ${ }^{29}$ Wunderlich also suggests that umlaut is triggered by a floating CORONAL feature, but sides with Wiese (1996a) in assuming that this is a lexical part of the stems which exhibit umlaut, not of the plural affix. That umlaut only appears in the plural is due to segmental faithfulness over-

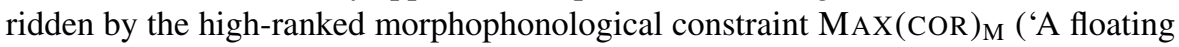
coronal feature in the input is realized in marked categories such as plural'). Alternations between different plural exponents are captured by the constraint NOREDUNDANCY ('Plural is marked only once'), and the templatic shape of plurals is attributed to the constraint REDUCFINSYLL ('A noun plural ends in a reduced syllable'). $-n$ is taken as a regular segmental suffix.

Wunderlich's analysis pursues a hybrid approach with concatenative elements (umlaut as a floating feature, and affixation of $-n$ ) and morphophonological spellout constraints such as REDUCFINSYLL, but it still faces technical and empirical problems.

Thus since $\operatorname{MAX}(\mathrm{COR})_{\mathrm{M}}$ in Wunderlich's analysis is undominated, it predicts that there shouldn't be exceptionless restrictions on the phonological shape of stems that can exhibit umlaut, but this is indeed the case: schwa-final stems never umlaut (Generalization III above). Crucially, Wunderlich couldn't import the intervention-based explanation for this pattern developed in Sect. 3.3 because this depends on the assumption that the floating CORONAL feature is part of the suffix, not of the stem itself

Also Wunderlich's proposal to derive the complementarity between suffix- $n$ and umlaut by a NOREDUNDANCY constraint leads to inherent contradictions. Since the constraint is obviously at odds with the combination of umlaut and schwa, as in Hand $\sim$ Hände 'hand(s)', where plural is marked redundantly by umlaut and suffixal -ə, Wunderlich stipulates that the schwa here (in line with Wiese 2009) is not a true

${ }^{29}$ Wunderlich also outlines a DATR analysis of noun plurals, but dismisses it in favor of the OT-analysis discussed here. 
affix, but the result of epenthesis triggered by the templatic constraint REDUCEDFINALS YLLABLE and hence doesn't count as plural exponence for NOREDUNDANCY. However, under this reasoning, umlaut should a fortiori also not count as a plural exponent because the floating CORONAL feature triggering it is already part of the stems which exhibit umlaut. Umlauting is hence not morphological affixation, but just phonological association of underlying stem material. Maybe even more problematic for Wunderlich's NoREDUNDANCY analysis is the existence of a segmental affix that requires umlaut (-er), for which he claims that all instances of this suffix must be fully lexically listed, a move which obscures the completely regular implications between umlaut and er-affixation in neuter nouns which is transparently derived in the analysis developed here. Crucially, the problems in Wunderlich's analysis highlight the fact that the implicational patterns in the noun plural are of a genuinely phonological kind, governed by the restricted availability of affixal CORONAL and VPLACE nodes predicted in a purely affixational approach.

\section{Summary}

In this paper, I have proposed a radically new perspective on German plural morphology: What has been traditionally described as complex allomorphy between the phonologically fully specified segmental affixes -e, -er, -en is reinterpreted as an epiphenomenon of 'defective', i.e. subsegmental exponents, whose different combinations are derived by phonological evaluation in an optimality-theoretic system. I have shown that this account provides a straightforward explanation for the fact that parts of the plural 'allomorphy' - such as the exceptionless appearance of - $n$ after schwa-final bases - are phonologically predictable, but also allows for deriving central generalizations on the plural systems which have been seen as purely morphological conditions, such as the co-occurrence restrictions between umlaut and different segmental plural exponents. Finally, I have demonstrated that a subsegmental analysis beyond allowing for a unified account of central morphological and phonological generalizations also provides a maximally simple formalization of lexical classes and exceptions which are characterized either by segmental underspecification or floating features. Crucially, the full set of generalizations on plural allomorphy can neither be captured by paradigmatic implications (Wurzel 1998) or morphophonological surface constraints (Neef 1998), nor as purely phonological Emergence of the Unmarked effects (Wiese 2009). This case study thus opens up new perspectives to the Generalized Nonlinear Affixation approach (Bermúdez-Otero 2012; Bye and Svenonius 2012) beyond the modular formalization of different types of nonconcatenative morphology such as reduplication (Paschen 2018) and length-manipulating morphology (Zimmermann 2017) in extending its explanatory potential to account for cases of apparently purely morphological conditions on allomorphy and lexical exceptionality.

Acknowledgements Open Access funding provided by Projekt DEAL.

Publisher's Note Springer Nature remains neutral with regard to jurisdictional claims in published maps and institutional affiliations. 
Open Access This article is licensed under a Creative Commons Attribution 4.0 International License, which permits use, sharing, adaptation, distribution and reproduction in any medium or format, as long as you give appropriate credit to the original author(s) and the source, provide a link to the Creative Commons licence, and indicate if changes were made. The images or other third party material in this article are included in the article's Creative Commons licence, unless indicated otherwise in a credit line to the material. If material is not included in the article's Creative Commons licence and your intended use is not permitted by statutory regulation or exceeds the permitted use, you will need to obtain permission directly from the copyright holder. To view a copy of this licence, visit http://creativecommons.org/licenses/by/4.0/.

\section{References}

Akinlabi, Akinbiyi. 1996. Featural affixation. Journal of Linguistics 32: 239-289.

Alber, Birgit. 2001. Regional variation and edges: Glottal stop epenthesis and dissimilation in standard and southern varieties of German. Zeitschrift für Sprachwissenschaft 20: 3-41.

Alderete, John. 2001. Dominance effects as transderivational anti-faithfulness. Phonology 18: 201-253.

Anderson, Stephen R. 1992. A-Morphous morphology. Cambridge: Cambridge University Press.

Archangeli, Diana, and Douglas Pulleyblank. 1994. Grounded phonology. Cambridge: MIT Press.

Augst, Gerhard. 1979. Neuere Forschungen zur Substantivflexion. Zeitschrift für germanistische Linguistik 7: 220-232.

Bank, Sebastian. 2017. Segmentation: a remark on the syncretism principle. Morphology 27(1): 1-20.

Beckman, Jill. 1998. Positional faithfulness. PhD diss, University of Massachusetts at Amherst.

Bermúdez-Otero, Ricardo. 2012. The architecture of grammar and the division of labour in exponence. In The morphology and phonology of exponence, ed. Jochen Trommer, 8-83. Oxford: Oxford University Press.

Bermúdez-Otero, Ricardo. 2018. Stratal phonology. In The Routledge handbook of phonological theory, eds. In S. J. Hannahs and Anna R. K. Bosch, 100-134. Abingdon: Routledge.

Bittner, Dagmar. 1991. Von starken Feminina und schwachen Maskulina: die neuhochdeutsche Substantivflexion; eine Systemanalyse im Rahmen der natürlichen Morphologie. PhD diss., Universität Jena.

Blevins, Juliette. 2006. Syllable typology. In Encyclopedia of language and linguistics, 2nd edition, ed. Keith Brown, Vol. 12, 333-337. Oxford: Elsevier.

Bye, Patrik, and Peter Svenonius. 2012. Exponence, phonology, and non-concatenative morphology. In The morphology and phonology of exponence, ed. Jochen Trommer, 427-495. Oxford: Oxford University Press.

Cahill, Lynne, and Gerald Gazdar. 1999. German noun inflection. Journal of Linguistics 35: 1-42.

Carstairs-McCarthy, Andrew. 1987. Allomorphy in inflexion. London: Croom Helm.

Carstairs-McCarthy, Andrew. 2008. System-congruity and violable constraints in German weak declension. Natural Language and Linguistic Theory 26 (775-793).

Casali, Roderic F. 1997. Vowel elision in hiatus contexts: Which vowel goes? Language 73(3): 493-533.

Casali, Roderick F. 1996. Resolving hiatus. PhD diss., UCLA.

Clements, G. N. 1991. Place of articulation in consonants and vowels: a unified theory. In Working papers of the Cornell phonetics laboratory, 77-123. Ithaca: Cornell.

Clements, G. N., and Samuel Jay Keyser. 1983. CV phonology: A generative theory of the syllable. Vol. 9 of Linguistic inquiry monograph. Cambridge: MIT Press.

Clements, George N. 1990. The role of the sonority cycle in core syllabification. In Papers in laboratory phonology I: Between the grammar and physics of speech, eds. John Kingston and Mary Beckman, 283-333. Cambridge: Cambridge University Press.

Clements, George N., and Elisabeth Hume. 1995. The internal organization of speech sounds. In The handbook of phonological theory, ed. John Goldsmith, 245-306. Cambridge: Blackwell.

Cole, Jennifer S. 1987. Planar phonology and morphology. PhD diss., MIT.

Embick, David. 2010. Localism versus globalism in morphology and phonology. Cambridge: MIT Press.

Embick, David, and Morris Halle. 2005. The status of stems in morphological theory. In Proceedings of going romance 2003, eds. Twan Geerts and Haike Jacobs, 59-88. Amsterdam: Benjamins.

Ettlinger, Marc. 2008. Input-driven opacity. PhD diss., UC Berkeley.

Evans, Roger, and Gerald Gazdar. 1996. DATR: A language for lexical knowledge representation. Computational Linguistics 22: 167-216.

Féry, Caroline. 1991. German schwa in Prosodic Morphology. Zeitschrift für Sprachwissenschaft 10(1): 65-85. 
Féry, Caroline. 1994. Umlaut and inflection in German. Ms., Universität Tübingen.

Flemming, Edward S. 2002. Auditory representations in phonology. London: Routledge.

Frey, Evelyn. 2002. Prototypenorientierte Untersuchungen zur Pluralbildung der Substantive und ihre didaktischen Folgen. Frankfurt am Main: Lang.

Giegerich, Heinz. 1987. Zur Schwaepenthese im Standarddeutschen. Linguistische Berichte 112: 449469.

Goldsmith, John A. 1976. Autosegmental phonology. PhD diss., MIT.

Golston, Chris, and Richard Wiese. 1996. Zero morphology and constraint interaction: Subtraction and epenthesis in German dialects. Yearbook of morphology 1995: 143-159.

Golston, Chris, and Richard Wiese. 1998. The structure of the German root. In Phonology and morphology of the Germanic languages, eds. Wolfgang Kehrein and Richard Wiese, 165-185. Tübingen: Niemeyer.

Hall, Tracy. 1993. The phonology of German /R/. Phonology 10: 83-105.

Hall, Tracy A. 1992. Syllable structure and syllable related processes in German. Tübingen: Niemeyer.

Halle, Morris, and Alec Marantz. 1993. Distributed Morphology and the pieces of inflection. In The view from building 20, eds. Kenneth Hale and S. Jay Keyser, 111-176. Cambridge: MIT Press.

Halle, Morris, Bert Vaux, and Andrew Wolfe. 2000. On feature spreading and the representation of place of articulation. Linguistic Inquiry 31(3): 387-444.

Hammond, Michael. 1995. There is no lexicon! Ms., University of Arizona.

Hermans, Ben, and Marc van Oostendorp. 2008. Umlaut is phonological: Evidence from ineffability. Talk at Manchester Phonology Meeting (MFM) 16, 2008.

Hume, Elizabeth. 1994. Front vowels, coronal consonants and their interaction in nonlinear phonology. New York: Garland.

Inkelas, Sharon. 2012. The morphology-phonology connection. In Berkeley Linguistics Society (BLS) 34 (2008), Vol. 34, 145-162.

Inkelas, Sharon. 2014. The interplay of morphology and phonology. Oxford: Oxford University Press.

Inkelas, Sharon, and Draga Zec. 1995. The syntax-phonology interface. In The handbook of phonological theory, ed. John A. Goldsmith, 535-549. Cambridge: Blackwell.

Inkelas, Sharon, and Cheryl Zoll. 2005. Reduplication: Doubling in morphology. Cambridge: Cambridge University Press.

Janda, Richard. 1982. On limiting the form of morphological rules: German umlaut, diacritics, and the cluster constraint. North East Linguistic Society (NELS) 12, 140-152.

Kager, René. 1999. Optimality Theory. Cambridge: Cambridge University Press.

Kilbury, James. 2001. German noun inflection revisited. Journal of Linguistics 37(2): 339-353.

Kim, Eun-Sook, and Douglas Pulleyblank. 2009. Glottalisation and lenition in Nuu-chah-nulth. Linguistic Inquiry 40: 567-617.

Kiparsky, Paul. 1982. Lexical phonology and morphology. In Linguistic Society of Korea: Linguistics in the morning calm, 3-92. Seoul: Hanshin Publishing Company.

Kiparsky, Paul. 2000. Opacity and cyclicity. The Linguistic Review 17: 351-367.

Kiparsky, Paul. 2015. Stratal OT: A synopsis and FAQs. In Capturing phonological shades, eds. Yuchau E. Hsiao and Lian-Hee Wee, 2-44. Cambridge: Cambridge Scholars Publishing.

Kisseberth, Charles. 1970. On the functional unity of phonological rules. Linguistic Inquiry 1: 291-306.

Klein, Thomas B. 2000. Umlaut in Optimality Theory: A comparative analysis of German and Chamorro. Tübingen: Niemeyer.

Konoshenko, Maria. 2008. Tonal systems in three dialects of the Kpelle language. Mandenkan 44: 21-42.

Köpcke, Klaus-Michael. 1988. Schemas in German plural formation. Lingua 74: 303-335.

Köpcke, Klaus-Michael. 1993. Schemata bei der Pluralbildung im Deutschen. Tübingen: Niemeyer.

Köpcke, Klaus-Michael. 1994. Zur Rolle von Schemata bei der Pluralbildung monosyllabischer Maskulina. In Funktionale Untersuchungen zur deutschen Nominal- und Verbalmorphologie, ed. Klaus-Michael Köpcke, 81-96. Tübingen: Niemeyer.

Krämer, Martin, and Draga Zec. 2017. Coda typology, the sonority myth, and positive markedness. Talk at OCP 14, Düsseldorf, 20-22 February 2017.

Kurisu, Kazutaka. 2001. The phonology of morpheme realization. PhD diss., UC Santa Cruz.

Lahiri, Aditi, and Vincent Evers. 1991. Palatalization and coronality. In The special status of coronals: Internal and external evidence, eds. Carole Paradis and Jean-Francois Prunet, 79-100. San Diego: Academic Press.

Lieber, Rochelle. 1987. An integrated theory of autosegmental processes. Albany: State University of New York Press. 
Lieber, Rochelle. 1992. Deconstructing morphology. Chicago: University of Chicago Press.

Liljencrants, L., and Björn Lindblom. 1972. Numerical simulations of vowel quality systems: The role of perceptual contrast. Language 48: 839-862.

Lodge, Ken. 1989. A nonsegmental account of German umlaut: diachronic and synchronic perspectives. Linguistische Berichte 124: 470-491.

MacBride, Alexander. 2004. A constraint-based approach to morphology. PhD diss., UCLA.

Marantz, Alec. 1982. Re reduplication. Linguistic Inquiry 13: 483-545.

McCarthy, John. 1979. Formal problems in Semitic phonology and morphology. PhD diss., MIT.

McCarthy, John. 2008. The gradual path to cluster simplification. Phonology 25: 271-319.

McCarthy, John, and Alan Prince. 1993. Prosodic morphology: Constraint interaction and satisfaction. ROA 485-1201.

McCarthy, John J. 1994. The phonetics and phonology of Semitic pharyngeals. Papers in Laboratory Phonology III: Phonological Structure and Phonetic Form 86: 191-233.

McCarthy, John J. 1996. Remarks on phonological opacity in Optimality Theory. In Studies in Afroasiatic grammar. Papers from the second conference on Afroasiatic linguistics, Sophia Antipolis, 1994, eds. Jacqueline Lecarme, Jean Lowenstamm, and Ur Shlonsky, 215-243. The Hague: Holland Academic Graphics.

McCarthy, John J. 2003. Comparative markedness. Theoretical Linguistics 29(29): 1-51.

McCarthy, John J., and Alan Prince. 1996. Prosodic morphology 1986. Technical Report 32, Rutgers University Center for Cognitive Science. Available at: http://works.bepress.com/John_j_mccarthy/54, last accessed 21 June 2020.

Mugdan, Joachim. 1977. Flexionsmorphologie und Psycholinguistik. Untersuchungen zu sprachlichen Regeln und ihrer Beherrschung durch Aphatiker, Kinder und Ausländer, am Beispiel der deutschen Substantivdeklination. Tübingen: Gunter Narr.

Müller, Gereon. 2003. On decomposing inflection class features: Syncretism in Russian noun inflection. In Explorations in nominal inflection, eds. Lutz Gunkel, Gereon Müller, and Gisela Zifonun, 189-228. Berlin: Mouton de Gruyter.

Müller, Gereon. 2005. Syncretism and iconicity in Icelandic noun declensions: A Distributed Morphology approach. Yearbook of Morphology 2004: 229-271.

Neef, Martin. 1996. Wortdesign: Eine deklarative Analyse der deutschen Verbflexion. Tübingen: Stauffenburg Verlag.

Neef, Martin. 1998. The reduced syllable plural in German. In Models of inflection., eds. Ray Fabri, Albert Ortmann, and Teresa Parodi. Vol. 388 of Linguistische arbeiten, 244-265. Tübingen: Niemeyer.

Nespor, Marina, and Irene Vogel. 1986. Prosodic phonology. Dodrecht: Foris Publications.

Ní Chiosáin, Máire, and Jaye Padgett. 2001. Markedness, segment realization and locality in spreading. In Segmental phonology in Optimality Theory, ed. Linda Lombardi, 118-156. Cambridge: Cambridge University Press.

Noske, Roland. 1993. A theory of syllabification and segmental alternation: With studies on the phonology of French, German, Tonkawa, and Yawelmani. Tübingen: Niemeyer.

Orgun, Cemil Orhan. 1996. Sign-based morphology and phonology with special attention to Optimality Theory. PhD diss., UC Berkeley.

Padgett, Jaye. 2011. Consonant-vowel place feature interactions. In The Blackwell companion to phonology, eds. Marc van Oostendorp, Colin J. Ewen, and Keren D. Rice, 1761-1786. London: Wiley Blackwell. Chap. 75.

Paschen, Ludger. 2018. The interaction of reduplication and segmental mutation: A phonological account. $\mathrm{PhD}$ diss., Leipzig University.

Pater, Joe. 2000. Nonuniformity in English stress: The role of ranked and lexically specific constraints. Phonology 17(2): 237-274.

Pater, Joe. 2007. The locus of exceptionality: Morpheme-specific phonology as constraint indexation. In Papers in Optimality Theory III, eds. Leah Bateman, Michael O'Keefe, Ehren Reilly, and Adam Werle, 259-296. Amherst MA: GLSA.

Pounder, Amanda. 1996. Inflection and the paradigm of German nouns. American Journal of Germanic linguistics and literatures 8(2): 219-263.

Prince, Alan, and Paul Smolensky. 1993. Optimality Theory: Constraint interaction in generative grammars. Technical reports of the Rutgers University Center of Cognitive Science.

Rasin, Ezer, and Roni Katzir. 2015. Compression-based learning for OT is incompatible with Richness of the Base. In North East Linguistic Society (NELS) 45, eds. Thuy Bui and Deniz Özyıldız, 267-274. 
Revithiadou, Anthi. 2007. Colored turbid accents and containment: A case study from lexical stress. In Freedom of analysis?, eds. Sylvia Blaho, Patrick Bye, and Martin Krämer, 149-174. Berlin: De Gruyter.

Rose, Sharon. 1997. Theoretical issues in comparative Ethio-Semitic phonology and morphology. PhD diss., McGill University.

Rose, Sharon. 2007. Chaha (Gurage) morphology. In Morphologies of Asia and Africa, ed. Alan S. Kaye, 399-424. University Park: Eisenbrauns.

Russel, Kevin. 1995. Morphemes and candidates in Optimality Theory. Ms., University of Manitoba, ROA44-0195.

Russel, Kevin. 1999. MOT: Sketch of an OT approach to morphology. Ms., University of Manitoba, ROA352-1099.

Sagey, Elizabeth. 1986. The representation of features and relations in non-linear phonology. PhD diss., MIT.

Scharinger, Mathias. 2009. Minimal representations of alternating vowels. Lingua 119: 1414-1425.

Scharinger, Matthias. 2006. The representation of vocalic features in vowel alternations. Phonological, morphological and computational aspects. PhD diss., Universität Konstanz.

Selkirk, Elisabeth. 1986. On derived domains in sentence phonology. Phonology Yearbook 3: 371-405.

Sonnenstuhl, Ingrid, Sonja Eisenbeiss, and Harald Clahsen. 1999. Morphological priming in the German mental lexicon. Cognition 72: 203-236.

Sonnenstuhl-Henning, Ingrid. 2003. Deutsche Plurale im mentalen Lexikon: experimentelle Untersuchungen zum verh/ältnis von Speicherung und Dekomposition. Tübingen: Niemeyer.

Staubs, Robert. 2011. Operational exponence: Process morphology in Harmonic Serialism. Challenges of complex morphology to morphological theory. Handout. Linguistic Society of America Summer Institute, Boulder.

Trommer, Jochen. 2011. Phonological aspects of Western Nilotic mutation morphology. Habilitation Thesis, University of Leipzig.

Trommer, Jochen. 2014. Moraic prefixes and suffixes in Anywa. Lingua 140: 1-34.

Trommer, Jochen. 2015. Moraic affixes and morphological colors in Dinka. Linguistic Inquiry 46(1): 77112.

Trommer, Jochen. 2016. Structural cumulativity in German umlaut. Presentation at the 24th Manchester Phonology Meeting, Manchester. May 2016.

Trommer, Jochen, and Eva Zimmermann. 2014. Generalised mora affixation and quantity-manipulating morphology. Phonology 31(3): 463-510.

Vago, Robert M. 1976. Theoretical implications of Hungarian vowel harmony. Linguistic Inquiry 7(2): 243-263.

van Oostendorp, Marc. 1995. Vowel quality and phonological projection. PhD diss., Katolieke Universiteit Brabant.

van Oostendorp, Marc. 2006. A theory of morphosyntactic colours. Ms., Meertens Institute, Amsterdam..

van Oostendorp, Marc. 2007. Derived environment effects and consistency of exponence. In Freedom of analysis?, eds. Sylvia Blaho, Patrik Bye, and Martin Krämer, 123-148. Berlin: de Gruyter.

van Oostendorp, Marc. 2008. Incomplete devoicing in formal phonology. Lingua 118(9): 1362-1374.

Walker, Rachel. 1998. Nasalization, neutral segments, and opacity effects. PhD diss., University of California, Santa Cruz.

Walther, Markus. 2001. Correspondence theory: More candidates than atoms in the universe, Marburger Arbeiten zur Linguistik 6, Institut für Germanistische Sprachwissenschaft Philipps-Universität Marburg.

Wegener, Heide. 1999. Die Pluralbildung im Deutschen - ein Versuch im Rahmen der Optimalitätstheorie. Linguistik online 4 (3).

Wiese, Bernd. 2000. Warum Flexionsklassen? Über die deutsche Substantivdeklination. In Deutsche Grammatik in Theorie und Praxis, eds. Rolf Thieroff, Matthias Tamrat, Nanna Fuhrhop, and Oliver Teuber, 139-153. Tübingen: Niemeyer.

Wiese, Richard. 1986. Schwa and the structure of words in German. Linguistics 24: 697-724.

Wiese, Richard. 1988. Silbische und lexikalische Phonologie. Studien zum Chinesischen und Deutschen. Tübingen: Niemeyer.

Wiese, Richard. 1996a. Phonological vs. morphological rules: On German umlaut and ablaut. Journal of Linguistics 32: 113-135.

Wiese, Richard. 1996b. The phonology of German. Oxford: Clarendon Press. 
Wiese, Richard. 2009. The grammar and typology of plural noun inflection in varieties of German. Journal of Comparative Germanic Linguistics 12(2): 137-173.

Wolf, Matthew. 2007. For an autosegmental theory of mutation. In University of Massachusetts occasional papers in linguistics 32: Papers in Optimality Theory III, eds. Leah Bateman, Michael O'Keefe, Ehren Reilly, and Adam Werle, 315-404. Amherst: GLSA.

Wunderlich, Dieter. 1999. German noun plural reconsidered. Ms., University of Düsseldorf.

Wurzel, Wolfgang Ullrich. 1984. Flexionsmorphologie und Natürlichkeit. Berlin: Akademieverlag.

Wurzel, Wolfgang Ullrich. 1998. Drei Ebenen der Struktur von Flexionsparadigmen. In Models of inflection, eds. Ray Fabri, Albert Ortmann, and Teresa Parodi, 225-243. Tübingen: Niemeyer.

$\mathrm{Xu}$, Zheng, and Mark Aronoff. 2011. A Realization Optimality Theory approach to blocking and extended morphological exponence. Journal of Linguistics 47(3): 673-707.

Yang, Charles. 2016. The price of linguistic productivity. Cambridge: MIT Press.

Yu, Si-Taek. 1992. Unterspezifikation in der Phonologie des Deutschen. Tübingen: Niemeyer.

Zaleska, Joanna. 2018. Coalescence without coalescence. PhD diss., Universität Leipzig.

Zimmermann, Eva. 2013. Vowel deletion as mora usurpation: The case of Yine. Phonology 30: 125-163.

Zimmermann, Eva. 2014. A phonological account of morphological length. PhD diss., Universität Leipzig.

Zimmermann, Eva. 2017. Morphological length and prosodically defective morphemes. Oxford: Oxford University Press.

Zoll, Cheryl. 1996. Parsing below the segment in a constraint-based framework. PhD diss., UC Berkeley. 